NUREG/CR-2546

RECEUED BY TIC JUL 061982

SAND82-0319

RS, 15

Printed March 1982

\title{
Reactor Safeguards Against Insider Sabotage
}

Harold A. Bennett

Prepared by
Sandia National Laboratories

Albuquerque, New Mexico 87185 and Livermore, California 94550

for the United States Department of Energy

under Contract DE-AC04-76DP00789

Prepared for

U. S. NUCLEAR REGULATORY COMMISSION 


\section{DISCLAIMER}

This report was prepared as an account of work sponsored by an agency of the United States Government. Neither the United States Government nor any agency Thereof, nor any of their employees, makes any warranty, express or implied, or assumes any legal liability or responsibility for the accuracy, completeness, or usefulness of any information, apparatus, product, or process disclosed, or represents that its use would not infringe privately owned rights. Reference herein to any specific commercial product, process, or service by trade name, trademark, manufacturer, or otherwise does not necessarily constitute or imply its endorsement, recommendation, or favoring by the United States Government or any agency thereof. The views and opinions of authors expressed herein do not necessarily state or reflect those of the United States Government or any agency thereof. 


\section{DISCLAIMER}

Portions of this document may be illegible in electronic image products. Images are produced from the best available original document. 


\section{NOTICE}

This report was prepared as an account of work sponsored by an agency of the United States Government. Neither the United States Government nor any agency thereof, or any of their employees, makes any warranty, expressed or implied, or assumes any legal liability or responsibility for any third party's use, or the results of such use, of any information, apparatus product or process disclosed in this report, or represents that its use by such third party would not infringe privately owned rights.

\section{Available from}

GPO Sales Piugiam

Division of Technical Information and Document Control

U.S. Nuclear Regulatory Commission

Washington, D.C. 20555

and

National Technical Information Service

Springfield, Virginia 22161 


\section{PAGES 1 to 2 WERE INTENTIONALLY LEFT BLANK}


NUREG/CR-2546

SAND 8 2-0319

Unlimited Release

RS

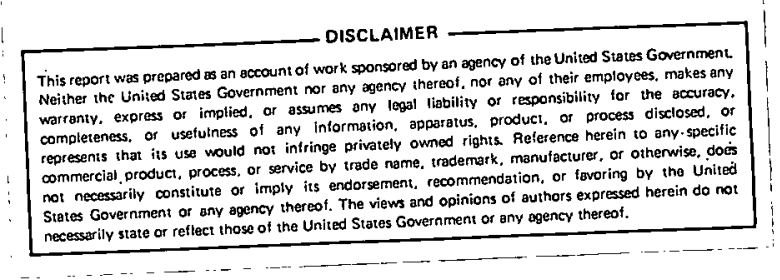

REACTOR SAFEGUARDS AGAINST INSIDER SABOTAGE

Harold A. Bennett

Systems Analysis and Technology Applications Division 4416

Sandia National Laboratories

Albuquerque, New Mexico 87185

Date Published: March 1982

NUREG/CR--2546

DE82 016279

Sandia National Laboratories

Albuquerque, New Mexico 87185

operated by

Sandia Corporation

for the

U.S. Department of Energy

Prepared for

Division of Facility Operations, Safeguards Branch

Office of Nuclear Regulatory Research

U. S. Nuclear Regulatory Commission

Washington, DC 20555

Under Memurandum of Understanding 40-550-75

NRC FIN No. AI060 
A conceptual safeguards system is structured to show how both reactor operations and physical protection resources could be integrated to prevent release of radioactive material caused by insider sabotage. Operational recovery capabilities are addressed from the viewpoint of bôth detection of and response to disabled components. Physical protection capabilities for preventing insider sabotage through the application of work rules are analyzed. Recommendations for further development of safeguards system structures, operational recovery, and sabotage prevention are suggested. 


\section{EXECUTIVE SUMMARY}

For a reactor facility employee to cause release of radioactive material from the facility, the employee (insider) must successfully complete a specific sequence of sabotage activities which lead to an unsafe reactor condition. This unsafe condition must continue until radioactive material is released, e.g., until core meltdown occurs. Therefore, the potential for averting radioactive material release exists not only in preventing the sabotage act, a physical protection objective, but also in recovering from the unsafe reactor condition, an operational objective.

The objectives of this study are

- To develop a conceptual safeguards system structure that integrates both reactor operational recovery and physical protection functions to prevent release of radioactive material caused by insider sabotage.

- To address facility operational capabilities for detecting and responding to sabotage-induced events.

- To assess physical protection capabilities for preventing insider sabotage through application of work rules, specifically operational zoning, area zoning, and team zoning.

The need for completeness in coping with the insider reactor sabotage problem has led to the development of a hierarchical structure that reflects a comprehensive view of the problem and indicates the wide range of resources which the facility has at its disposal for countering the problem. All functions known to play a role in preventing the release of radioactive material from the reactor facility are identified. This structural development transforms a mental concept of the system into a clear, graphic model portraying all system functions and their interrelationships. Such a model can serve both as a focal point for clarifying discussions and, perhaps of greater importance, as a structure for a system assessment methodology.

Operational recovery capabilities are addressed from the viewpoint of both detection of and response to disabled components and other initiating sabotage events. The operational recovery concept is that the loss of vital functions must be detected while there is still sufficient lime remaining for their restoration. This functional restoration must occur before a critical condition is reached in which radioactive material release cannot be prevented. Functional restoration (damage control) can take the form of repair, replacement, or substitution. The damage-control results presented in this report reflect current efforts in other programs. 
For cases in which core meltdown can occur, damage-control response time seems to limit opportunities for disabled component repair or replacement only to those components with long-term functions, e.g., the heating, ventilation, and air-conditioning (HVAC) system, the containment heat removal system, etc. In cases in which core meltdown cannot occur, * damage-control response may not present any problem. However, the ability to sense disabled components appears inadequate, particularly in the case of standby components that have been subtly altered. Therefore, it seems that a fairly large set of systems still requires physical protection to preclude sabotage by an insider.

A resolute saboteur can be interrupted only if the response force is informed of the sabotage attempt while there is still sufficient time remaining in the sabotage sequence for the force to respond. The set of work rules (operational zoning, area zoning, and team zoning) addressed in this study essentially provides a means of detecting unauthorized activities and conditions in vital areas (VAs). As such, the performance of the work rules can be measured by a probability of detection $\left(P_{d}\right)$ and a time of occurrence within the sabotage sequence.

The impact of a particular sensing system on physical protection system (PPS) performance is a function of the probability of detection and the post-detection delay/response time relationship for the case in question. Wherever work rules seem unsatisfactory, the values of alternative PPS parameters can usually be modified, at a cost, to make the PPS acceptable. Application of the three work rules to the hypothetical example facility provided the following conclusions.

If the saboteur had authorized access to all but the last vital area in a sabotage sequence, then operational zoning as a means of sensing unauthorized access appeared to place detection too late in the sabotage sequence for a timely response. Additional vital-area access restrictions could improve PPS performance but only for sabotage combinations of three or more targets. This could have implications for the "key" (minimum protected set) vital-area concept.

For target combinations seemingly well-suited to area zoning, the PPS performance was marginal when area zoning was applied. For adjoining or closely located vital-area combinations, area zoning became equivalent to operational zoning, with the same conclusions applicable.

Team zoning, applied as the two-man rule, provided the earliest detection time in the sabotage sequences analyzed. Therefore, on the positive side, this rule offers the greatest potential for. PPS performance. However, on the negative side, this rule may be the least reliable due to the vagaries of human performance in a surveillance mode.

\footnotetext{
Limited, symbolic, or protracted sabotage attempts.
} 
The following recommendations regarding reactor safeguards system structure, operational recovery, and sabotage prevention are suggested for further development:

- The development of a uniform, logical, and defensible assessment method for insider sabotage protection is recommended. The structure described in Chapter 2 could serve as a framework to unify responses to questionnaires that can provide explicit, comprehensive treatment of both subjective and objective aspects of operational, safety, and physical protection systems.

- A comprehensive, in-depth impact-benefits study should be made in the area of sensing vital component tampering and failures. This study should address the subject from operations, safety, and safeguards viewpoints.

- Defensible methods for assessing the impact of safeguards system options on both operations and safety should be developed. The availability of such methods would provide a means of making and supporting objective decisions regarding proposed options. The question of Type I vital areas in connection with insider sabotage should be investigated to determine the conditions, if any, for which there are no Type I vital areas. If such conditions exist, then the impact on PPS requirements should be assessed. 
CONTENTS

Chapter

$\underline{\text { Page }}$

1 INTRODUCTION

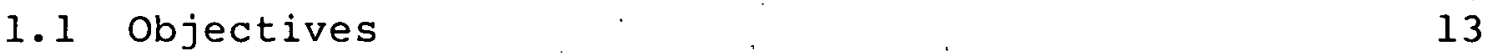

1.2 Background . . 13

1.3 Scope 13

2 REACTOR SAFEGUARDS STRUCTURE '

2.1 Introduction 15

2.2 Safeguards Structure $\quad 15$

2.2.1 Overview 15

2.2.2 Structure Development 15

3 OPERATIONAL RECOVERY * 39

3.1 Discussion 39

3.2 Results to Date 40

4 SABOTAGE PREVENTION : 45

4.1 Discussion $\quad 45$

4.2 SAI Study Results 45

4.2.1 Discussion . . . . 45

4.2.2 Results 45

4.3 SAFE Analysis $\cdots \cdots \cdots$

4.3.1 Discussion 46

4.3.2 Reactor Facility Characterization 47

4.3.3. Results. 52

5 CONCLUSIONS $\quad 73$

5.1 System Structure 73

5.2 Operational Recovery . . . $\quad 73$

5.3 Sabotage Prevention 73

6 RECOMMENDATIONS $\quad 75$

6.1 System Structure.

$\begin{array}{lll}6.2 & \text { Operational Recovery } & 75\end{array}$

6.3 Sabotage Prevention 75

7 REFERENCES $\quad 77$

APPENDIX A--Example Facility Layout Drawings . . . . . . . : $\quad 79$

APPENDIX B--Example Facilitý Data : -

GLOSSARY OF TERMS AND ACRONYMS $\quad \ldots \quad \ldots \ldots \ldots$ 


\section{ILLUSTRATIONS}

Figure

Page

1 Insider Reactor Safeguards Functional Hierarchy

PWR Safety Function Timeline (Initiating Event $=$ LOSP)

Summary of System Requirements for the Four Protection Strategies as a Function of Time After an Initiating Event

Reactor Facility--Ground Level

5 Level 2 (Ground Level, Quarter 3) Showing Insider Path

Level 3 Showing Insider Path

$P_{I}$ vs. Response Force Time for Targets $205+307$ ( Case 4)

P I vs. Sabotage Task Time for Targets $205 \rightarrow 307$

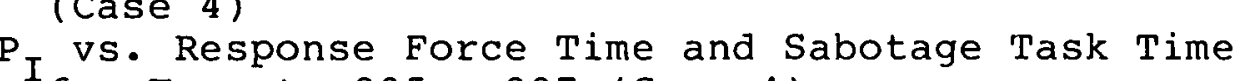
for Targets $205 \rightarrow 307$ (Case 4)

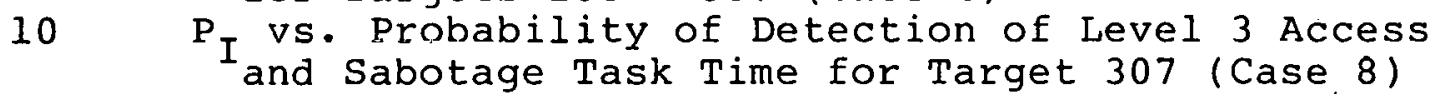

$11 \quad P_{I}$ vs. Response Force Time for Targets $205+307$ I (Case 8)

$12 \mathrm{P}_{\mathrm{I}}$ vs. Probability of Detection at End of Sabotage

$12 \mathrm{P}_{\mathrm{I}}$ vs. Probability of Detection at End of Sabotage

13 P Is. Probability of Detection at End of Sabotage Iat Target 205 (Case 11)

14 Level 2 (Ground Level, Quarter 3) Showing Insider Path

15 Level 2 (Ground Level, Quarter 4) Showing Insider Path

${ }^{P}$ Vs. Time for Task 11 at Target 290 (Case 17)

17

PI vs. Probability of Detection Using Two-Man Rule (Sensor 2) (Case 18)

$\mathrm{P}_{\mathrm{I}}$ vs. Probability of Detection with Two-Man Rule

I (Sensor 2) and Time for Task 11

TABLES

Table

1

2

3

4

5

6

Vital Areas

Type II Vital-Area Combinations

Base-Case Results for Vital Areas with Operational Zoning

Results for Vital Areas with Area Zoning

Results for Team Zoning

Team Zoning Comparison (Direct vs. Two-Stage Response) 


\section{INTRODUCTION}

\subsection{OBJECTIVES}

The objectives of this study are

- To develop a conceptual safeguards system structure that integrates both reactor operations and physical protection functions to prevent release of radioactive material caused by insider sabotage.

- To address facility operational capabilities for detecting and responding to sabotage-induced events.

- To assess facility physical protection capabilities for preventing insider sabotage through application of work rules, specifically operational zoning, area zoning, and team zoning.

\subsection{BACKGROUND}

If the goal of an insider saboteur is to cause release of radioactive material from a facility, the insider must successfully complete a specific sequence of sabotage activities which lead to an unsafe reactor condition. Then, this unsafe reactor condition must continue until radioactive material is released, e.g., until core meltdown occurs. Therefore, the potential for preventing radioactive release exists not only in preventing the sabotage attempt (physical protection) but also in recovering from the unsafe reactor condition (operational actions). The Nuclear Regulatory Commission (NRC) is exploring operational capabilities for post-sabotage recovery in an effort to ameliorate the very difficult problem of protection against insider sabotage.

\subsection{SCOPE}

The need for completeness in coping with the insider reactor. sabotage problem has led to the development of a hierarchical reactor safeguards structure, described in Chapter 2, that reflects a broad view of the problem and indicates the range of resources which the reactor facility might employ to oppose it. In addition, a conceptual. method is sugqested for using this structure in conjunction with component and system questionnaires to provide a broad assessment of system capability to counter the insider problem.

Operational recovery capabilities are addressed in Chapter 3 from the viewpoint of both detection of and response to disabled components. The results presented reflect current efforts in other programs. 
At the request of: the NRC, a specific set of work rules was analyzed to determine the effectiveness of the rules in protecting against reactor sabotage by an insider. A dynamic analysis of the insider actions required to enact sabotage for a selected set of pressurized water reactor (PWR) sabotage targets was performed using the Safeguards Automated Facility Evaluation (SAFE) method. The results of this analysis are presented in Chapter 4.

Conclusions and recommendations are presented in. Chapters 5 and 6, respectively. 


\section{REACTOR SAFEGUARDS STRUCTURE}

\subsection{INTRODUCTION}

Taking a combined prevention and recovery approach to precluding sabotage-induced release of radioactive material at a reactor facility requires the development of a complex safeguards system. Common to all complex systems, however, are the structures that describe them. These structures can range from sets of mathematical equations, such as those used to define mechanical or electrical systems, to less concisely expressed relationships, such as those used in the social sciences. A safeguards structure is expected to be a composite of the whole range. Regardless of the type of structure involved, better-informed decisions concerning a system can be made when the structure of the system is well-defined.

\subsection{SAFEGUARDS STRUCTURE}

\subsubsection{Overview}

In order to study a problem as complex as that of reactor sabotage by an insider, it is necessary to view the safeguards system in terms of its smaller, more manageable subsystems and their interrelationships. This decomposition of the safeguards system allows the insider sabotage problem to be treated as a hierarchy of subsystem performance objectives. To develop such a hierarchy, first the overall objective in addressing the insider sabotage problem must be determined. Then, this overall objective is partitioned into the system functions which contribute to the achievement of the overall objective. Each system function, in turn, is decomposed into the system subfunctions that contribute directly to the performance of the system function. This functional decomposition process continues until it reaches a level comprising system components that have defensible performance measures that can be quantified. The resulting hierarchy can serve to organize an assessment of system performance with respect to the overall objective. By logically combining individual performance measures or scores at each level of the hierarchy, beginning at the component level, into an aggregate score at the next higher level, seemingly intractable performance measures can be obtained for high-level functions and ultimately for the overall system objective. Furthermore, by structuring the contributing system components in this way, the importance of each component's performance to the system objective can be estimated.

\subsubsection{Structure Development}

To develop a functional hierarchy for a qiven objective, the functions and subfunctions required to achieve that objective must be identified. Such a functional decomposition is not singular in nature 
but rather is dependent upon the intended scope and purpose of the structure.

The structure developed for the insider reactor sabotage problem (shown in Figure 1 ) reflects a broad view of the problem and indicates the range of resources. which the reactor facility might employ to oppose it.

At the top of the hierarchy is the overall objective:

Prevent release of radioactive material

from the reactor facility.

Once this overall objective is established, the next step is to develop a set of more specific secondary objectives based upon identification of facility locations from which radioactive material could be released. Nuclear power reactor facilities contain three significant sources of radioactive materials: the spent fuel storage pool, the reactor core, and the radioactive (RAD) waste system. Identification of these three sources leads to the development of three secondary objectives:

1. Prevent radioactive release from the spent fuel storage area,

2. Prevent radioactive release from reactor containment, and

3. Prevent radioactive release from the RAD waste system.

The amount of radioactive release from each of the three preceding sources is affected by operational conditions at the facility. For instance, the potential release from reactor containment (item 2 above) depends upon which one of the three basic modes of reactor operation is in effect at the time: reactor shutdown, reactor power operation, or reactor refueling.

The prevention of radioactive material release from all logical combinations of radioactive source locations and operational conditions can be expressed as a set of specific system objectives. A separate hierarchy can be developed from a functional decomposition of each objective. Of the nine possible source/operational-condition combinations, radioactive material release from containment as a result of core meltdown during reactor power operation has been chosen for consideration in this study since it potentially offers the most significant consequences from sabotage. Therefore, the remainder of the hierarchy is based upon a decomposition of the following system objective:

Prevent radioactive material release from reactor core containment during reactor power operation.

To identify the system functions required to prevent radioactive material release as stated in the system objective, it is necessary to determine what an insider must do to achieve such a goal. 


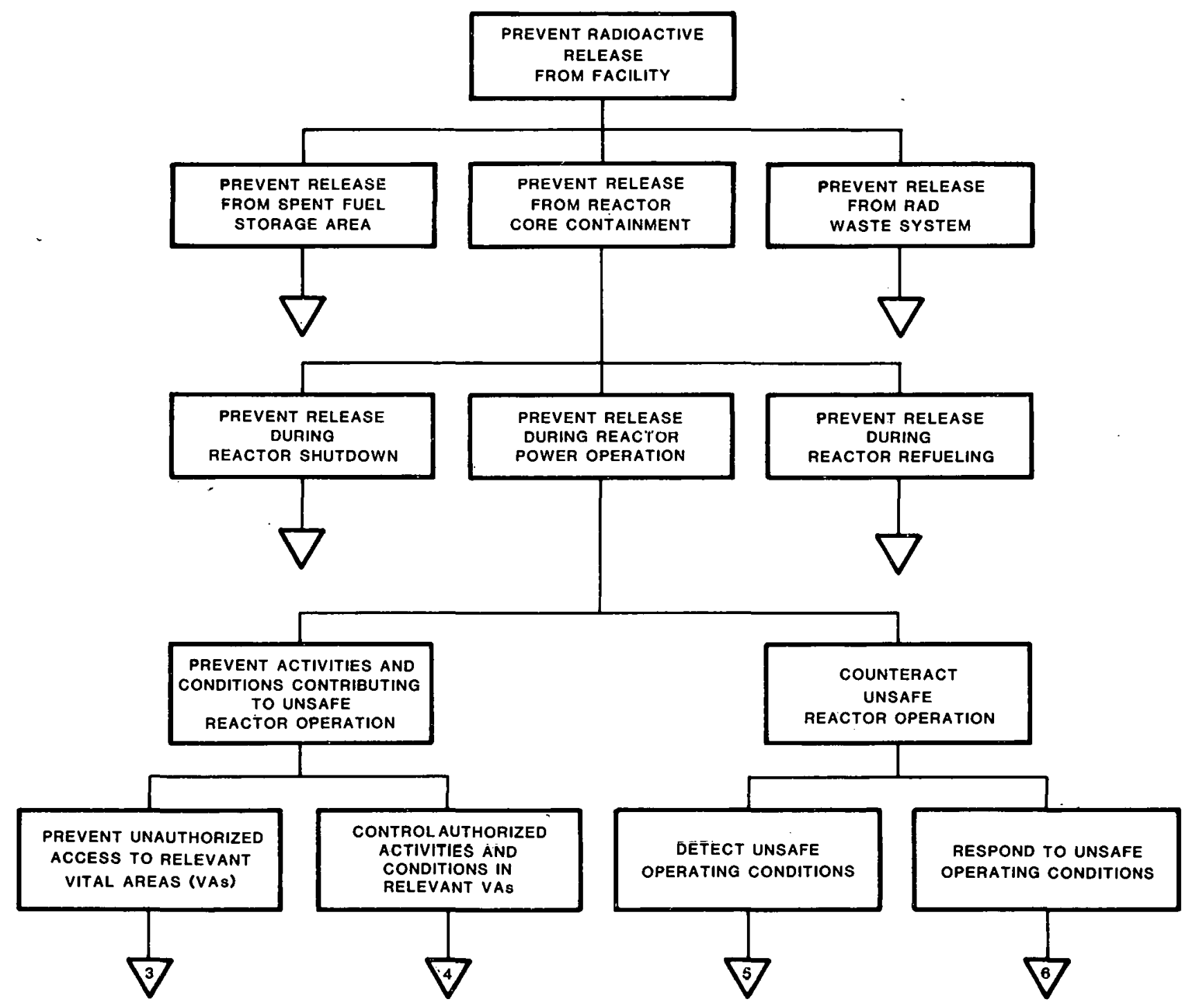

Figure 1. Insider Reactor Safeguards Functional Hierarchy 


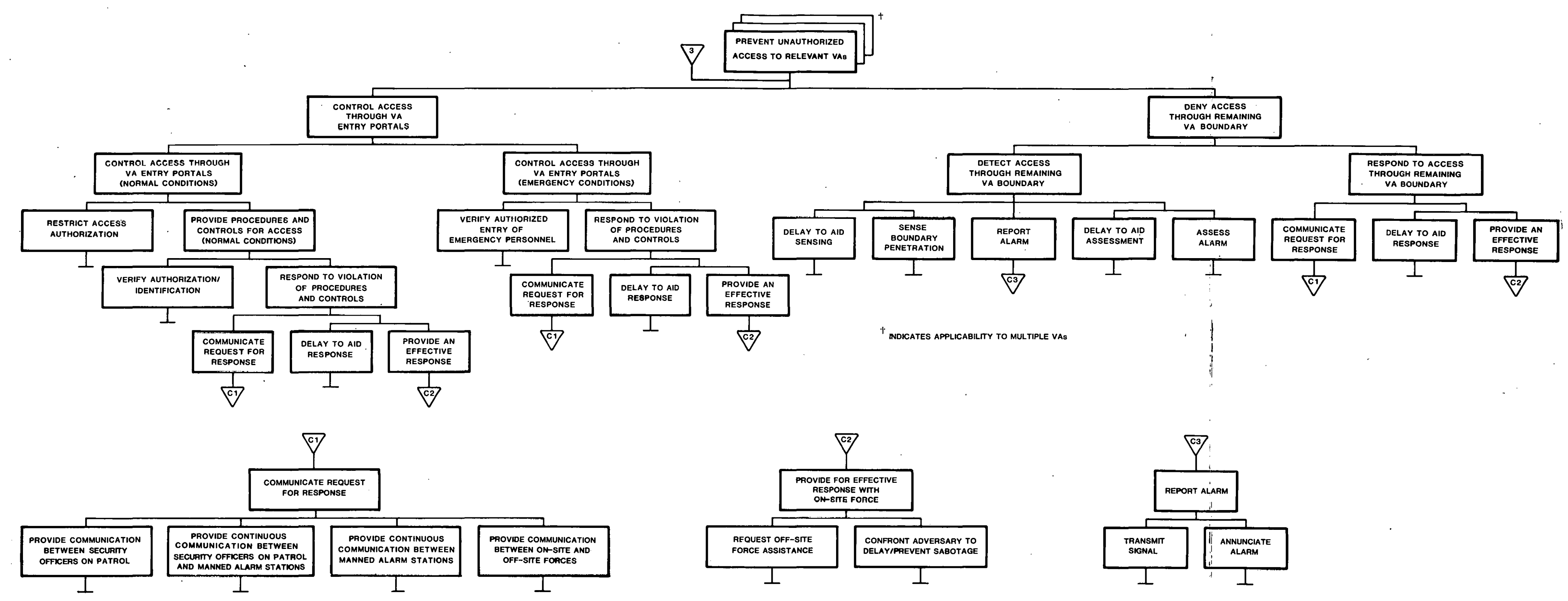

Figure 1. Insider Reactor Safeguards Functional Hierarchy (Continued) 


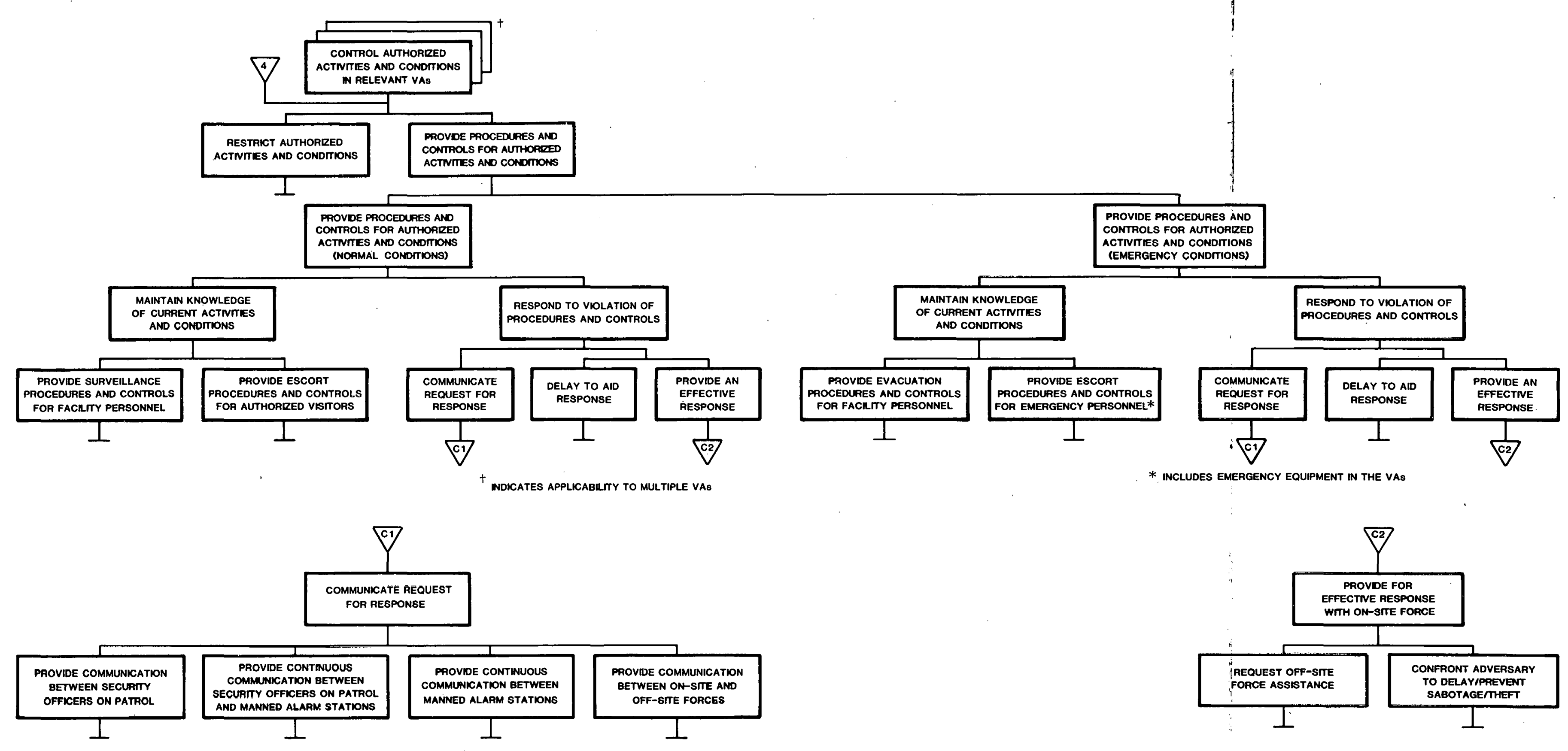

Figure 1. Insider Reactor Safeguards Functional Hierarchy (Continued) 

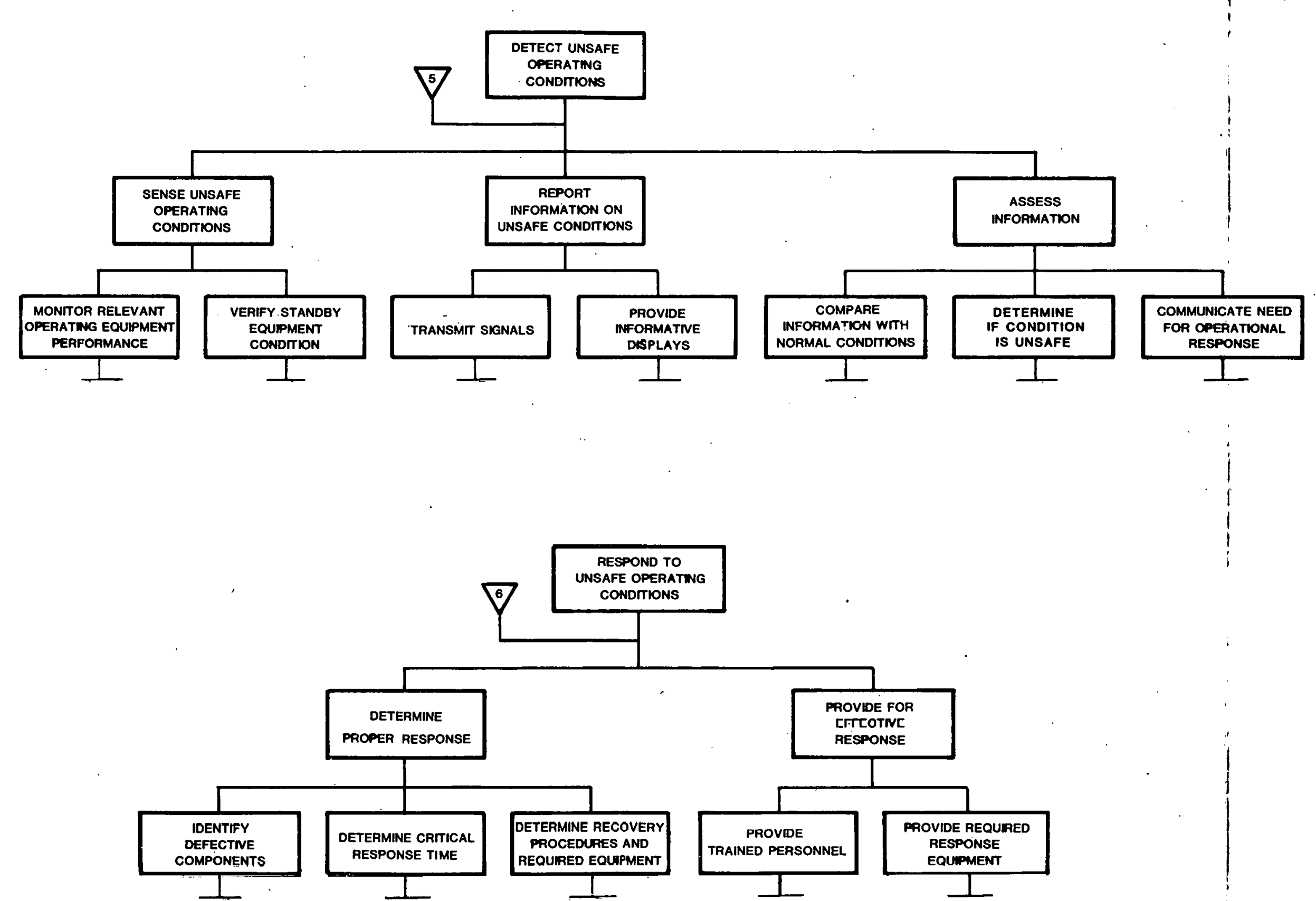

Figure 1. Insider Reactor Safeguards Functional Hierarchy (Concluded) 
First, the insider must successfully complete a specific sequence of sabotage activities which lead to an unsafe reactor condition. Then, the insider must ensure that the unsafe reactor condition continues until radioactive material is released. Therefore, to prevent radioactive release, either of the following system functions must be performed:

1. Prevent activities and conditions contributing to unsafe reactor operation, or

2. Counteract unsafe reactor operation.

The fragment of the functional hierarchy structure that corresponds to these system functions is shown below:

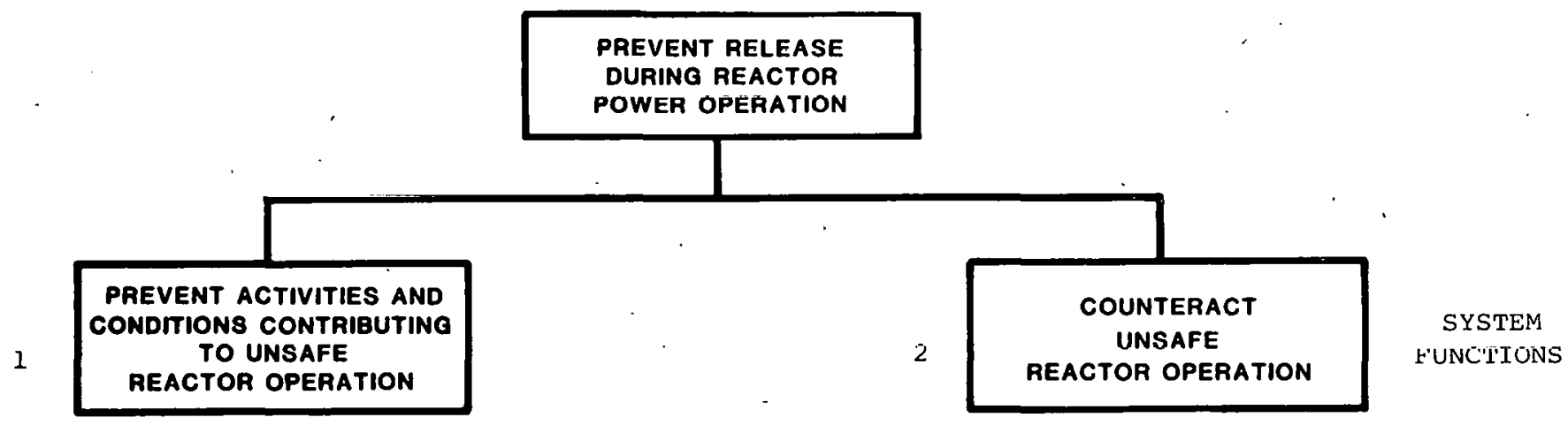

Each of these two system functions can be further decomposed into its respective constituent subfunctions. To accomplish System Function 1, the physical protection system (PPS) must have the capability of preventing unauthorized access to relevant vital areas (VAs) and controlling authorized activities and conditions in relevant VAs.* Thus, the following Level 1 (Ll) subfunctions must be performed:

1.Ll.1 Prevent unauthorized access to relevant vital areas (VAs).

1.L1.2 Control authorized activities and conditions in relevant VAs.

The hierarchical decomposition of system Function 1 into its constituent subfunctions follows:

"The term "relevant vital areas" refers both to Type I vital areas and to sets of Type II vital areas at which sabotage can be accomplished. 


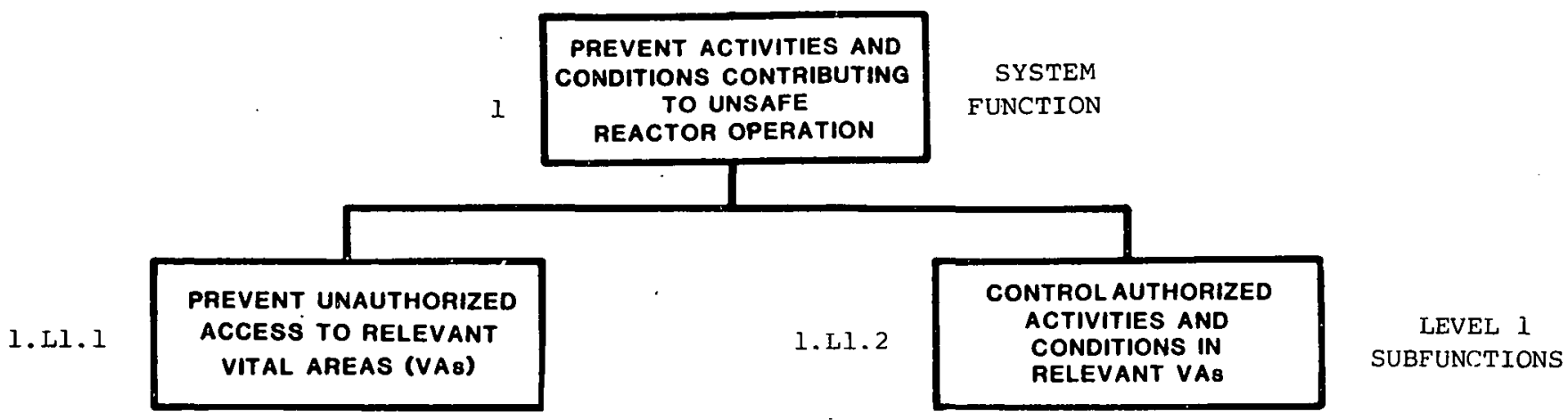

In order to ensure that Subfunction 1.Ll.1, PREVENT UNAUTHORIZED ACCESS TO RELEVANT VAs, is accomplished, it is necessary to determine how an insider might gain access into a VA. There are two possibilities: (1) through an entry portal or door to the VA or (2) through the remaining VA boundary, e.g., wall, vent, etc. Therefore, to prevent unauthorized access into a VA, the following Level 2 (L2) subfunctions must be performed:

1.L2.1 Control access through VA entry portals.

1.L2.2 Deny access through remaining VA boundary.

The segment of the hierarchical structure that corresponds to these subfunctions is shown below:

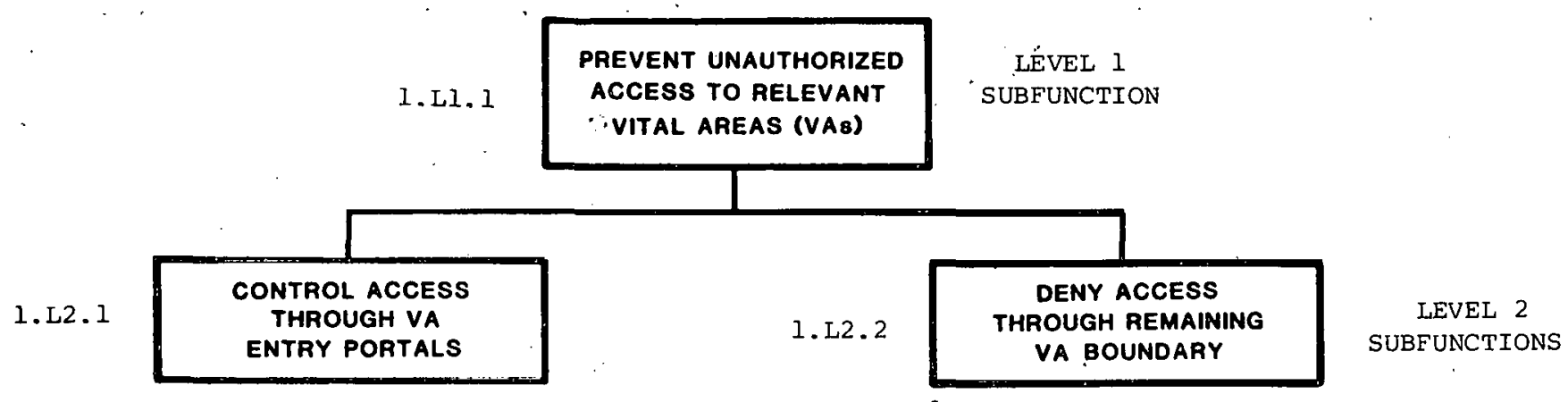

In order for Subfunction 1.L2.1 to be performed, personnel access must be controlled under both normal and emergency conditions. This requires the following Level 3 (L3) subfunctions:

1.L3.1 Control access through VA entry portals under normal conditions.

1.L3.2 Control access through VA entry portals under emergency conditions.:

Examination of access control under normal conditions indicates that there are three ways an insider might gain access: (1) the insider may actually obtain access authorization, (2) the insider ma 
attempt to gain admittance using false credentials, e.g., a counterfeit card key, or (3). the insider may attempt to obtain access by force. Therefore, in order to control access under normal conditions, the following Level 4 (L4) subfunctions are required:

1.L4.1 Restrict access authorization.

1.L4.2 Provide procedures and controls for access (normal conditions).

The purpose of Subfunction $1 . L 4.1$ is to address access authorization criteria, e.g., who is authorized access, where, when, etc. It is important that such criteria be developed to minimize sabotage opportunities; however, it also is necessary to balance the safeguards value of these criteria against their operational impact. Since the access authorization criteria have been addressed, no further decomposition of Subfunction 1.24 .1 is made.

Subfunction 1.L4.2, PROVIDE PROCEDURES AND CONTROLS FOR ACCESS (NORMAL CONDITIONS), can be partitioned further. To prevent an insider from defeating authorized access procedures and controls, the PPS must have a capability to detect any attempts to gain access through deceit (e.g., with false identification, counterfeit entry card, etc.) by verifying authorization and identification. However, detection alone is not sufficient. If an attempt at deceitful or forcible entry is detected, then a response to violations of access procedures and controls is necessary to render the attempt ineffective. Decomposition of Subfunction 1.L4.2 to provide these capabilities yields the Level 5 (L5) subfunctions shown below:

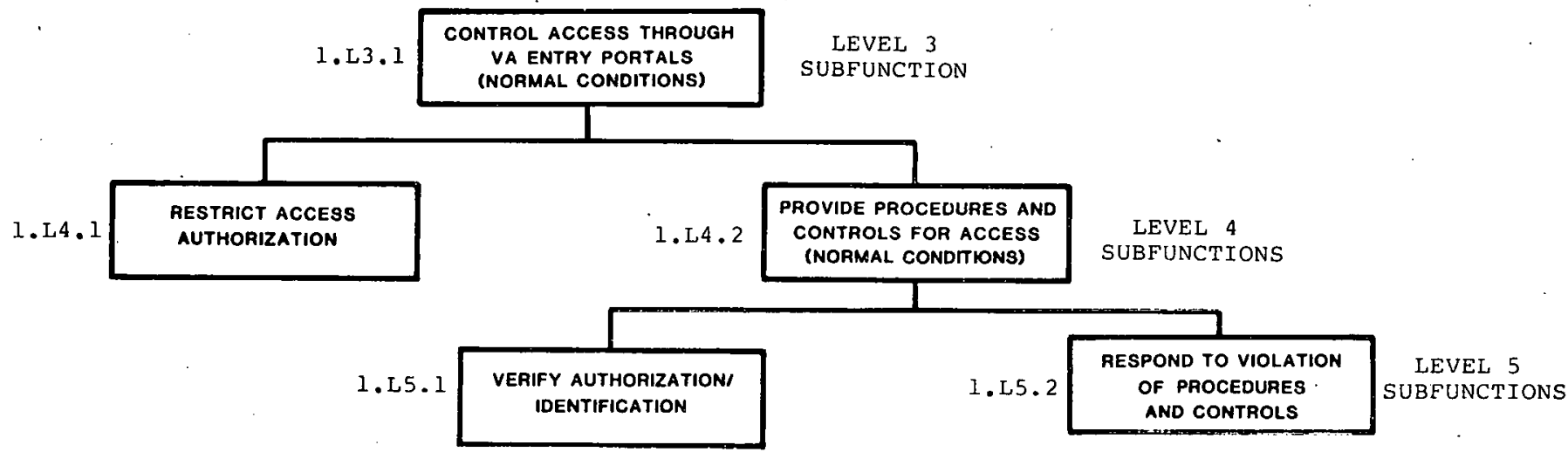

Subfunction 1.L5.1, VERIFY AUTHORIZATION/IDENTIFICATION, is defined in sufficient detail to permit performance assessment without further decomposition. Performance criteria and methods to evaluate verification procedures are required at this point. Subfunction 1.L5.2, RESPOND TO VIOLATION OF PROCEDURES AND CONTROLS, however, can be further subdivided into its constituent parts. 
To ensure a successful response, as required in subfunction 1.L5.2, several capabilities are required. First, if access control personnel require assistance from security personnel, an effective means of communication must be available. Given a request for response force assistance, the PPS must provide a timely response. A timely response reflects a close interaction between the delay of insider actions provided by the PPS and the ability of the response force to arrive within that delay time. This interaction is shown in the following hierarchy segment:

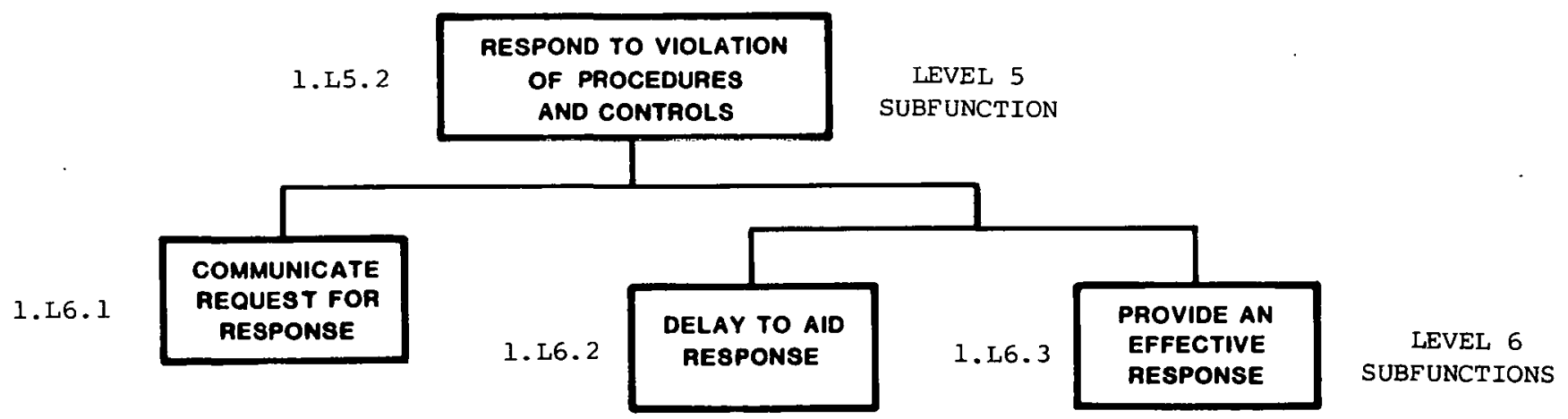

Subfunction 1. L6.2 represents the delay provided by the PPS in response to a procedure/control violation. Its purpose is to impede the progress of the insider between the point at which an unauthorized attempt to gain access is detected and the point at which the insider's progress must be stopped if sabotage is to be prevented: No further expansion of this subfunction is necessary. The remaining two Level 6 subfunctions require further decomposition: the communication subsystem (Subfunction 1.L6.1) and the effective response subsystem (Subfunction 1.L6.3).

In order to ensure effective communication (Subfunction 1.L6.1), several different lines of communication must be available (as shown in the L7 subfunctions). Security officers (response force personnel) on patrol must be able to communicate with each other if assistance is required (1.L7.1). These personnel also should be able to communicate readily with manned alarm stations since this is where response decisions and commands usually originate (1.L7.2). There should also be continuous communication between the central and secondary Alarm stations (CAS and SAS) for assistance in receipt of information and in the response effort (1.L7.3). Finally, if the threat posed requires assistance from off-site response forces, provisions must exist for communication with local law enforcement agency officers (1.L7.4). The segment of the hierarchy describing this decomposition follows: 


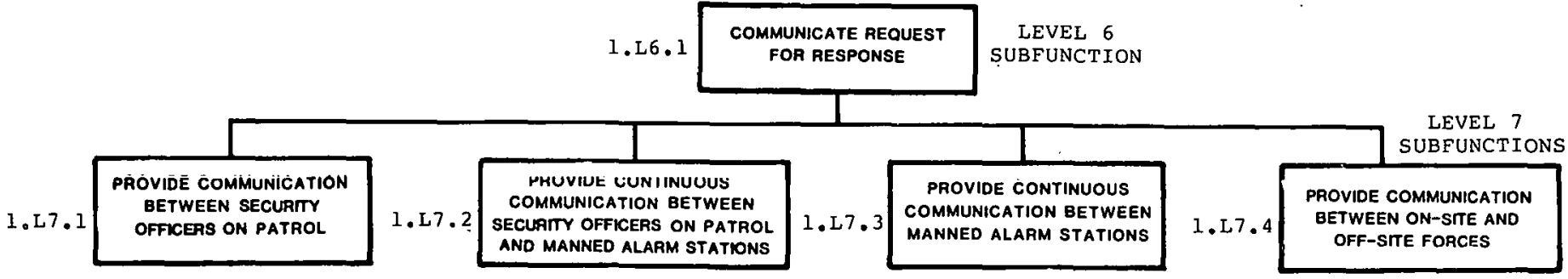

Further decomposition of these subfunctions is unnecessary.

To ensure that an effective response (Subfunction 1.L6.3) can be provided over a wide range of insider threats, provisions must be made for both an effective on-site and off-site response. Decomposition of Subfunction 1.L6.3 to provide these capabilities yields the Level 7 (L7) subfunctions shown below:

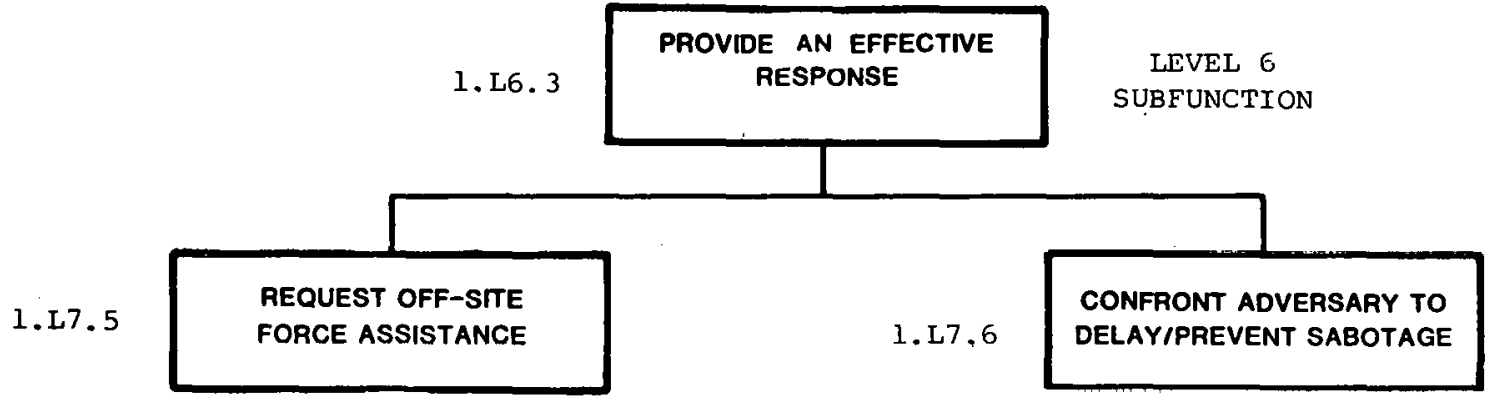

L.EVEL 7 SUBFUNCTIONS

This completes the hierarchy development for subfunction 1.L3.1. A functional decomposition of Subfunction 1.L3.2, CONTROL ACCESS THROUGH VA ENTRY PORTALS (EMERGENCY CONDITIONS), is presented next.

The subfunctions necessary to control access to a VA under emergency conditions are somewhat similar to those required during normal conditions in that some means of detecting and responding to unauthorized attempts to gain access to the VA must be provided. However, emergency conditions also pose significant problems to the PPS not encountered during normal conditions since controls on personnel access during emergency conditions are usually minimal. In most cases, medical, fire, or other emergency personnel who are not usually authorized to access the VA require hasty admittance. Thus, controlling personnel access is limited to verifying with the security entrycontrol personnel that emergency personnel who have been admitted actually were authorized to enter the facility and providing an effective response if any violations occur. The decomposition of subfunction 1.L3.2 follows: 


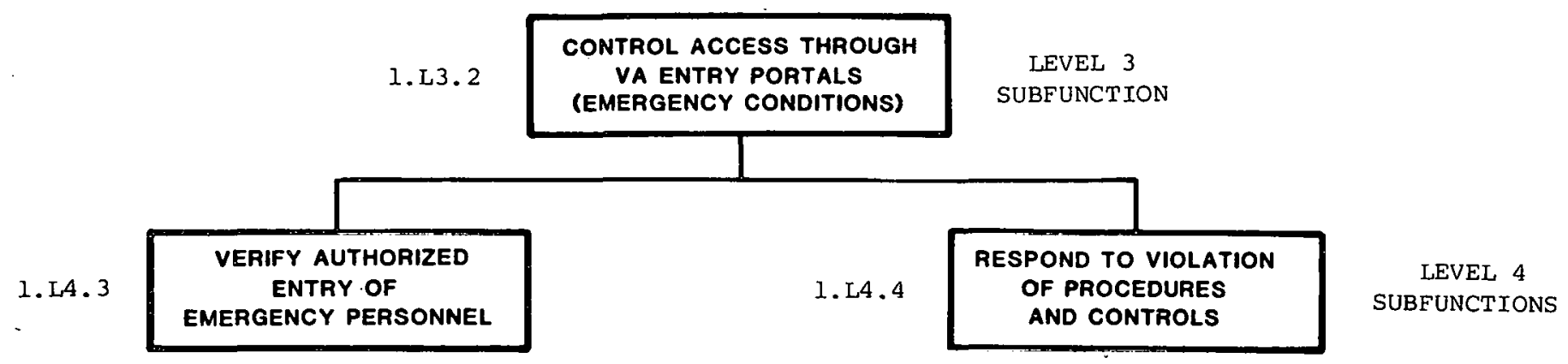

Subfunction 1.L4.3 is detailed sufficiently for assessment purposes; therefore, no further decomposition is required. The response Subfunction $1 . \mathrm{L} 4.4$ is not decomposed here since the constituent subfunctions required to perform the response subfunction under emergency conditions are the same as those for normal conditions (see subfunction 1.L5.2).

The functional decomposition for subfunction 1.L2.1, CONTROL ACCESS THROUGH VA ENTRY PORTALS, is now complete. System Subfunction 1.L2.2, DENY ACCESS THROUGH REMAINING VA BOUNDARY, is expanded next.

There is a noticeable similarity between the Level 2 subfunctions required to prevent unauthorized access to relevant VAs through VA entry portals (1.L2.1) and those required to prevent access through the remaining VA boundary $(1 . L 2.2)$. In both cases, the PPS must ensure detection of and response to the insider threat. The decomposition of Subfunction 1.L2.2 is shown below:

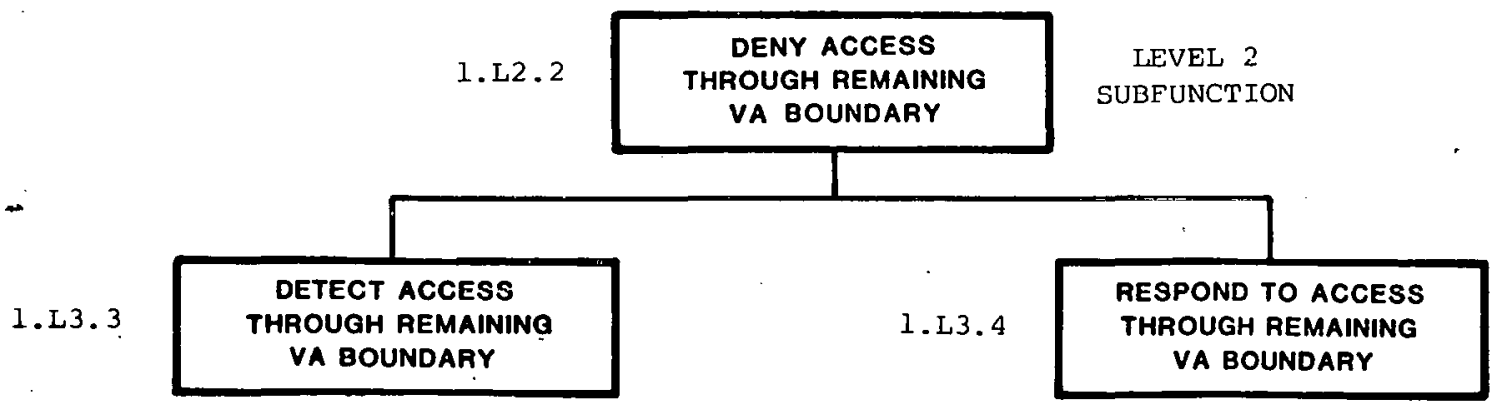

LEVEL 3 SUBFUNCTIONS

The decomposition of the response subfunction (1.L3.4) is expected to be the same as that for subfunction 1.L5.2 and, therefore, is not included here.

Subfunction 1.L3.3, DETECT ACCESS THROUGH REMAINING VA BOUNDARY, does require a different set of subfunctions from those previously identified for detection under subfunction. 1.L2.1. In the latter case, the insider attempts to gain access through a VA entry portal either by force or by feigning authorized access. In either 
instance, the detection subfunction is heavily dependent upon the entry-control system and procedures at the VA portal. However, detection of attempts to gain access through the remaining VA boundary, e.g., through a vent duct, rely primarily on electromechanical components. In either case, a security force may sense the intrusion attempt. Sensing the intrusion, however, is not sufficient to prevent unauthorized access; adequate response is also required.

Subfunction 1.L3.3 can be further decomposed depending upon the type of access detection used. First, detection by some periodic means, e.g., a closed-circuit television (CCTV) camera which scans an entire room a section at a time or a security force patrol which patrols around a building once an hour, is considered. In this case, sensing of an intrusion will not occur unless there is sufficient delay to allow the sensor (equipment or personnel) to cover the point of intrusion during that time. For example, if it takes the insider 1 minute to pick a door lock to a room and it takes the security officer 30 minutes to patrol the building, then the insider can begin the intrusion process once the security officer has passed the access point. By the time the security officer returns to the access point, the insider will have gained access, possibly without leaving any signs of entry. If sensing is not periodic, the delay task does not play a part in ensuring that the intrusion is sensed. Because the detection subsystem must be effective over a wide range of conditions, its decomposition reflects the case in which delay is necessary. Two interrelated tasks have been identified in this decomposition:

\section{L4.5 Delay to aid sensing. \\ 1.L4.6 Sense boundary penetration.}

Sensing of an intrusion by either electromechanical or human means, however, is not sufficient to ensure detection. The alarm must be reported by either electronic means or by personnel who have sensed the intrusion (1.L4.7). These factors alone still do not constitute detection. Because the incidence of false alarms is a possibility, assessment must also take place (1.L4.9). Assessment is similar to sensing by periodic means in that sufficient delay (1.L4.8) must be provided to detain the adversary long enough to verify that a valid alarm has been received and to obtain sufficient information to initiate an appropriate response. The resulting decomposition for the detection subfunction is shown below:

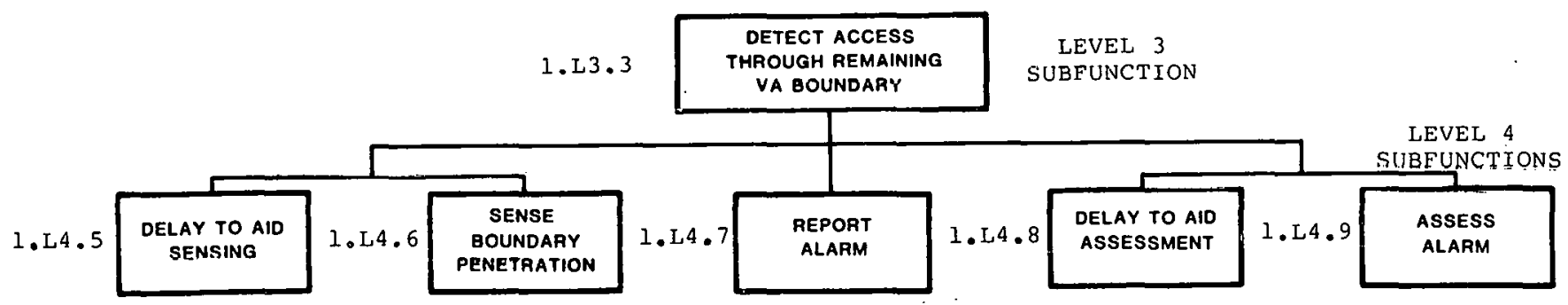


Only one of the above subfunctions requires further decomposition, Subfunction 1.L4.7, REPORT ALARM. The other subfunctions have been defined in sufficient detail to permit assessment of the components required to achieve the desired subfunction performance.

Subfunction 1.L4.7, REPORT ALARM, need not be partitioned further if access is detected by a human sensor. If a piece of equipment constitutes the sensor, the signal from the sensor must be transmitted (Subfunction $1 . \mathrm{L} 5.6$ ) and the alarm must be annunciated (Subfunction 1.L5.7) at the alarm station in order for alarm reporting to occur. The tasks resulting from this final decomposition are shown below:

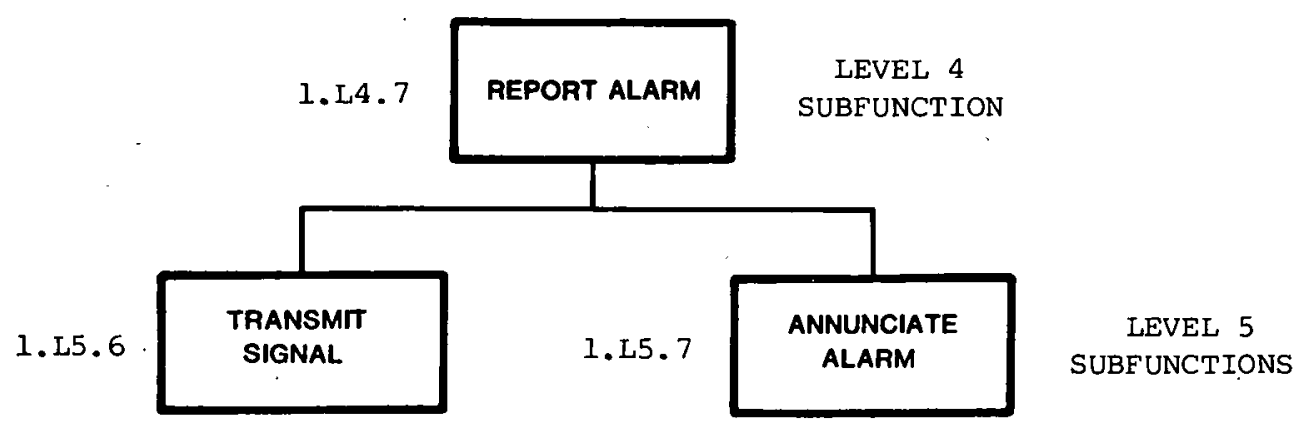

This concludes the functional decomposition of the Level 1 System Subfunction 1.L1.1, PREVENT UNAUTHORIZED ACCESS TO RELEVANT VITAL AREAS.

System Subfunction 1.Ll.2, CONTROL AUTHORIZED ACTIVITIES AND CONDITIONS IN RELEVANT VAs, is subdivided next. Subfunction 1.LI.2 requires that criteria be established for authorizing work functions within a VA, e.g.., who, what, when, etc. The value of these criteria in minimizing sabotage opportunities should be balanced against their operational impact. In addition, there must be some means of ensuring that only authorized activities. are carried out. These concerns lead to the development of the following Level 2 (L2) subfunctions:

1.L2.3 Restrict authorized activities and conditions.

1.L2.4 Provide procedures and controls for authorized activities and conditions.

Subfunction 1.L2.3 has been defined in sufficient detail to permit performance assessment without further subdivision. Subfunction 1.L2.4, however, requires further decomposition. In order for Subfunction 1.L2.4 to be performed, authorized activities and conditions must be controlled and procedures established for both normal and emergency conditions. These considerations lead to the development of the following Level 3 (L3) subfunctions:

1.L3.5 Provide procedures and controls for authorized activities and conditions under normal conditions. 
1.L3.6 Provide procedures and controls for authorized activities and conditions under emergency conditions.

The resulting decomposition is shown below:

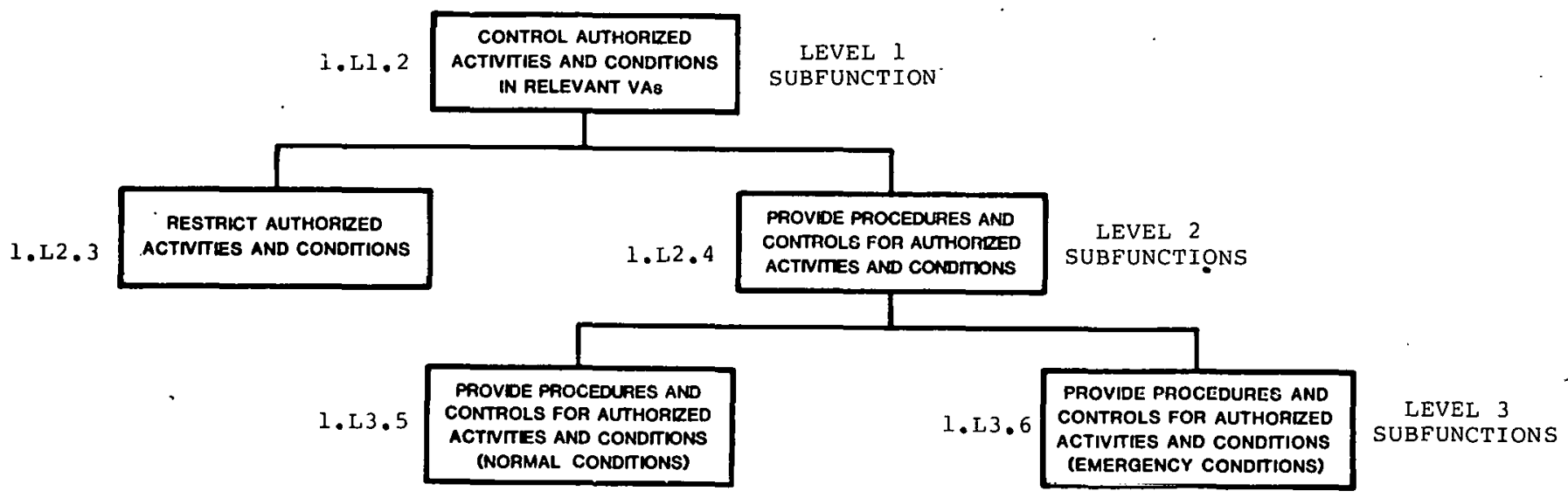

As can be expected, in all physical protection oriented systems there is a definite correspondence between the decomposition of subfunction 1.L4.2 and Subfunction 1.L3.5, which provide procedures for controlling access and for controlling authorized activities, respectively. This similarity is dictated by the basic premise that both detection and response functions are necessary for an effective PPS. The decomposition of Subfunction 1. L3.5 is shown below:

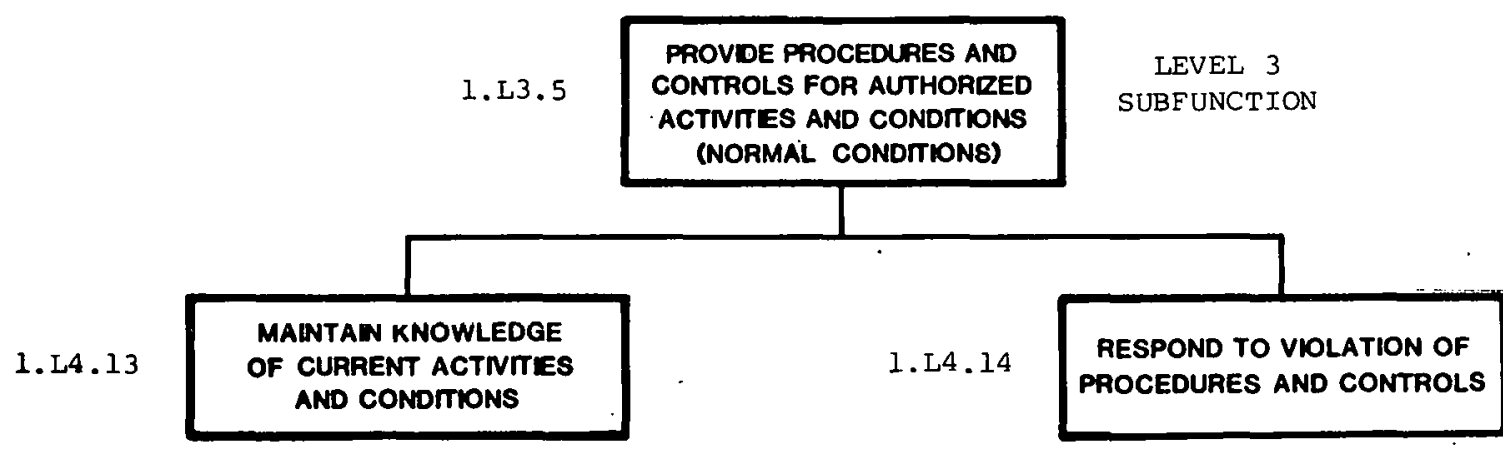

LEVEL 4 SUBFUNCTIONS

The similarity between response subfunction $1 . L 4.14$ and $1 . L 5.2$ suggests the same decomposition; therefore, a description of subfunction 1.L4.14 is not. included here.

Knowledge of current activities and conditions (Subfunction 1.L4.13), while providing à form of detection, requires a different set of subfunctions from previously identified detection subfunctions. Maintaining an awareness of activities and conditions within the VA requires close supervision or surveillance of employees (1.L5.8) and 
authorized visitors, i.e., anyone not an employee (1.L5.9). This results in the decomposition shown below:

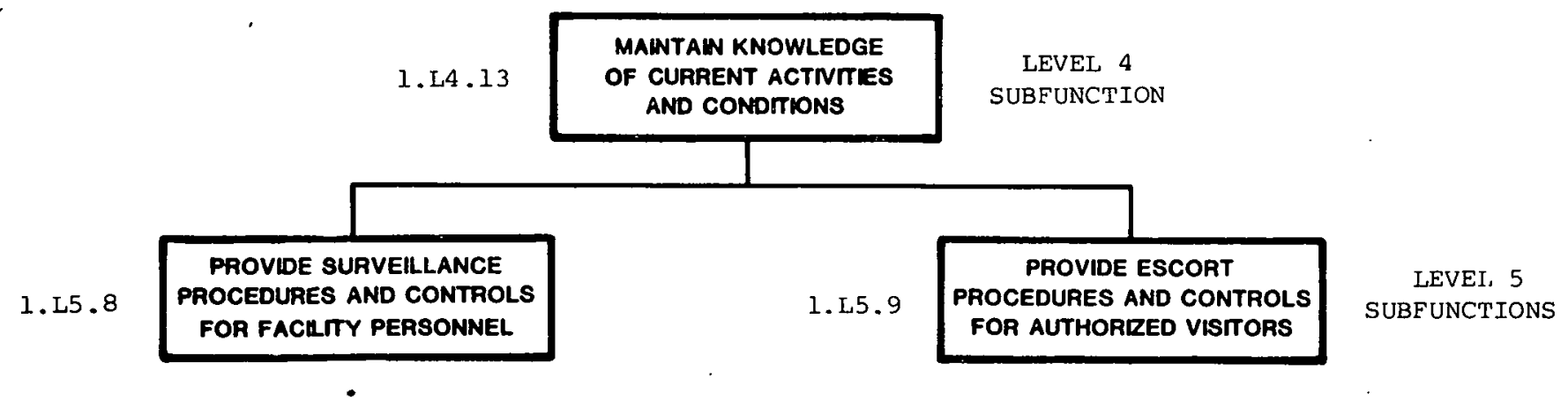

The subfunctions necessary to control activities and conditions under emergency conditions (1.L3.6) are similar to those required under normal conditions (1.L3.5), except that emergency controls are usually minimal. Decomposition of Subfunction 1.L3.6 therefore is not included here.

The decomposition of the functions and subfunctions required to prevent insider sabotage of a reactor facility by preventing activities and conditions contributing to unsafe reactor operation (System Function 1) is now complete. Although not specifically included in this structure, physical protection controls and procedures to prevent the introduction of contraband into the protected area, while they may not prevent sabotage, do provide an important function in limiting insider sabotage options.

Next, the functions and subfunctions required in the event an insider has been successful in disabling vital systems are structured. This hierarchy begins with system Function 2, COUNTERACT UNSAFE REACTOR OPERATION, which is decomposed next.

To counteract unsafe reactor operation (System Function 2), it is necessary for the operating system to detect any unsafe conditions which exist and then respond to them. To accomplish this, the following Level 1 (Ll) system subfunctions must be performed:

2.L1.1 Detect unsafe operating conditions.

2.Ll.2 Respond to unsafe operating conditions.

For an unsafe operating condition to be detected, the condition first must be sensed either by hardware or by human sensors (e.g., by a facility operator making his rounds). However, sensing alone is not sufficient. The sensed information must be transmitted to the appropriate place (e.g., the control room) where an assessment can be made. To accomplish this, the following three subfunctions are required:

2.L2.1 Sense unsafe operating conditions.

2.L2.2 Report information on unsafe conditions. 


\section{L2.3 Assess information.}

The resulting decomposition for the System Function 2 detection subfunction (Subfunction 2.L1.1) is shown below:

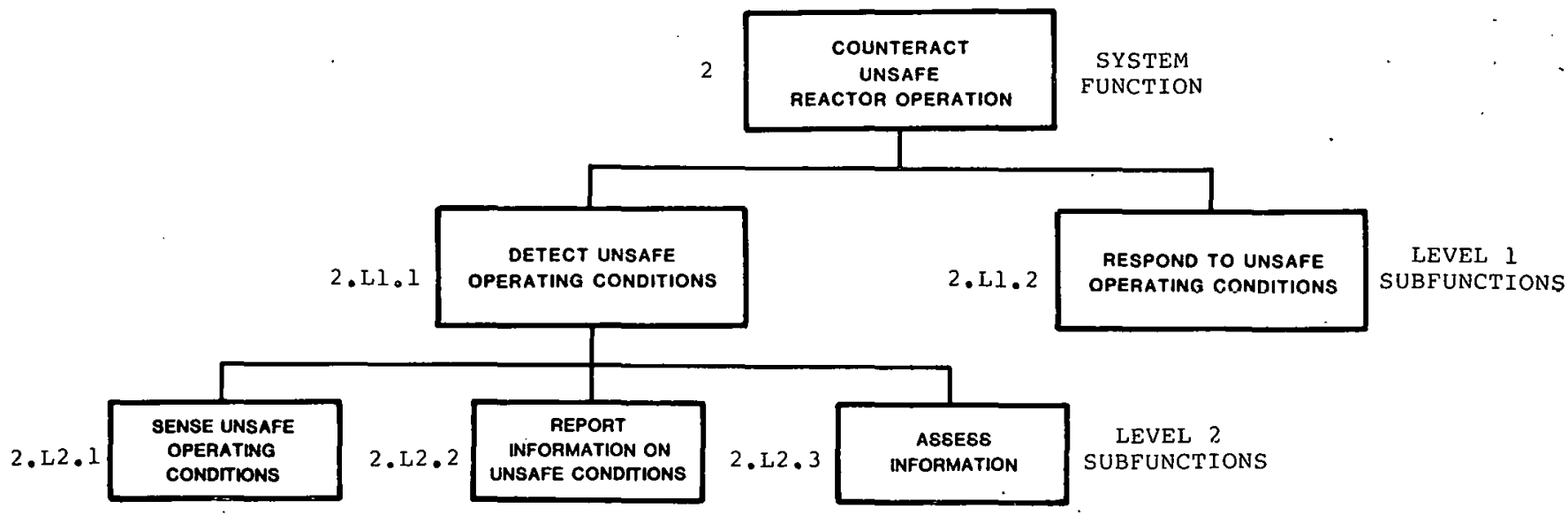

To ensure safe reactor operating conditions, all reactor support equipment as well as standby safety-related equipment must be in proper functional condition on demand. The performance of much of the facility's equipment is sufficiently monitored while it is operating for deviations from normal operating conditions to be recognized. However, continuous assurance that equipment in standby mode, e.g., safety-related systems, will respond properly on demand may be very difficult to achieve. While periodic testing and inspections can indicate equipment condition at the time of inspection, some means of indicating any subsequent changes in condition may be necessary to permit a timely response to unsafe conditions. These considerations lead to the development of the following Level 3 (L3) subfunctions:

2.L3.1 Monitor relevant operating equipment performance.

2.L3.2 Verify standby equipment condition.

The resulting decomposition is shown below:

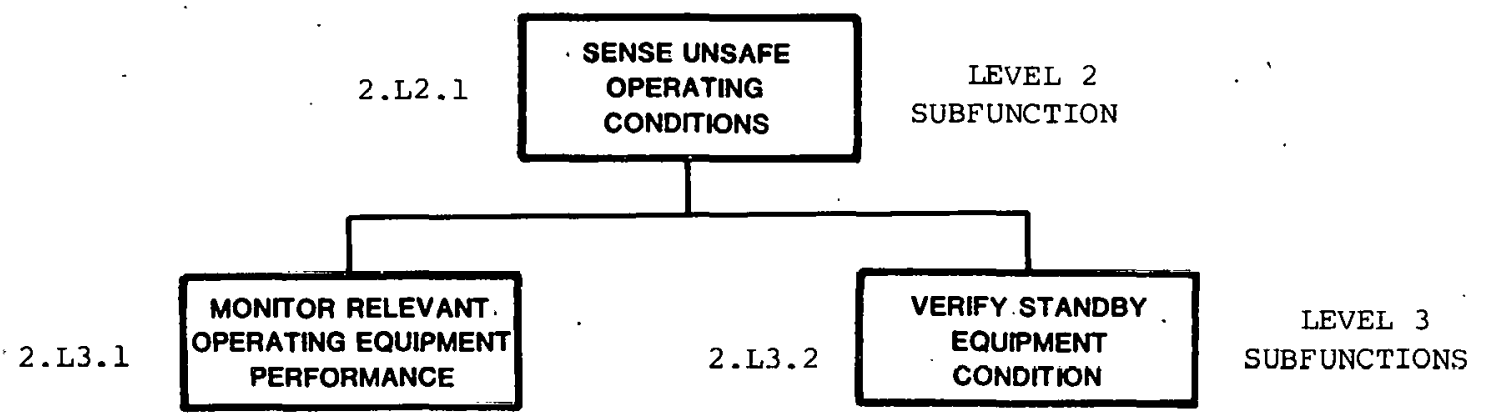


Subfunctions $2 . \mathrm{L} 3.1$ and $2 . \mathrm{L} 3.2$ seem sufficiently detailed to permit assessment of the components required to achieve the desired subfunction performance. Therefore, no further decomposition is made.

If the monitoring of facility equipment indicates that any of the equipment is in an unsafe or disabled condition, this information must be reported (Subfunction 2.L2.2). The information must be transmitted to the appropriate place, e.g., the control room, and displayed in a readily comprehendable form. The hierarchy segment identifying these required subfunctions is shown below:

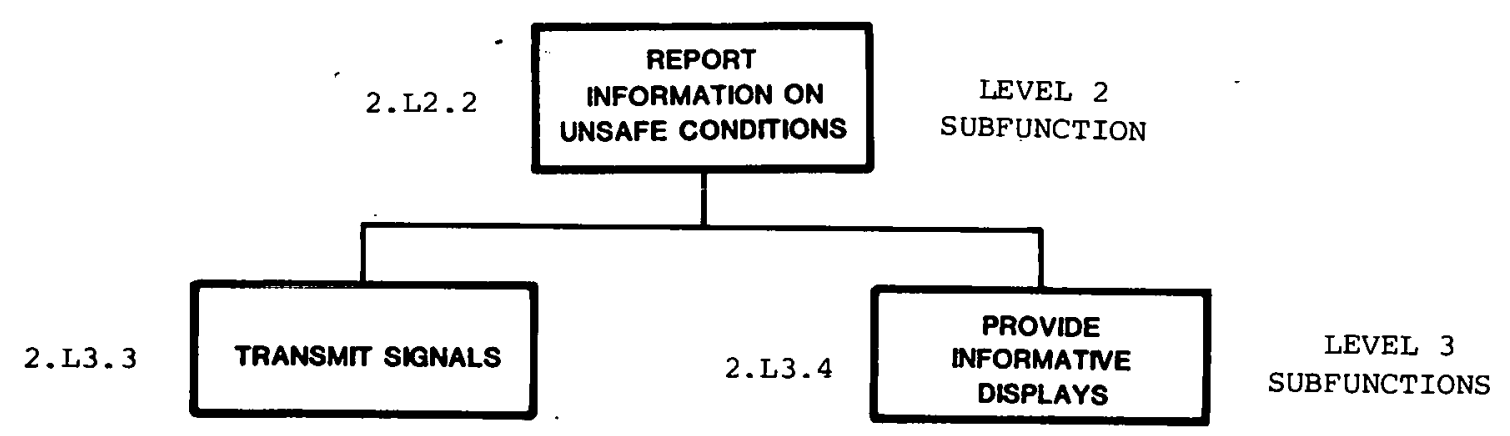

Next, the information must be assessed (Subfunction 2.L2.3). Basically, this consists of comparing the received data with normal data, deciding if there is an unsafe condition, and if so, communicating a need for an operational response. The Level 3 (L3) subfunctions required for effective information assessment are decomposed below:

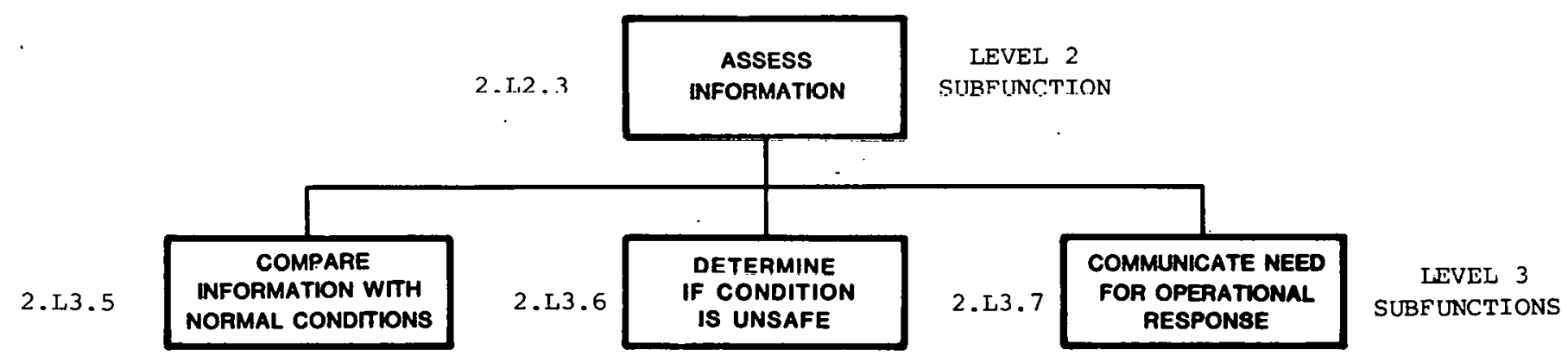

These Level 3 subfunctions seem sufficiently detailed to eliminate the need for further partitioning. This completes the functional decomposition of Subfunction 2.L1.1. Next, Subfunction 2.L1.2, RESPOND TO UNSAFE OPERÀTING CONDITIONS, is decomposed.

In order to return an unsafe reactor to a safe and stable condition with no radioactive material released, the operating system must respond to the unsafe operating conditions (Subfunction 2.L1.2). This capability can be subdivided into two constituent subfunctions: the control room operators must determine the proper response to correct the unsafe condition (2.L2.4) and then must provide for effective response (2.L2.5). This decomposition follows: 


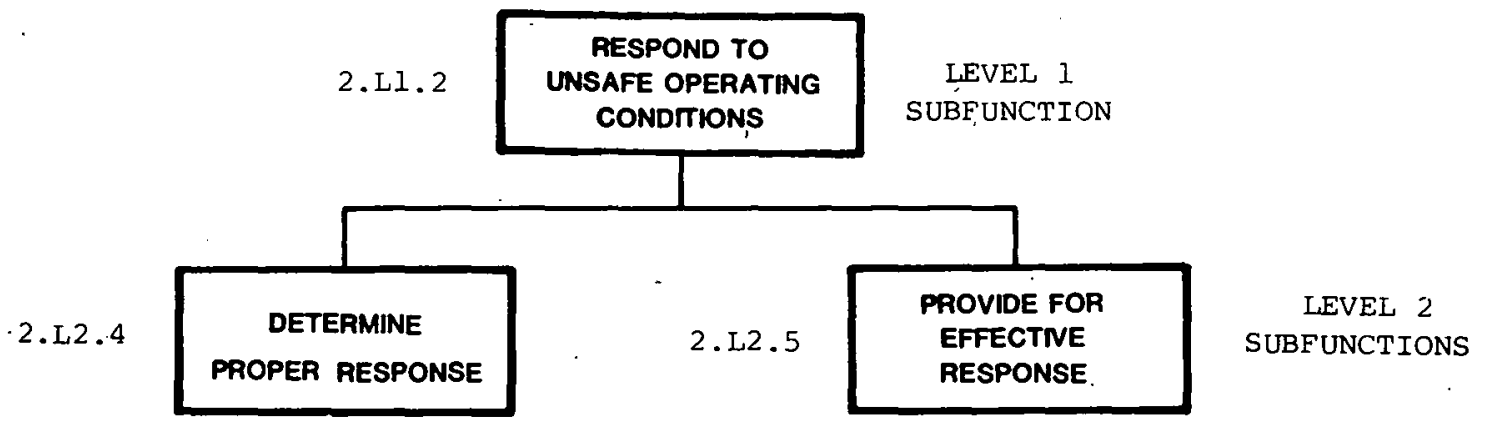

Determining a proper response (Subfunction 2.L2.4) èntails identifying the defective critical components (2.L3.8), determining how much time is available before the point occurs at which the reactor cannot be recovered (critical response time) (2.L3.9), and deciding upon the best recovery procedures and equipment (2.L3.10). This decomposition is shown below:

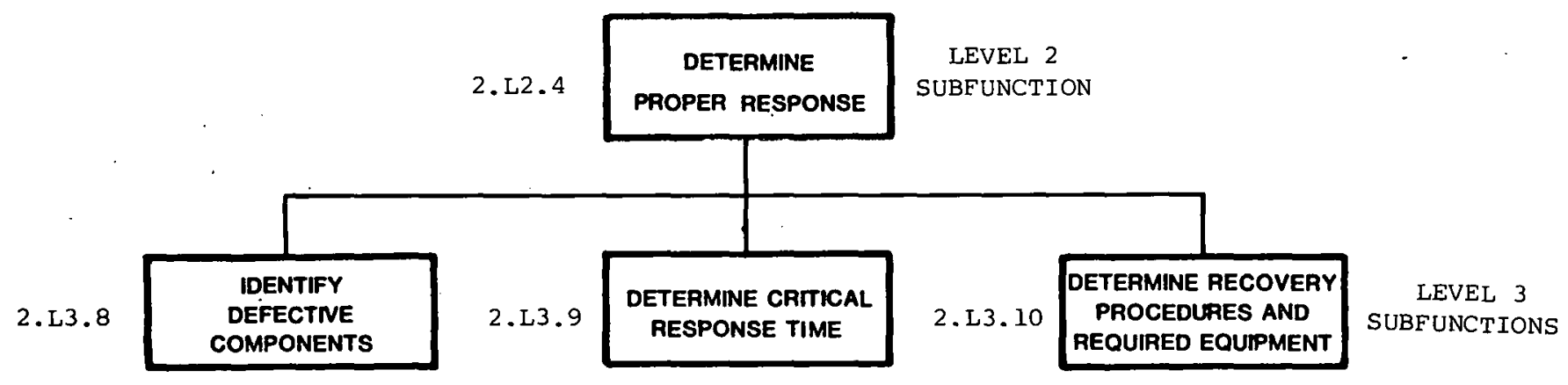

These subfunctions seem sufficiently detailed to permit assessment of subfunction performance and hence are not decomposed further.

Since time can be a critical factor in the success of an operational response (Subfunction 2.L2.5), it is essential that response team personnel be well-trained (2.L3.11) and have the required equipment readily available (2.L3.12). This decomposition is shown below:

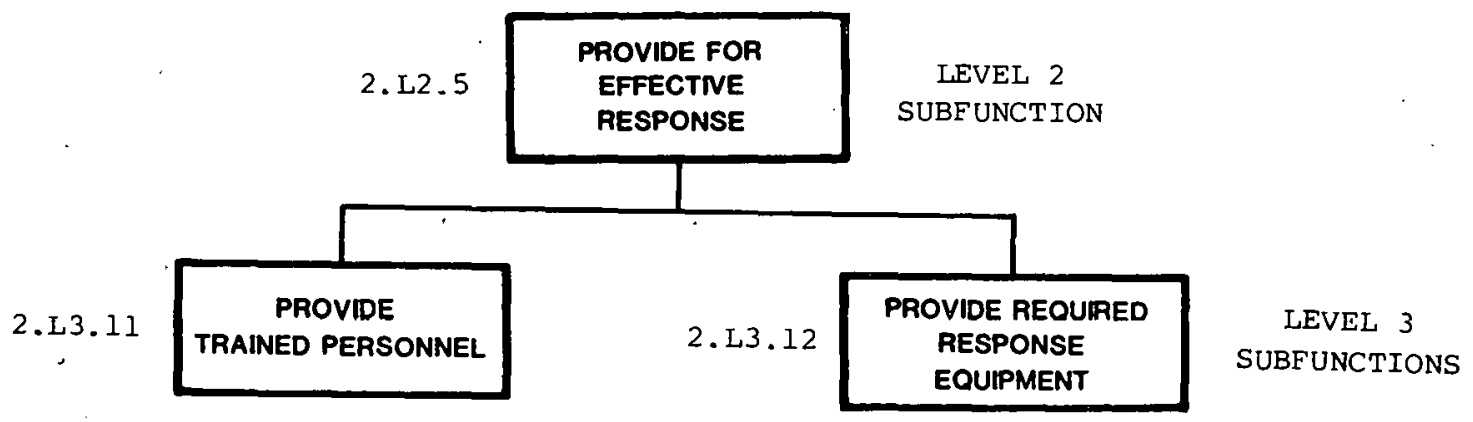


These Level 3 subfunctions are sufficiently detailed to permit assessment of subfunction performance and therefore are not decomposed further.

This completes decomposition of Subfunction $2 . \mathrm{L} 1.2$ and of the entire insider reactor safeguards functional hierarchy. All functions known to play a role in preventing the release of radioactive material from the reactor facility have been identified. Structural modeling has transformed a mental concept of a system into a clear, graphic model that portrays all system functions and their interrelationships. Such a model can serve both as a focal point for clarifying discussions and, perhaps of greater importance, as a structure for an assessment methodology. This methodology could provide a means of explicitly incorporating measures for highly important performance factors that are often difficult to quantify, such as component compatibility, installation, operation, and maintenance, as well as personnel training and proficiency levels. This could be achieved by aggregating responses to component and system questionnaires through successive levels of the functional hierarchy. The resulting overall measure of system performance would reflect a broader treatment of the insider sabotage problem than is provided by current dynamic models. 


\section{OPERATIONAL RECOVERY}

\section{$3.1 \quad$ DISCUSSION}

Operational recovery is concerned with post-sabotage responses that can be made by reactor operators to prevent radioactive materiál release from a nuclear power facility. Conceptually, such responses could include (1) temporary repairs of a disabled system, or (2) temporary substitution of an alternate, but suitable, set of components to perform the functions of a disabled system. For operational recovery to be successful, the loss of vital functions must be detected while there is still sufficient time remaining for their restoration. This restoration must occur before a critical. condition is reached in which radioactive material release cannot be prevented. This implies that two basic functions must be provided: (1) detect unsafe reactor operating conditions and (2) respond to unsafe operating conditions. These functions have been discussed and structured generically in Section 2.2. The constraints on the success of an operational recovery, therefore, are availability. of information, time, trained personnel, and required equipment.

Current sources of information on operational status within the facility include (1) instrumentation used to monitor normal facility operation, (2) facility safety-related display instrumentation, and (3) periodic equipment checks by facility personnel.

Facility-operation-monitoring instrumentation and facility safety-related instrumentation provide component status indications for many components, e.g., valve open/close, pump on/off, etc. These status indicators provide a reasonable capability for detecting sabotage of equipment if an alteration in the operating status of a component should occur, e.g., an open valve closes. Even if a saboteur should disable the component status indicator, for given conditions, variations in monitored facility parameters could (if properly interpreted) provide a means of inferring component status. The safetyrelated status indicators, however, cannot detect sabotage of a component when its status is not altered, e.g., an open valve is disabled open. Therefore, additional status detection methods may be of value.

Standby components, e.g., auxiliary feedwater (AFW) pumps and diesel. generators, appear to present the greatest difficulty in detection of sabotage acts. In general, sabotage of these components consists of preventing their operation when demanded, rather than causing their unscheduled operation. Again, status indicators are not capable of detecting this type of sabotage mode. Such sabotage acts may not be detected until facility personnel conduct periodic equipment checks or until component operation is demanded. For additional information on the subject of status/tamper indicators, see Reference 1. 
Recovery of a reactor to a safe and stable condition with no radioactive material released depends, to a large extent, upon the time required to take remedial action. The earlier sabotage detection occurs, the more time and options are available for recovery. Detection of sabotage of two or more vital components at the time of demand places the greatest stress on the recovery system personnel and equipment.

For operational recovery to be a dependable option against sabotage, contingency planning is necessary. An inventory should be made of any existing facility equipment that may act as a suitable substitute for a vital component. Furthermore, to effectively deal with such emergencies, facility personnel require considerable training in this mode of operation. Of course, extensive preparations for operational recovery make sense only for credible responses.

\subsection{RESULTS TO DATE}

In an earlier study on design concepts for sabotage protection, 2 a number of damage control concepts and possible options were identified which might be employed to mitigate the effects of a sabotage act at a nuclear facility. Within this same study, currently in Phase II, Science Applications, Inc. (SAI) is now analyzing those early concepts. ${ }^{2}$ The results to date indicate that many of the original concepts identified do not stand the test of an in-depth evaluation. However, there are some which appear to have both sabotage and safety-related implications.

Five basic assumptions concerning postulated sabotage at a nuclear facility were made in the current SAI work.

- Pressurized water reactor (PWR) reactor, initially in power operation

- Single-insider threat without explosives

- Loss of off-site power (LOSP)

- Only radioactive release from the reactor core is of concern

- An open pressurizer relief valve constitutes a small lossof-coolant accident (LOCA) [LOCA Type I]

The assumption of no explosives has the greatest impact on the study since it eliminates the possibility of a large LOCA inside containment as a sabotage event.

The time urgency of operational recovery methods is illustrated in Figure 2,* which depicts the required time schedule for safety functions for various PWR designs to avert uncovering the core after an LOSP initiating event.

* The illustration shown in Figure 2 is derived from Reference 3. 


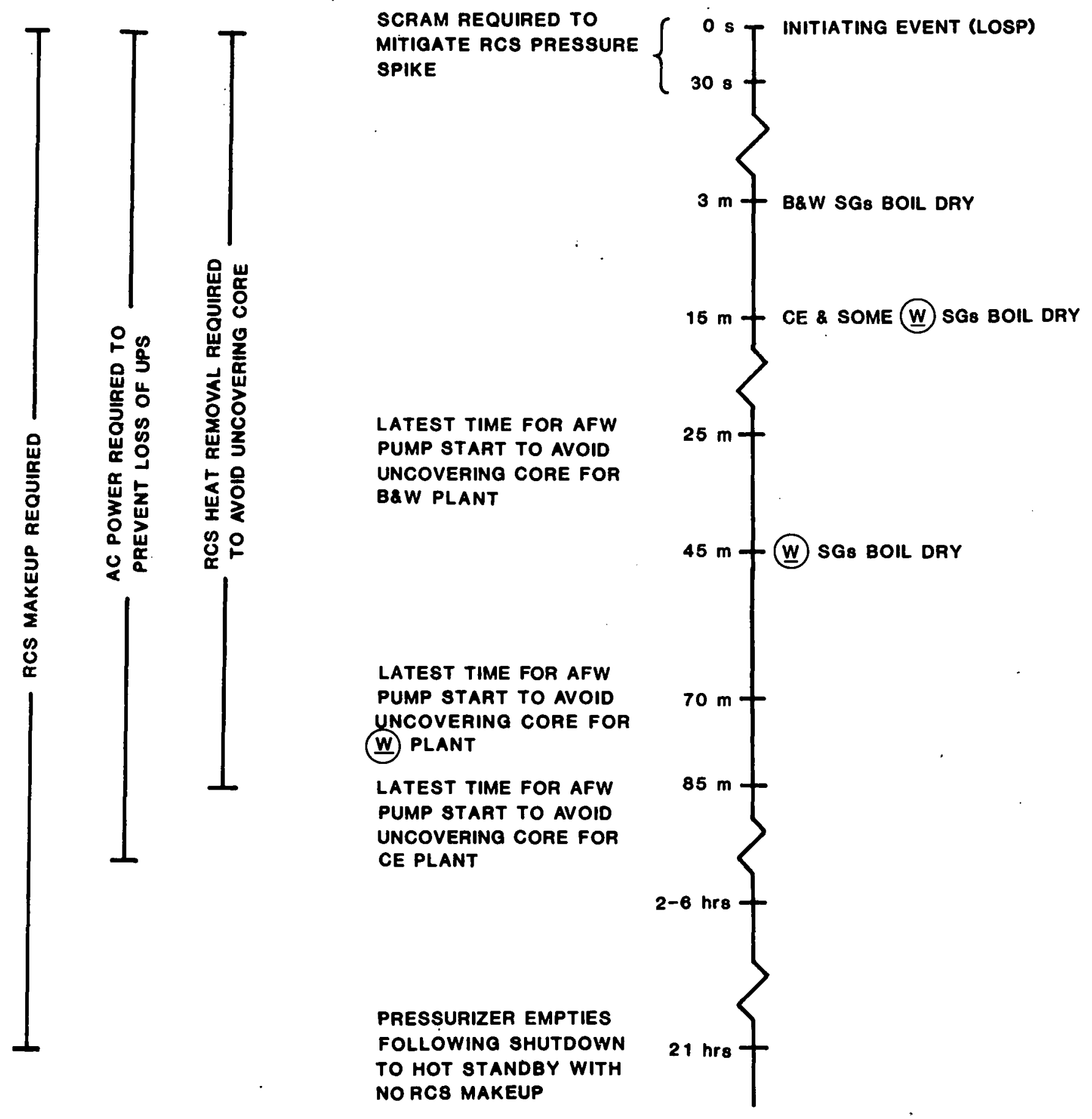

Figure 2. PWR Safety Function Timeline (Initiating Event $=$ LOSP) 
For an example PWR, the SAI fault-tree solutions result in essentially four basic strategies for coping with the insider scenario described above:

1. Prevent a LOCA in the shutdown cooling suction line, i.e., a LOCA outside containment (hereafter referred to as LOCA F), protect or take credit for time requirements associated with mitigating systems for transients, pressurizer valve LOCAS (LOCA I), and failure of a letdown line outside containment (LOCA L).

2. Prevent LOCA $F$ and LOCA I, protect or take credit for time requirements associated with mitigating systems for transients and LOCA L.

3. Prevent LOCA $F$ and LOCA I, protect or take credit for time requirements associated with mitigating systems for transients and the isolation capability for LOCA L.

4. Prevent LOCA F, LOCA I, and LOCA L, protect or take credit for time requirements associated with mitigating systems for transients.

Figure 3 illustrates the system requirements for each of the four basic protection strategies that have evolved.* All strategies require protection of the same base set of systems, as indicated. However, only one safety train must be preserved ( $A$ or $B$ ) to meet this requirement. Damage control is not an option for protecting these systems.

By examining any branch shown in Figure 3 for a particular strategy, additional systems that require protection against sabotage can be identified. The first item(s) encountered (containment local, LOCA I source, or LOCA L source) are essentially required at $t$ ime $t=$ 0 . As the selected branch continues toward the right (i.e., in the direction of increasing time), additional system requirements are defined. If a system is not available by the specified time after the initiating event, it is assumed that core meltdown cannot be prevented. The time events included in the PWR fault tree and represented in Figure 3 consist of the following:

- SLOCA I--the time it takes for a small LOCA I (pressurizer safety valve or power-operated relief valve (PORV), typically in the 2- to 6-inch-diameter break-size range) to uncover the core without makeup.

- AFWT--the time at which the auxiliary feedwater system (AFWS) must be placed in operation to prevent core meltdown.

- SLOCA L--the time it takes for a small LOCA L (letdown or sample line break outside containment, typically less than 2-inch-diameter break size) to uncover the core without makeup.

* The illustration shown in Figure 3 is taken from Reference. 3. 


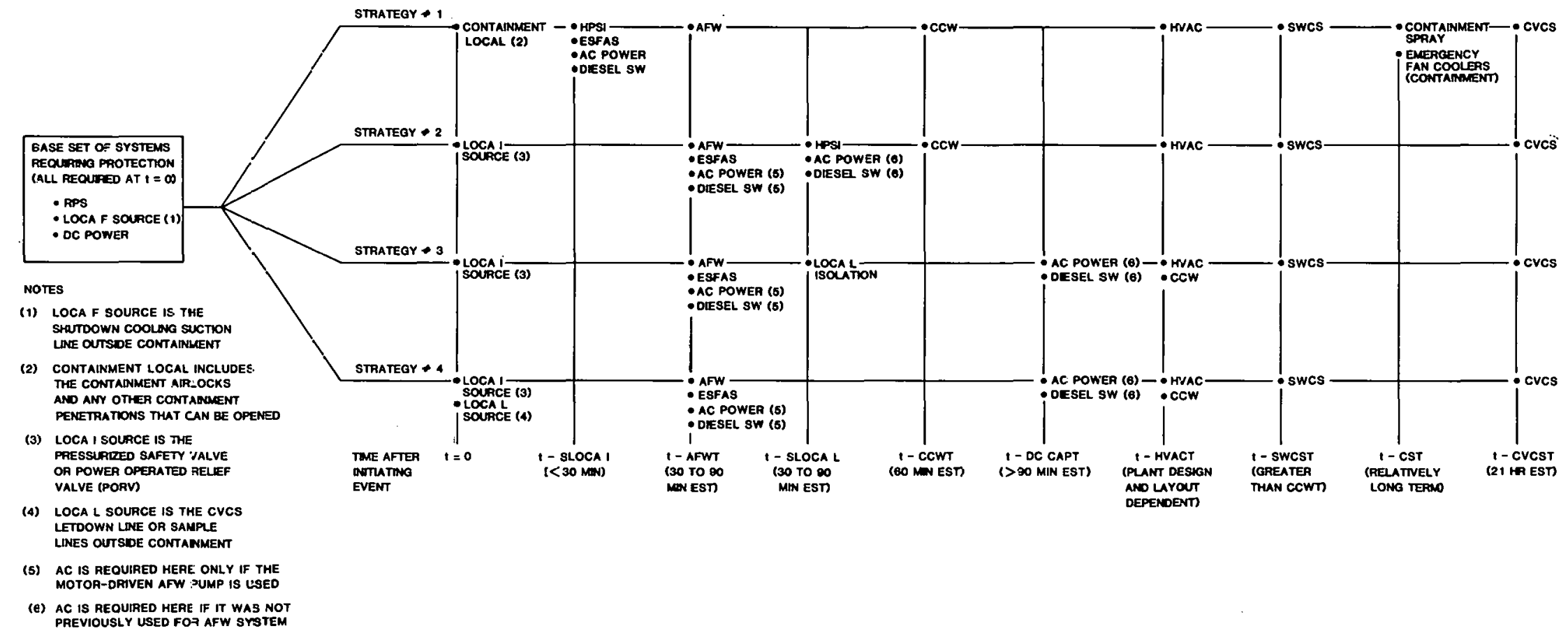

Figlire 3. Summary of System Requirements Eor the Four Frotection Strategies as a Furction of Time After an Initiating Event 
- CCWT--the time at which the component cooling water (CCW) system must be in operation to support high-pressure safety injection (HPSI), containment spray, or HVAC system operation.

- DC CAPT--the time at which the DC emergency batteries will be drained due to the emergency load assuming no AC supply. (DC power is required for AFW pump controls as well as for instrumentation.)

- HVACT--the time at which emergency HVAC systems must be in operation to maintain environmental conditions suitable for continued operation of other safety equipment (e.g., HPSI, AFWS and CCW pumps, electrical systems, and instrumentation and control systems).

- SWCST--the time at which the salt water cooling system (SWCS) must be in operation to maintain the component cooling function.

- CST--the time at which containment heat removal is required to prevent containment failure following a LOCA I (pressurizer safety valve or PORV stuck open).

- CVCST--the time at which reactor coolant makeup must be provided following a transient to prevent core meltdown due to normal post-transient coolant loss from reactor coolant pump seal leakage and cooling shrink during cooldown (LOCA K).

The first five time events (SLOCA I, AFWT, SLOCA I, CCWT, and DC CAPT) do not present realistic damage-control opportunities in the sense of system repair or replacement because of their relatively short-term time requirements (which range from <30 minutes to approximately 90 minutes). Damage control, therefore, would not be considered as a potential alternative to protecting the HPSI, $A F W$, and CCW systems, the LOCA L isolation capability, or potential LOCA I and LOCA L sources.

The last four time events (HVACT, SWCST, CST, and CVCST) represent relatively longer-term concerns. Therefore, it may be reasonable to consider a variety of damage-control options as means for restoring operation of the HVAC and SWCSs, the CVCS and/or the containment heat removal (containment spray and emergency fan cooler) systems.

One obvious conclusion, so far, is that a fairly large set of systems must be physically protected to preclude sabotage by an insider. Efforts by SAI and Sandia National Laboratories are continuing in this area to identify implementation techniques for the protection strategies. 


\section{SABOTAGE PREVENTION}

\section{$4.1 \quad$ DISCUSSION}

For a saboteur to be successful, a specific sequence of actions leading to release of radioactive material must be completed. The role of the PPS is to prevent all such actions leading to radioactive release. A basic axiom of physical protection is that a resolute saboteur can be interrupted in his sabotage attempt only if the security response force is informed of the attempt while there is still sufficient time remaining in the sabotage sequence for the force to respond.

The range of safeguards measures available to the PPS for dealing with the insider problem is quite restricted. This is particularly true in coping with the class of insiders who, during the course of their duties, require access to vital components for inspections, tests, or maintenance. There are two basic functions which can be applied in such cases: (1) vital-area access controls and (2) vitalarea activities controls. These functions have been discussed and structured in general terms in Section 2.2.2. In addition, SAI has developed a set of work rules for implementing these functions.

\subsection{SAI STUDY RESULTS}

\subsubsection{Discussion}

SAI has studied the insider threat with respect to nuclear reactor facilities ${ }^{4}$ using a computer-based methodology called Matrix Analysis of the Insider Threat (MAIT). MAIT identifies potential weaknesses in the PPS in dealing with insiders who misuse access and activity authorizations in an attempt to commit sabotage. Facility characterization data, e.g., vital equipment locations, safeguards function locations, personnel types and authorizations, operational conditions, etc., as well as adversary attributes are converted into matrices. Working from the matrix data base, the computer generates each possible path for all facility/threat combinations.

\subsubsection{Results}

The results of the SAI study indicate that a large number of employees in the example facility have access to all vital areas at any given time. The facility has no protection from an insider saboteur in any of the following categories: maintenance-electrical, radiation protection, operations, and management.

In an effort to improve security, a set of five work rules based on zoning regulations was developed: (1) team zoning, (2) area 
zoning, (3) operational zoning, (4) time zoning, and (5) function zoning. The potential effectiveness of these work rules was then studied using MAIT. Conclusions based on the results of these studies follow.

The concept of team zoning is to limit personnel access in such a way that no one person has unobserved access to a vital area, i.e., either a multi-man rule or some type of surveillance is enforced. The results indicate that team zoning (multi-man rule employed) provides effective safeguards for both Type $I$ and Type II vital areas. The increased manpower costs were estimated at $8 \%$.

Area zoning is applied to limit the access which unescorted personnel have to combinations of specific vital areas which are required to complete sabotage. MAIT results indicate this concept alone, while sufficient for Type II vital areas, cannot provide protection for Type I vital areas.

Operational zoning through the use of access control monitors, tamper indicators, and/or closeout inspections prevents unauthorized actions that could result in sabotage. This concept, when used alone, was found to be effective in the majority of Type II vital areas but insufficient for Type I vital areas.

The concept of time zoning is based upon the restriction of access and/or work authorization in specific vital areas to certain times. MAIT results indicate no protection against a single insider can be obtained using time restriction only.

Function zoning restricts the type of work specific personnel can perform within a vital area. The study results indicate that function zoning offers little or no protection against sabotage by a single insider.

MAIT seems well-suited to identifying the vulnerabilities of a PPS with respect to potential insiders. Its weakness, however, is its implied assumption of $100 \%$ effectiveness of all safeguards elements employed in the PPS. To address this issue of safeguards effectiveness, a dynamic analysis of the insider actions necessary to enact sabotage is required. One means of performing such an analysis is the Safeguards Automated Facility Evaluation (SAFE) 5 method developed at Sandia National Laboratories.

4. 3 SAFE ANALYSIS

4.3.1 Discussion

The SAFE method consists of a collection of operational phases for facility representation, component performance, adversary path analysis, and effectiveness evaluation. SAFE combines these phases into a continuous stream of operations. Through the use of SAFE, a global evaluation of a safeguards system can be provided by systematically varying the parameters that characterize the physical protection components of a facility to reflect the perceived adversary attributes 
and strategies, environmental conditions, and site-operational conditions. Global worst-case paths or scenarios are generated by SAFE for each target in the analysis.

\subsubsection{Reactor Facility Characterization}

The hypothetical nuclear reactor facility ${ }^{2} 5$ used in this report is a complex multilevel facility that contains nine levels in all: the ground level, two underground levels, and six aboveground levels. The base-case facility safeguards for this facility approximate in modeling complexity those required for power reactors.

A digitized drawing (as produced by SAFE) of the ground level of the example facility is depicted in Figure 4. The facility is surrounded by an outer fence and contains numerous buildings, including a radwaste building, a fuel building, a diesel generator building, a control building, a reactor containment building, auxiliary buildings, and a turbine building. A complete set of digitized facility drawings (generated by SAFE) is contained in Appendix A, Figures A-I through A-13. Symbols on the drawings represent access points, stairwells, and targets; node labels are also included on the drawings for reference. (Definitions of the symbols used on the facility layout drawings can be found in Table A-l.)

The facility contains 32 targets in all. Table 1 contains a listing of the target node labels. All of the targets represent vital areas where an adversary can perform certain events which contribute to his accomplishing a goal of sabotage. To identify the vital areas, a transformation was made between primary events in the sabotage fault-tree logic equation and their locations. Due to the vulnerability of exposed power lines, the vital-area combinations reflect the basic sabotage study assumption of loss of off-site power concurrent with disabled components. Five of the targets are Type I and twentyseven are Type II. Type II targets must be visited in combination with another target(s) in order to achieve sabotage, while Type I targets need not be, i.e., a Type I target includes sufficient vital component(s) to achieve sabotage.

The Type II combinations of targets which could result in successful sabotage if visited by the adversary are listed in Table 2. For doubles, the adversary must visit two different targets; for triples, the adversary must visit three targets; and for quadruples (quads), the adversary must visit four targets.

The on-site security response force includes five security officers. All security officers are stationed in a security building, which is located at the fence (at node 284 on the facility drawings). Periodically, a security officer is sent out to patrol the fence perimeter area. Security officers are assumed to be equipped with handguns and have access to shotguns.

Problem Complexity -- In order to obtain global performance measures for the reactor facility, all targets and all possible sequences of targets which can be visited by the adversary must be considered. Combinations of targets which can be visited contribute 
LEVEL 2

(Ground Leve1)

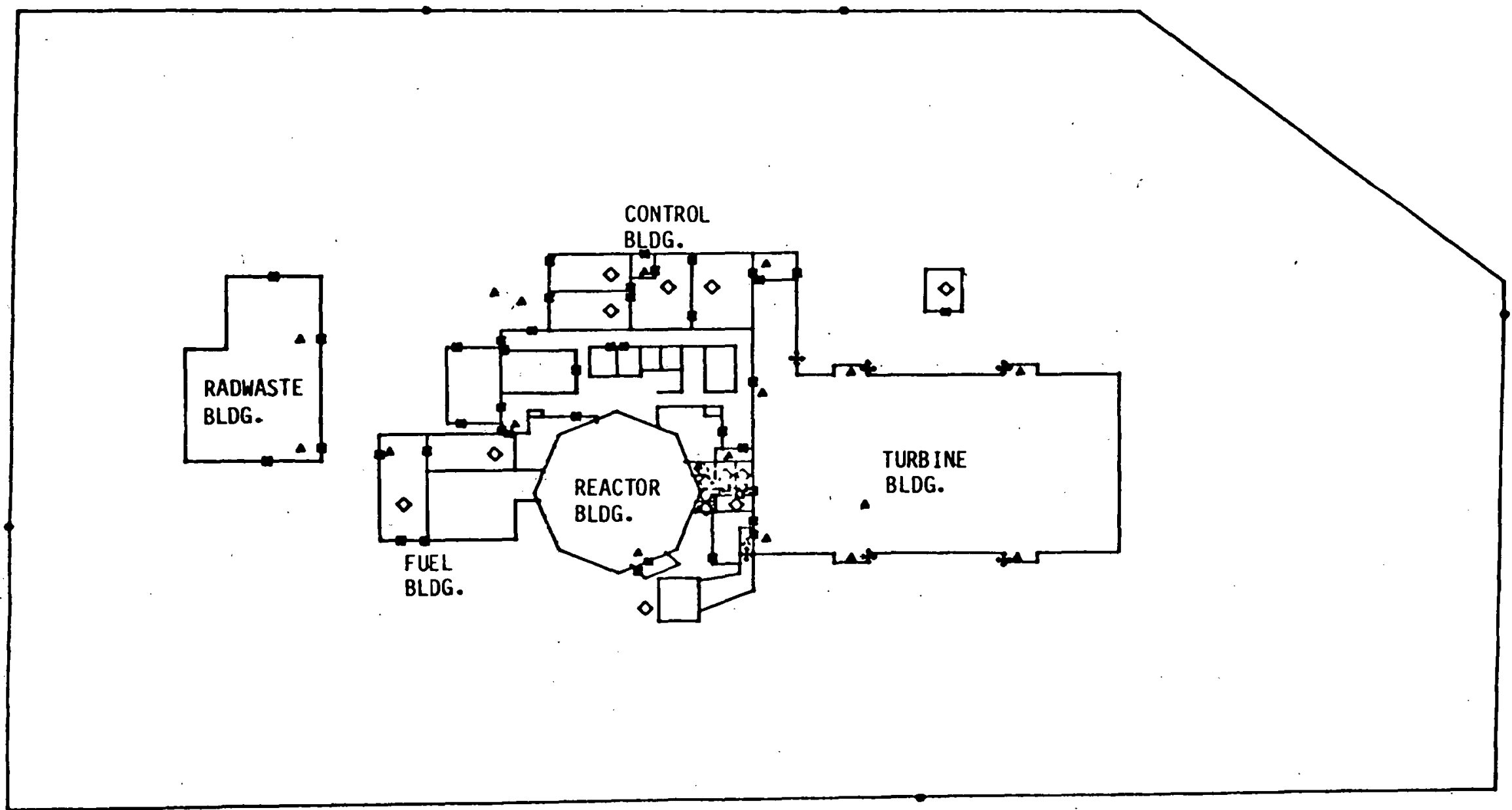

Figure 4. Reactor Facility--Ground Level 


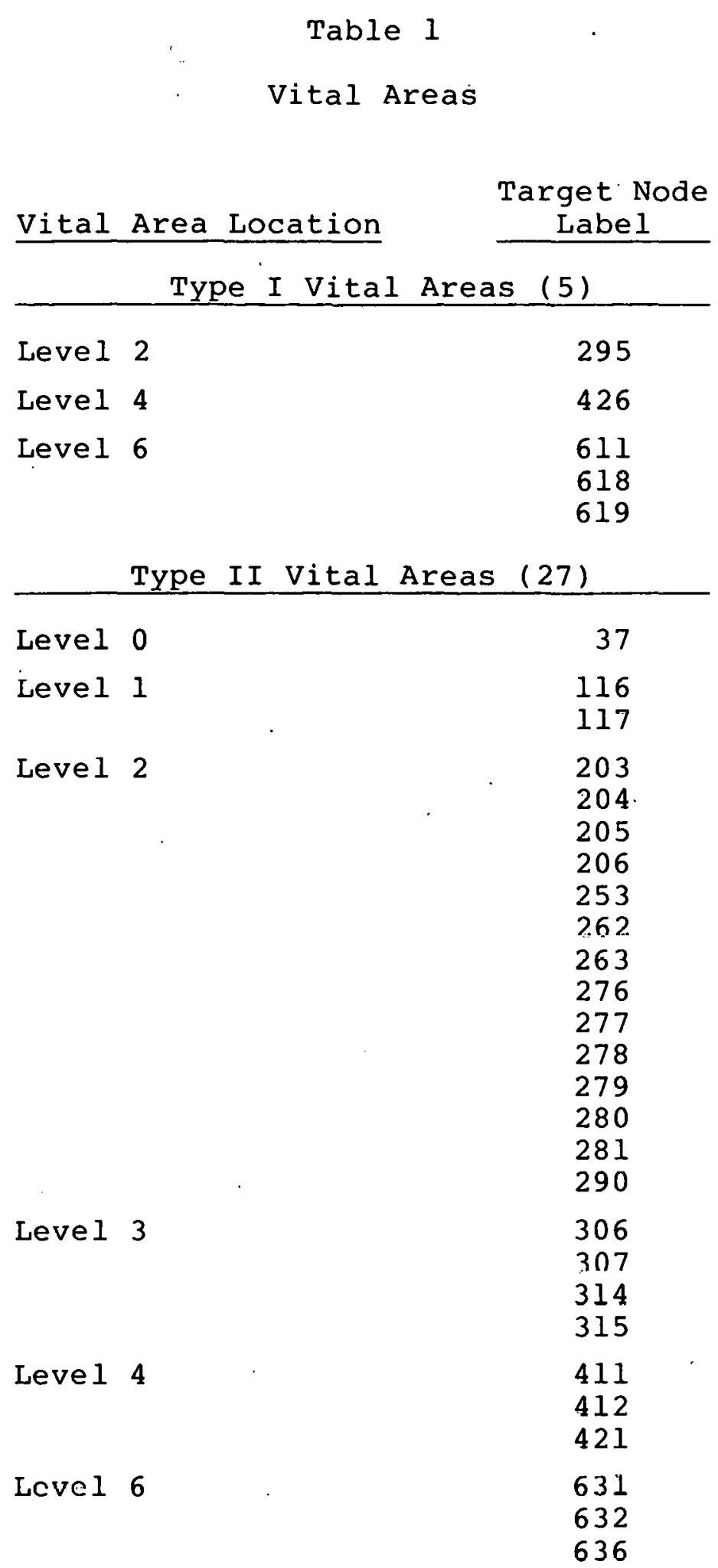


Table 2

Type II Vital-Area Combinations

Doubles (22)

$\begin{array}{llll}307-306 & 262-306 & 206-203 & 631-632 \\ 203-307 & 262-203 & 206-421 & 412-411 \\ 205-307 & 262-205 & 205-206 & 618-636 \\ 204-306 & 276-290 & 263-206 & 253-636 \\ 204-203 & 276-37 & 116-117 & \\ 205-204 & 206-306 & 314-315 & \end{array}$

Triples (10)

$\begin{array}{lll}281-307-306 & 281-204-306 & 281-262-421 \\ 281-421-307 & 281-421-204 & 281-262-263 \\ 281-263-307 & 281-263-204 & \\ 281-307-306 & 281-262-306 & \end{array}$

Quads (1)

$280-279-278-277$

NOTE: Target combinations are designated by node labels

heavily to problem complexity since, not only must each combination be considered, but each possible sequence of targets for each combination must be considered. For example, the combination 307-306 can be visited by the adversary in the order $307 \rightarrow 306$ or $306 \rightarrow 307$. For each double combination, there are 2 possible sequences which must be evaluated or bounded in terms of physical protection performance; for each triple, there are 6 possible sequences; and for each quad, there are 24 possible sequences. For a Type I target, of course, there is only one possible sequence. For this particular facility, the number of possible sequences of targets that must be considered totals 135 ; this total does not account for the virtually unlimited number of paths which can be used by the adversary in conjunction with each possible sequence.

The nuclear reactor facility clearly presents a very complex problem that requires an efficient technique such as SAFE for global evaluation. 
Target Selection -- As previously indicated, analyzing PPS effectiveness over all combinations of targets, paths, and conditions is beyond the scope of this study. Therefore, only a representative target set was selected for a dynamic performance evaluation of the work rules discussed earlier. The assumptions made in this study which affect target selection are as follows: (1) a PWR, initially in power operation, (2) only radioactive material release from the reactor core is of concern, (3) a single-insider threat without explosives.

The assumption that the threat consists of a single insider not equipped with explosives ( 3 above) implies an effective search of authorized personnel at the protected area (PA) portal. It all but eliminates sabotage in such Type I vital areas as reactor containment, the spent fuel pool, and the spent fuel shipping cask area since, in these areas, explosives would be needed to breach massive components in order to cause a rapid progression toward radioactive material release. Therefore, the only remaining Type $I$ vital areas are the control room and the auxiliary shutdown panel.

Sabotage by manipulation of the controls in either the control room or the auxiliary shutdown panel is estimated to require considerable time (approximately 20 minutes or more). Therefore, to be successful, a single insider either (1) must avoid detection during this time or (2) must somehow prevent counteractions by an operator at the alternate control location. Since facility status is continuously monitored, the first option of avoiding detection seems unlikely. The second option of preventing operator counteractions, on the other hand, may require the insider to perform additional tasks, implying a possible reclassification of the control room and auxiliary shutdown panel to Type II vital areas for a single-insider threat.

Although the above discussion is not substantial enough to support any definite conclusions, it just may be possible that no Type I vital areas exist for the single-insider threat within a facility as compartmentalized as the example facility and having an effective PA portal contraband search. Therefore, it seems more worthwhile to select several Type II vital-area combinations for the analysis.

The selection of specific Type II vital-area combinations for analysis was based on the following criteria:

1. The vital areas selected should permit implementation of the most promising work rules,

2. The choice of vital-area combinations should indicate any sensitivity of results to time intervals between access to each area, and

3. The vital area selected as the starting point for the sabotage sequence should maximize the saboteur's remaining options to indicate any sensitivity to the PPS response strategy.

The vital areas selected for analysis include the following Type II target combinations from Table 2: 205-307, 205-204, 262-205, 
205-206. This target set seems well-suited to the specified selection criteria. If the insider begins the sabotage sequence at 205, he then has the option of completing the sequence at either of the adjacent target locations 204 or 206, at target 262 on the same level, or at target 307 on the next level.

\subsubsection{Results}

The set of work rules addressed in this study is essentially a means of sensing unauthorized activities and conditions in vital areas. The impact of a particular sensing method on PPS performance is a function of the probability of detection and the post-detection delay/response time relationship for the case in question. Although the data used in the following analysis are considered typical, the resulting PPS performance for these work rules is confined to the examples analyzed. Should inadequacies show up in the utilization of these work rules, appropriate PPS parameter values usually can be changed, at a cost, to provide satisfactory PPS performance. The results of the SAFE analysis of the single-insider threat for the selected Type II vital areas with no detection and with each of three of the SAI-developed work rules in effect follow:

\section{- No Detection System at Vital Areas}

If no detection sensors or organized surveillance efforts exist in the vital area, then casual observance by another employee in the vicinity is the only means of sensing unauthorized access to or unauthorized activities in the vital area (assuming such activities cause no monitored change in equipment status). For detection to be complete, the observer must become sufficiently concerned to report the incident in time for the PPS to respond and interrupt the sabotage sequence prior to completion. In such a situation, sabotage prevention is intuitively very low.

\section{- Operational Zoning}

Next, operational zoning was implemented in the form of access control monitors for the given target set. For this case, the insider is alone and has access authorization only to target 205. After completing the appropriate sabotage act at 205, the insider has the option of forcibly gaining access to either $204,206,262$, or 307 . The nature of the act performed at 205 actually determines which target must be visited next, but this information generally is not available to the PPS at the time of the response.

Detection is assumed to occur when access to the second target is gained, e.g., operating the door switch without authorization causes an alarm. This assumption corresponds to normal operation conditions at reactor facilities; however, since access and alarm occur simultaneously, it does alter any PPS objective of preventing unauthorized access to one of preventing sabotage completion. Based on appropriate data from Appendix B, it is assumed that if the security force arrives within 2 minutes (average) after the insider gains access to the second target, it will interrupt the sabotage attempt 
before completion. The results of the analyses for the operational zoning cases are shown in Table 3. The path taken by the insider for each of these cases is shown in Figures 5 and 6 .

Table 3

Base-Case Results for Vital Areas with Operational Zoning

\begin{tabular}{|c|c|c|c|c|c|c|}
\hline $\begin{array}{l}\text { Case } \\
\text { No. }\end{array}$ & $\begin{array}{c}\text { Sabotage } \\
\text { Target } \\
\text { Sequence }\end{array}$ & $\begin{array}{c}\text { Initial } \\
\text { Detection }\end{array}$ & $\begin{array}{c}\text { Detection } \\
\text { Probability } \\
\left(\mathrm{P}_{\mathrm{d}}\right) \\
\end{array}$ & $\begin{array}{l}\text { Response } \\
\text { Location }\end{array}$ & $\begin{array}{c}\text { Average } \\
\text { Response } \\
\text { Time } \\
\text { (minutes) }\end{array}$ & $\begin{array}{c}\text { Probability } \\
\text { of } \\
\text { Interruption } \\
\left(P_{I}\right)\end{array}$ \\
\hline 1 & $205+204$ & Access to 204 & 0.95 & 204 & 2.6 & 0.18 \\
\hline 2 & $205+206$ & Access to 206 & 0.95 & 206 & 2.2 & 0.38 \\
\hline 3 & $205+262$ & Access to 262 & 0.95 & 262 & 2.4 & 0.23 \\
\hline 4 & $205 \rightarrow 307$ & Access to 307 & 0.95 & 307 & 2.7 & 0.14 \\
\hline
\end{tabular}

The results for the operational zoning cases shown in Table 3 are unassuring. However, it may be possible to improve pps performance by either reducing response time or increasing the sabotage task time. For Case 4 , Figure 7 indicates the sensitivity of the $P_{\text {to }}$ the response time. For the same case, Figure 8 shows the effect $\delta_{f}$ varying the sabotage task time (Task 13) at target 307. Figure 9 is a three-dimensional plot which illustrates the effect on $P_{I}$ for variations in both response time and sabotage task time.

As can be seen, for vital areas protected by operational zoning, substantial parameter improvements may be required. Such improvements may not be feasible economically. Similar results were obtained for the other target combinations, indicating the inadequacy of operational zoning in the form of unauthorized access detection, at least for cases similar to those analyzed. The range of total sequence time ( 5 to 9 minutes) in comparison to the range of response time ( 2 to 3 minutes) suggests that earlier detection, which could be provided by the addition of area restrictions, might be beneficial.

\section{- Area Zoning}

Area zoning was applied to limit personnel access to only those specific areas within the facility required for completion of a job assignment. For this example, the insider is alone and has access authorization to target 205. As in the previous case, he is unauthorized to access targets 204, 206, 262, and 307. In addition, with area zoning he is now unauthorized to enter door 232 (entry to a group of rooms, one of which contains target 262) or to enter the third level (where target 307 is located). Again, it is assumed that arrival of the security force within 2 minutes (average) of insider target access 


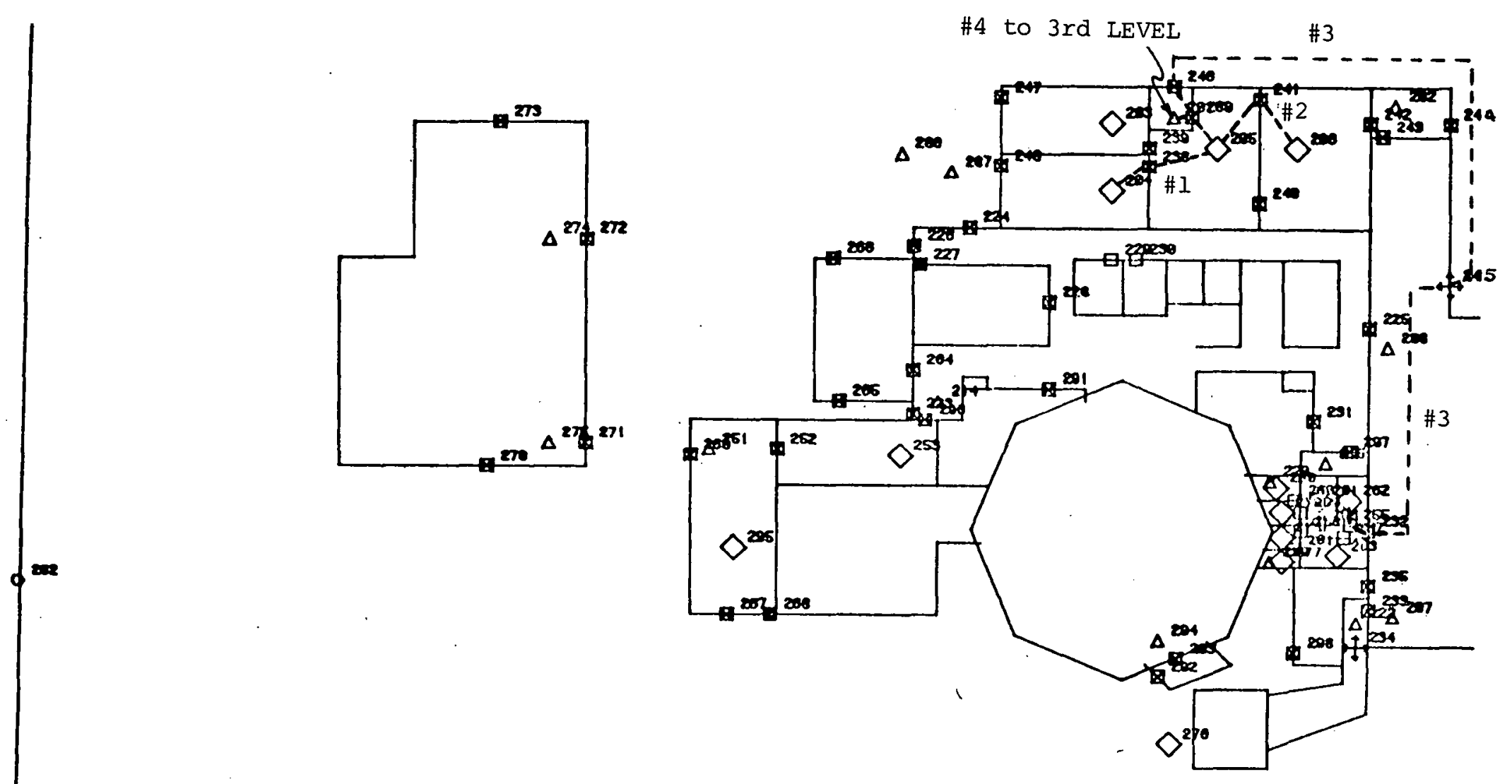

LEVEL 2 (GROUND LEVEL)

QUARTER 3

Figure 5. Level 2 (Ground Level, Quarter 3) Showing Insider Path 


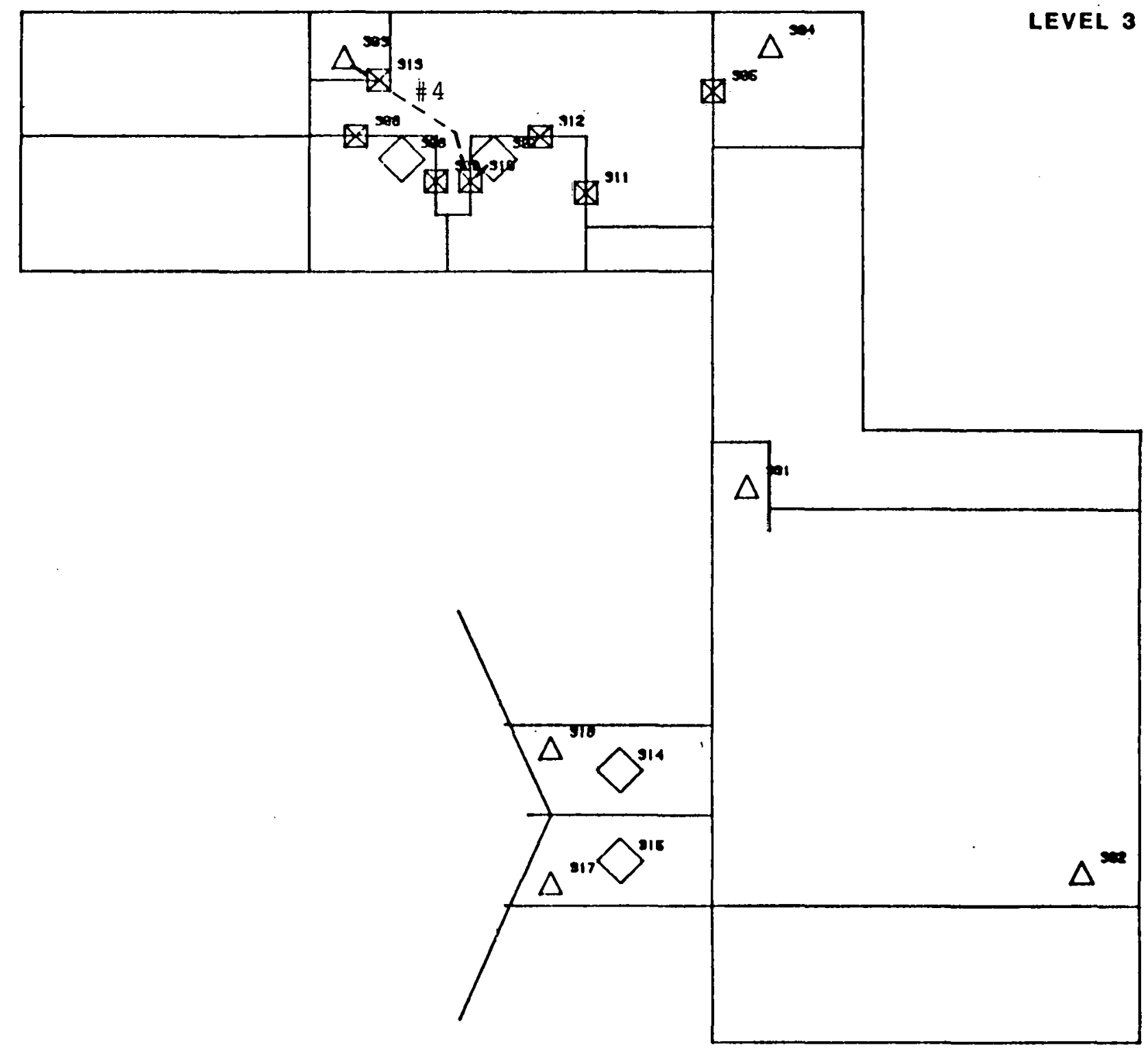

Figure 6. Level 3 Showing Insider Path 


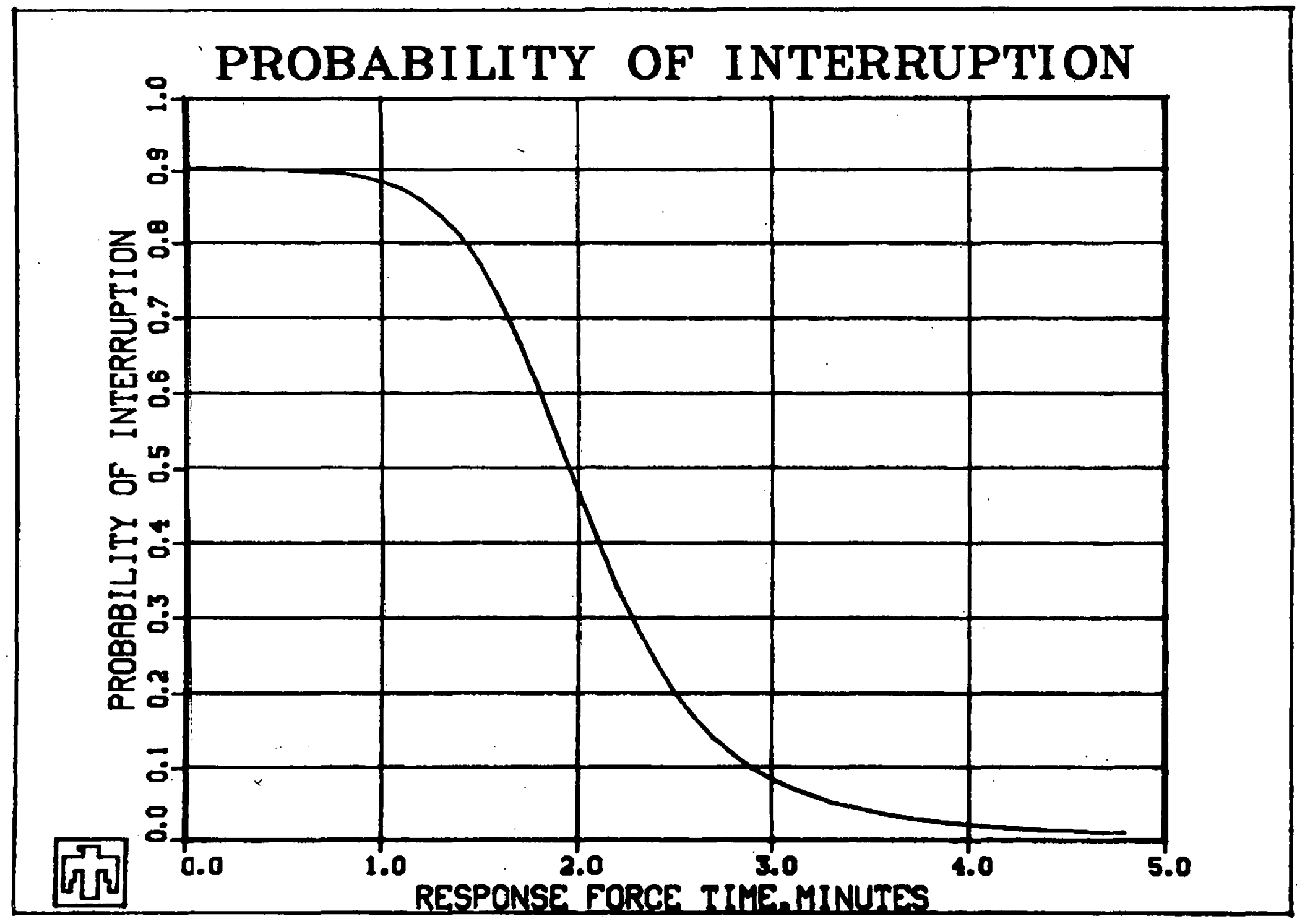

Figlre 7. $\mathrm{P}_{I}$ vs. Response Force Time for Targets $205+307$ (Case 4) 


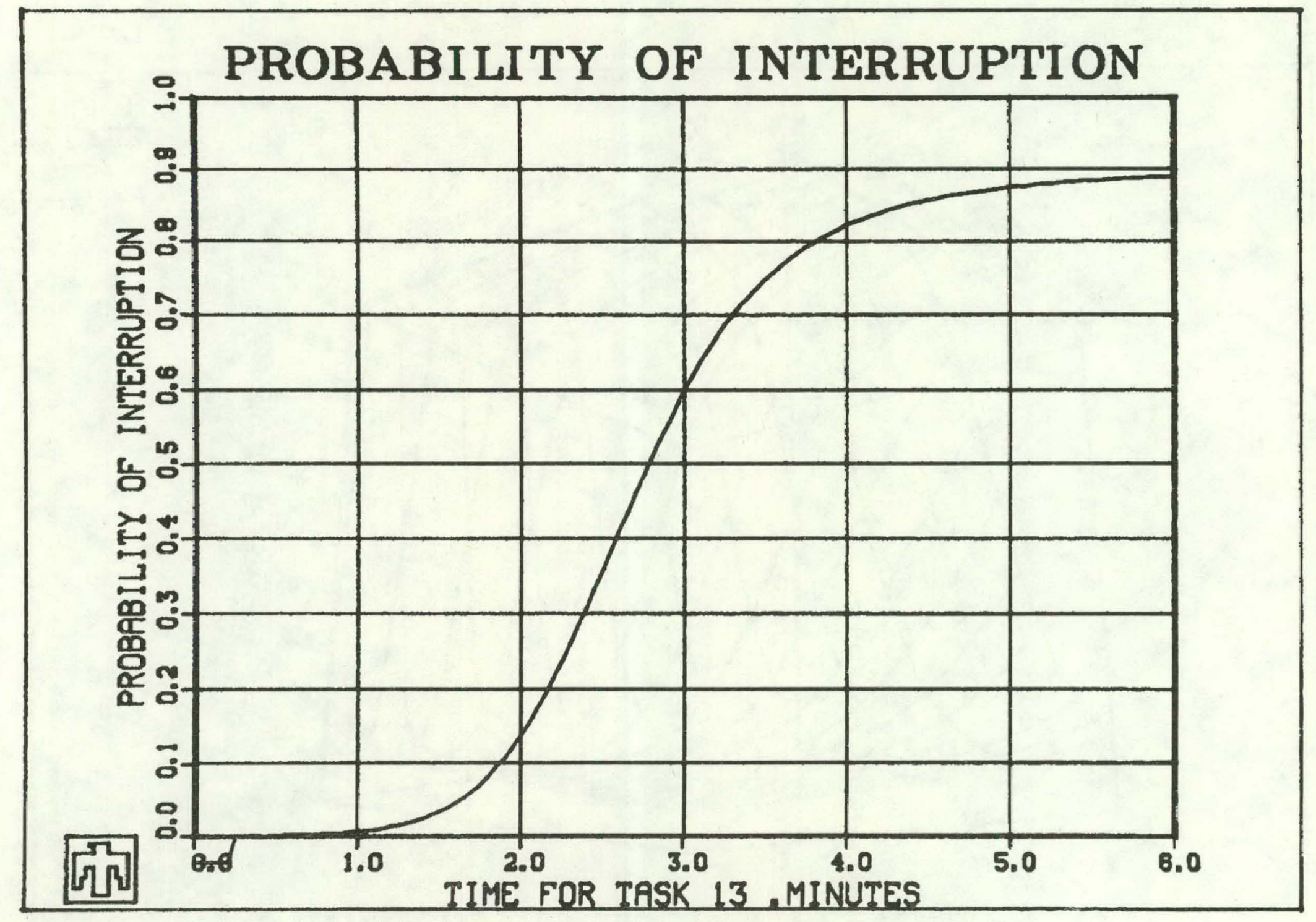

Figure 8. $P_{I}$ Vs. Sabotage Task Time for Targets $205+307$ (Case 4) 


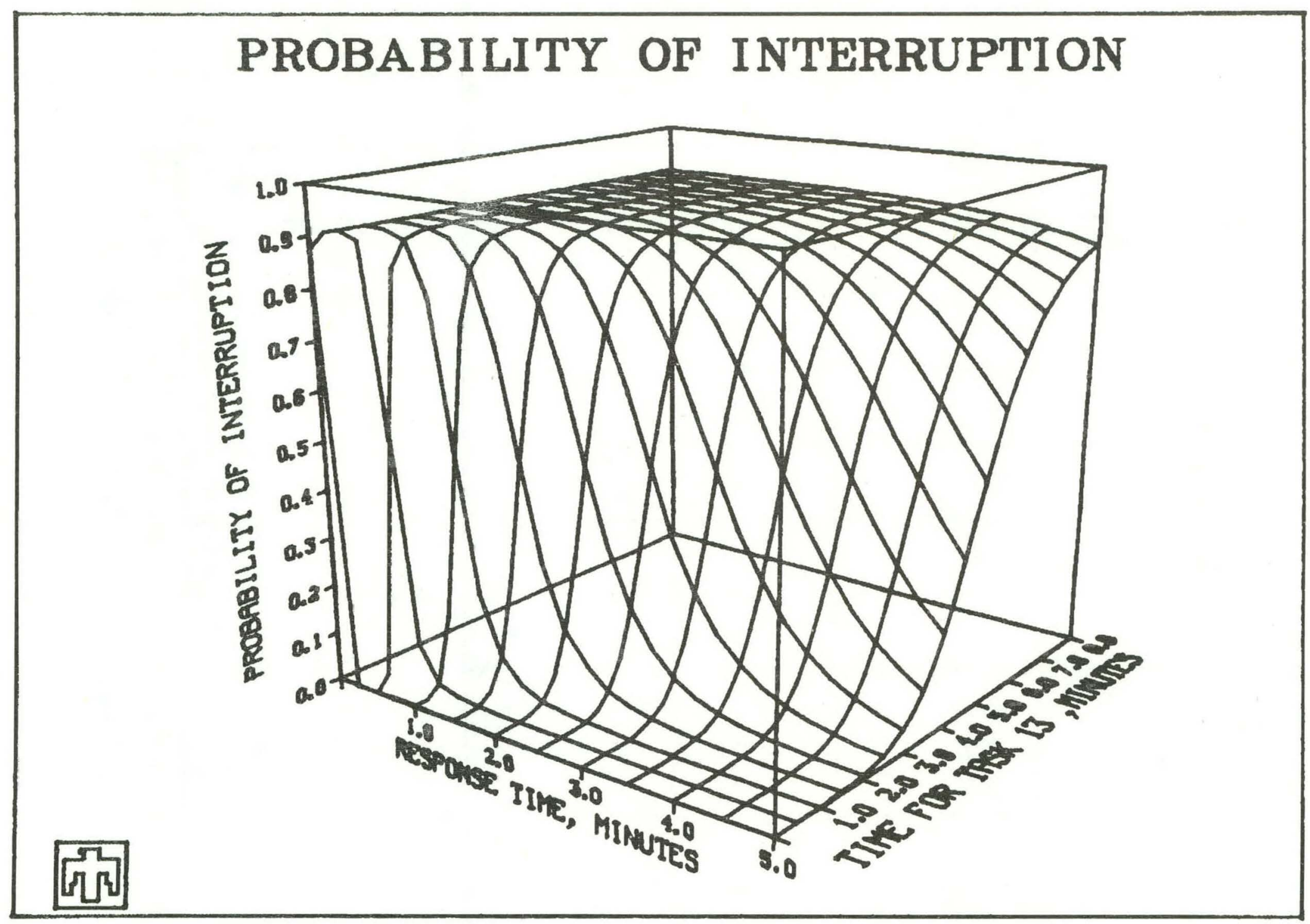

Figure 9. $\mathrm{P}_{\mathrm{I}}$ vs. Response Force Time and Sabotage Task Time for Targets $205+307$ (Case 4) 
is sufficient to interrupt the sabotage task. The analysis results produced for vital areas with area zoning in effect are shown in Table 4 .

\section{Table 4}

Results for Vital Areas with Area Zoning

\begin{tabular}{|c|c|c|c|c|c|}
\hline $\begin{array}{l}\text { Case } \\
\text { No. } \\
\end{array}$ & $\begin{array}{c}\text { Sabotage } \\
\text { Target } \\
\text { Sequence }\end{array}$ & $\begin{array}{c}\text { Initial } \\
\text { Detection }\end{array}$ & ${ }^{P_{d}}$ & $\begin{array}{l}\text { Response } \\
\text { Location }\end{array}$ & $\mathrm{P}_{\mathrm{I}}$ \\
\hline 5 & $205 \rightarrow 204$ & Access to 204 & 0.95 & 204 & 0.18 \\
\hline 6 & $205 \rightarrow 206$ & Access to 206 & 0.95 & 206 & 0.38 \\
\hline 7 & $205 \rightarrow 262$ & Entry at 232 & 0.95 & 262 & 0.69 \\
\hline 8 & $205+307$ & Entry at 313 & 0.95 & 307 & 0.68 \\
\hline
\end{tabular}

All paths taken by the insider and all data, except as noted, are the same as for Cases 1 through 4.

The results for Cases 5 and 6 are the same as those for Cases 1 and 2, respectively. This is due to the apparent equivalence between operational zoning and area zoning when target combinations are adjoining or closely located. On the other hand, for targets located in distinctly different regions of the facility, e.g., on different levels, area zoning can provide some improvement in PPS performance, as indicated by a comparison of Cases 3 and 7 or of Cases 4 and 8 .

The relative importance of detecting access to Level 3 of the facility with respect to the sabotage task time for target 307 is illustrated in Figure 10. As can be seen, if sabotage of target 307 (Task 13) is completed in much less than the 2-minute response time, detection of access to Level 3 (Sensor 10) does not occur early enough to be effective. The sensitivity of PPS performance to changes in response time is indicated in Figure 11. The average response time of 2.7 minutes to target 307 is near maximum sensitivity. Small changes in response time could result in substantial performance changes. All of which suggests the need for earlier detection. Requiring the presence of at least two knowledgeable persons when work is being performed in a vital area could provide the earliest detection possible when the initial sabotage act is committed.

\section{- Team Zoning}

The addition of team zoning in the form of the two-man rule was studied using the same target set. To maximize detection in this case, it is customary to require both persons to have equal ability. 


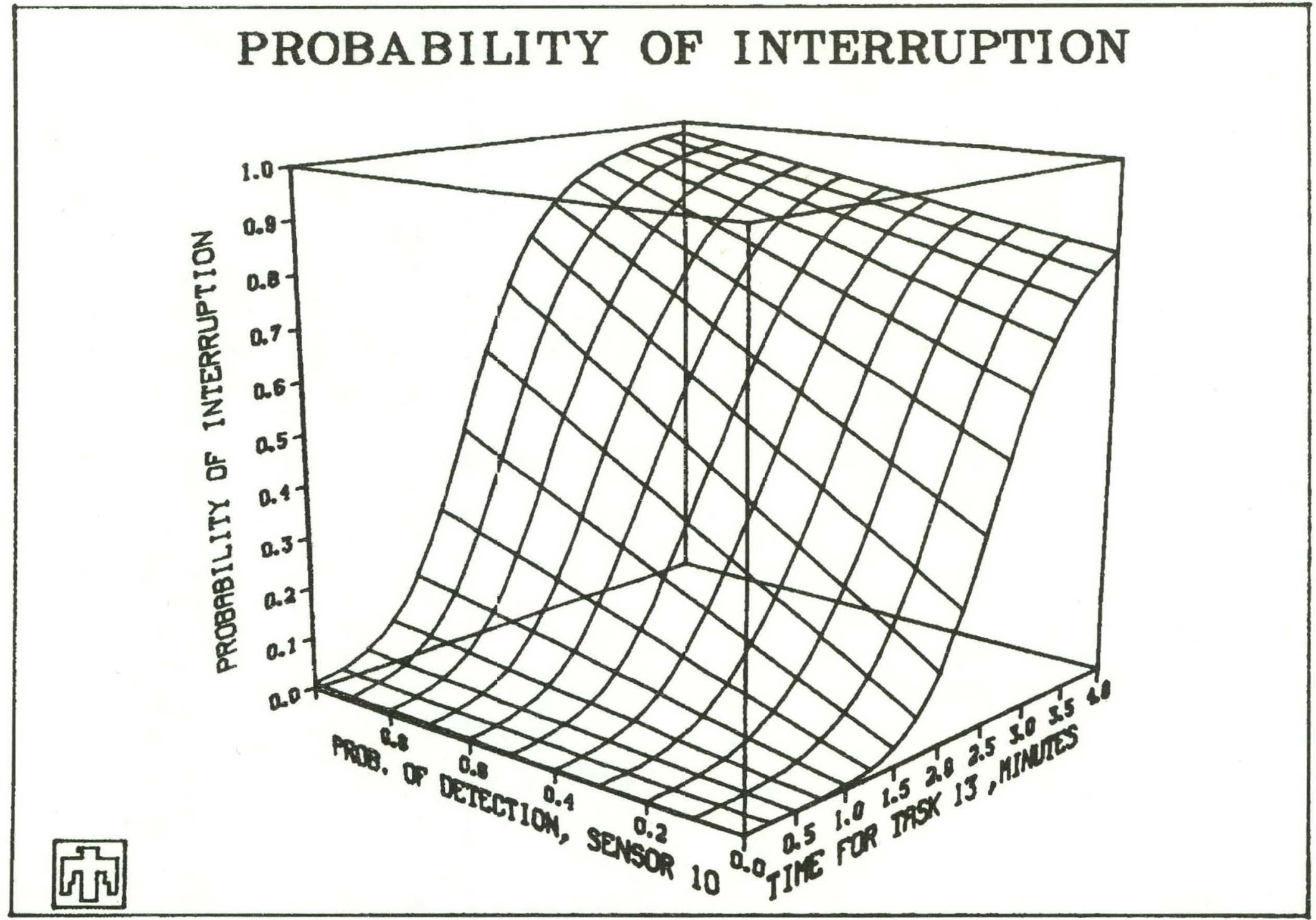

Figure 10. PI vs. Probability of Detection of Level 3 Access and Sabotage Task Time for Target 307 (Case 8) 


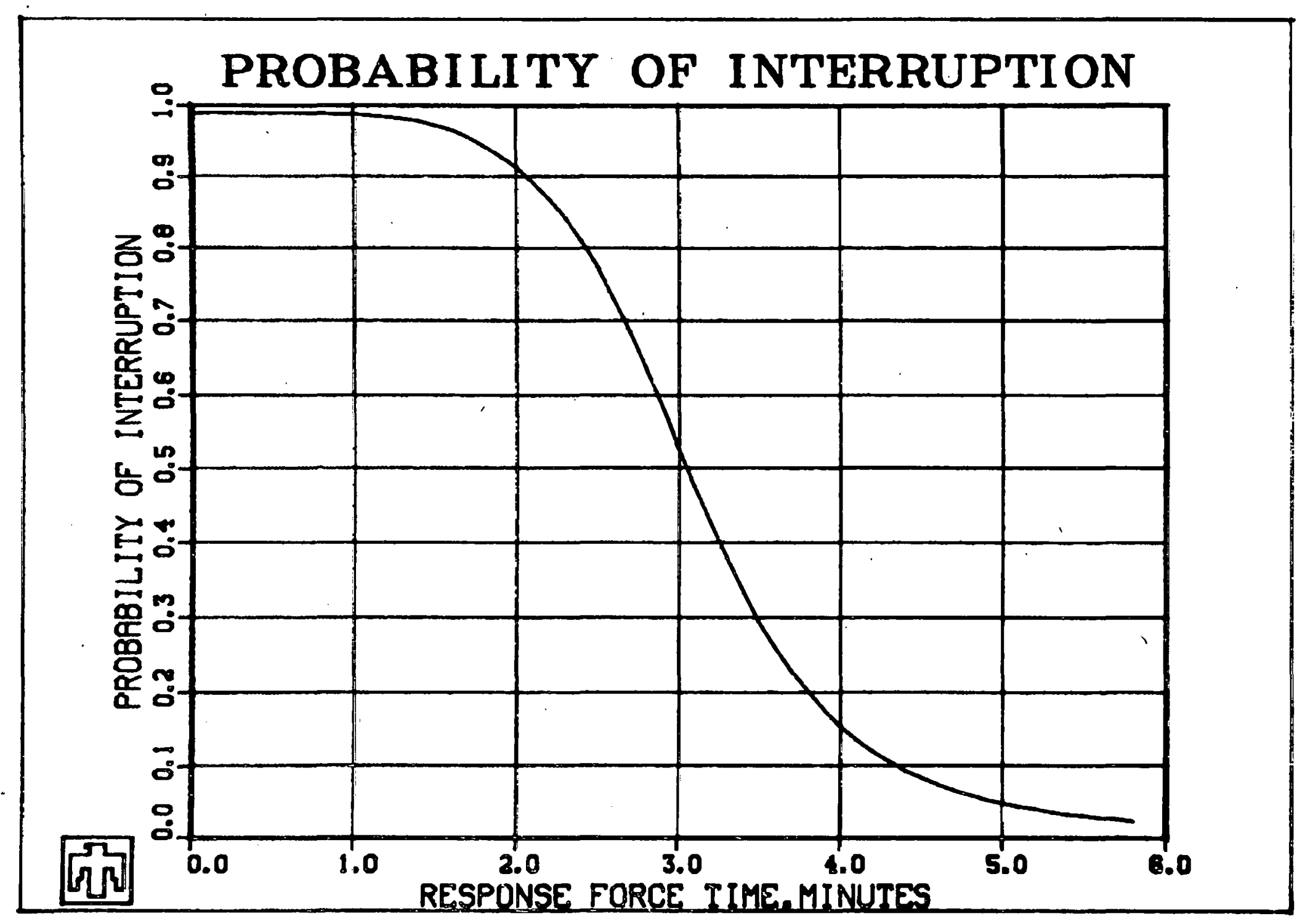

Figure 11. $\mathrm{P}_{\mathrm{I}}$ vs. Response Force Time for Targets $205+307$ (Case 8) 
However, attempts to utilize humans in the surveillance mode is subject to all of the vagaries of human behavior, e.g., short attention spans, personal problems, poor health, etc. Dealing with these problems is beyond the scope of this report. The reader is referred to Reference 6 for further information.

For this example, the insider is now accompanied by an equally knowledgeable person and has access authorization to target 205. Other than the fact that the insider's initial sabotage act at target 205 now can be detected, all the conditions in the preceding cases are unchanged. There is, however, some question as to when, during the sabotage act, detection will take place. While some early phase of the act may attract the second person's attention, reaching a conclusion probably will come late in the act. To bound the results for each case, detection has been assumed to occur at both the beginning and at the end of the sabotage act. In addition, it is assumed that the second person will provide only an alarm to the PPS. The results for the vital-area targets with team zoning in effect are shown in Table 5. It is evident from these results that the two-man rule has the potential to provide substantial improvements in sabotage prevention for all target combinations analyzed.

Table 5

Results for Team Zoning

\begin{tabular}{|c|c|c|c|c|c|c|}
\hline \multirow{3}{*}{$\begin{array}{l}\text { Case } \\
\text { No. } \\
\end{array}$} & \multirow{3}{*}{$\begin{array}{c}\text { Sabotage } \\
\text { Target } \\
\text { Sequence }\end{array}$} & \multirow{3}{*}{$\begin{array}{c}\text { Initial } \\
\text { Detection }\end{array}$} & & \multicolumn{2}{|c|}{$\mathrm{P}_{\mathrm{I}}$} \\
\hline & & & & Response & Initial De & ection at \\
\hline & & & d & Location & Start of Act & End of Act \\
\hline 9 & $205 \rightarrow 204$ & At 205 & 0.95 & 204 & 0.92 & 0.74 \\
\hline 10 & $205 \rightarrow 206$ & At 205 & 0.95 & 206 & 0.93 & 0.84 \\
\hline 11 & $205+262$ & At 205 & 0.95 & 262 & 0.97 & 0.97 \\
\hline 12 & $205+307$ & At 205 & 0.95 & 307 & 0.97 & 0.96 \\
\hline
\end{tabular}

Notice that for adjacent target combinations, e.g., 205-204 and 205-206, the results are somewhat sensitive to the time of detection during the sabotage attempt at target 205. Targets in the other combinations, which are separated by a longer time interval, show no sensitivity to when detection takes place at target 205 .

While the results in Table 5 appear interesting, it must be kept in mind that these figures represent an idealization. First, the probability of detection for the two-man rule is assumed to be 0.95 . Most will concede. this number is probably too high. Therefore, the sensitivity of results to the detection probability for the two-man rule was examined. Figure 12 shows the sensitivity of the results for 


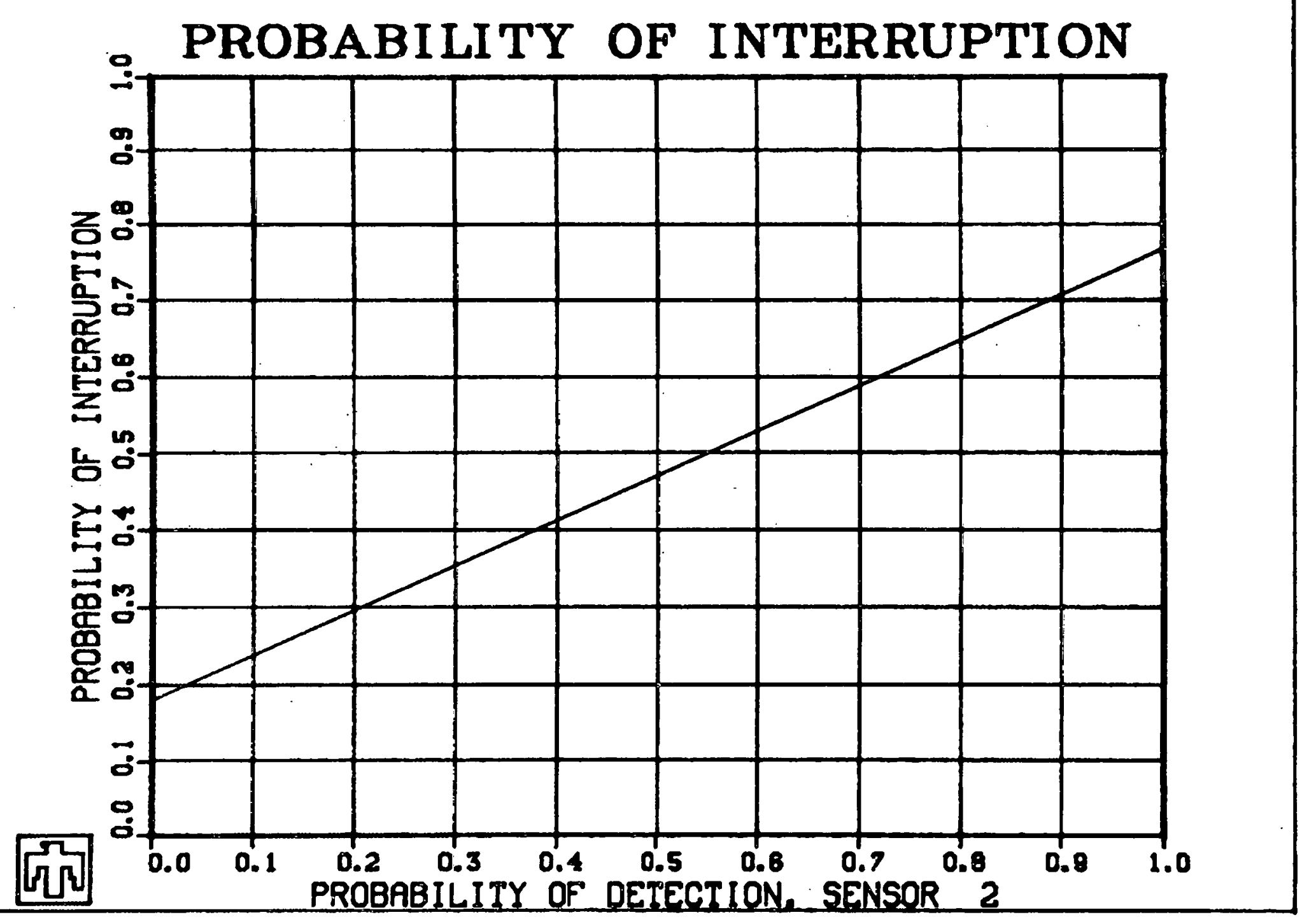

Figure 12. $P_{I}$ Vs. Probability of Detection at End of Sabotage at Target 205 (Case 10) 
the 205-206 combination, in which the targets are close together. Figure 13 indicates the sensitivity for the 205-262 combination, which is representative of more widely separated targets.

Another idealization is the assumption that the PPS could determine at the time of the initial alarm that there was insufficient time to interrupt the sabotage at target 205 and then could respond directly to the correct second target. In the cases in which the initial alarm came either at or from the vicinity of the second target, this assumption is reasonable. With the addition of team zoning, however, the first alarm can originate at the first target (205). Hence, at the time of the first alarm, the PPS can only guess the saboteur's next move.

To account for this inability to minimize response time, calculations were made based on the assumption that the security force initially responds directly to target 205. Upon receipt of later alarm information, the security force is redirected from target 205 to the correct second target. A comparison of the results of the calculations for this two-stage response with those for the direct response is shown in Table 6 .

It is evident from the results shown in Table 6 that the amount of PPS performance degradation is target-dependent. In Cases 14 and 15, the inclusion of the stop at target 205 caused a significant alteration in the response time for the security force, as compared to that for a direct response. For the other cases, the stop at target 205 essentially occurred along the way, causing little increase in response time to the second target.

Table 6

Team Zoning Comparison (Direct vs. Two-Stage Response)

\begin{tabular}{|c|c|c|c|c|c|}
\hline Case & $\begin{array}{l}\text { Sabotage } \\
\text { Target }\end{array}$ & Initial & & $\begin{array}{c}\text { Direct } \\
\text { Response }\end{array}$ & $\begin{array}{l}\text { Response } \\
\text { Includes }\end{array}$ \\
\hline No. & Sequence & Detection & d & To 2nd Target & Stop at 205 \\
\hline 13 & $205 \rightarrow 204$ & $\begin{array}{l}\text { Upon } \\
\text { sabotage } \\
\text { completion } \\
\text { at } 205\end{array}$ & 0.95 & 0.74 & 0.69 \\
\hline 14 & $205+206$ & Same & 0.95 & 0.84 & 0.70 \\
\hline 15 & $205 \rightarrow 262$ & Same & 0.95 & 0.97 & 0.84 \\
\hline 16 & $205+307$ & Same & 0.95 & 0.96 & 0.89 \\
\hline
\end{tabular}




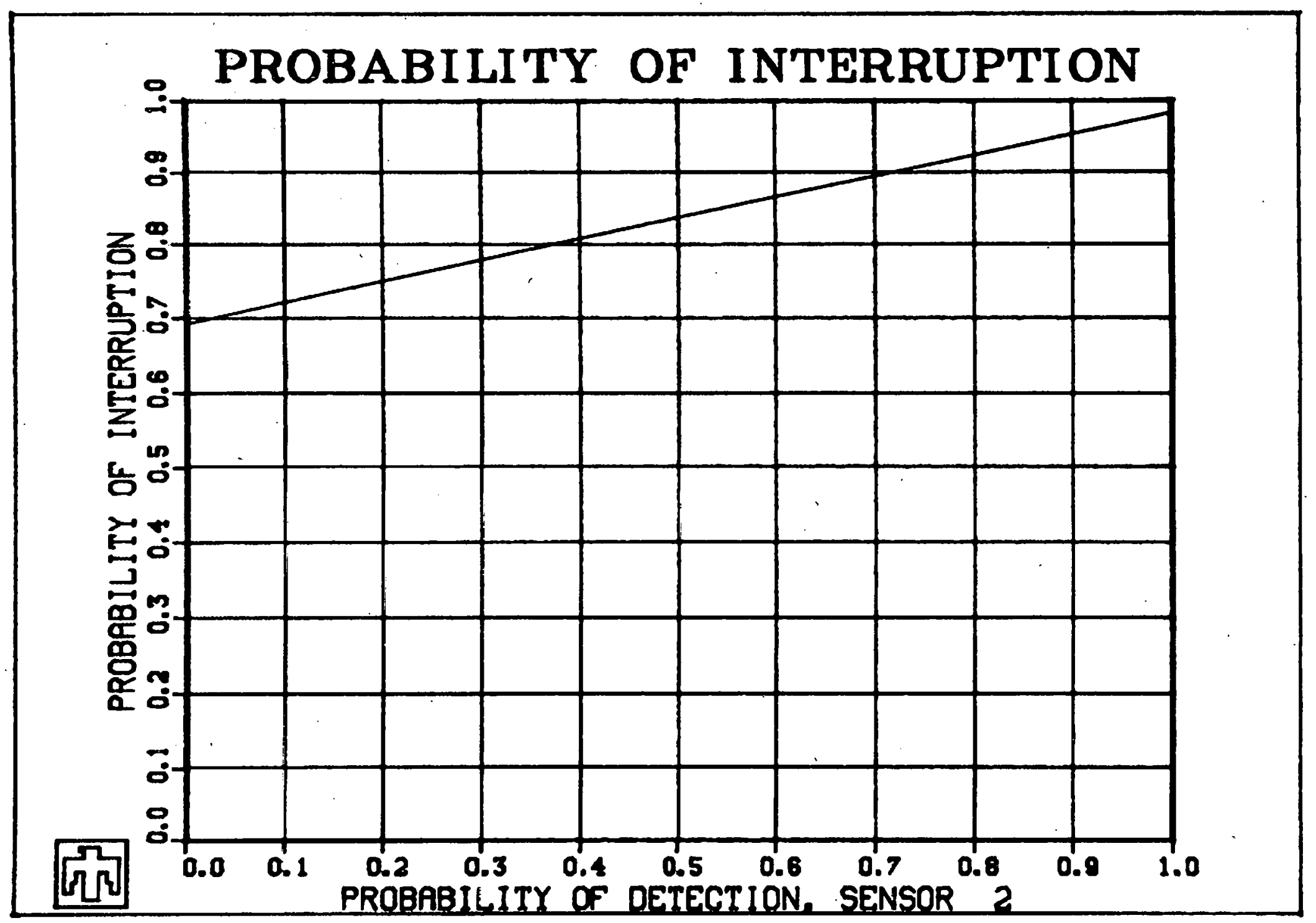

Figure 13. $\mathrm{P}_{\mathrm{I}}$ vs. Probability of Detection at End of Sabotage at Target 205 (Case 11) 
Up to now, the target combinations analyzed have been selected from the vital-area set listed in Table 2. The vital-area combinations reflect the basic sabotage study assumption of off-site power loss concurrent with disabled components. This assumption is considered reasonable if the insider either has off-site accomplices or if he sets up his own timed charges at the power lines in advance of the on-site sabotage attempt or after completing the on-site phase of the sabotage attempt undetected. In any case, the impact of this assumption should be assessed.

Forcing the insider to disable off-site power as part of the on-site sabotage sequence adds a third target to all the two-target combinations that have been analyzed. This third target's designation is 290 (see Figure 15). The example analyzed consists of the target sequence 205-206-290. The conditions for the first case considered are that the insider is alone and has authorized access to target. 205. After completing the sabotage act at 205, the insider forcibly gains access to target 206. It is assumed that either operational or area zoning is implemented through the use of a sensor on the door connecting 205 and 206. After sabotaging target 206, the insider exits the building (no alarms assumed) to disable target 290. The path taken by the insider is shown in Figures 14 and 15.

The sensor on the door between targets 205 and 206 provides the only alarm. Since this sensor signals only that the door has been opened, the PPS cannot be sure that the, direction of access is from 205 to 206 or the reverse. For this case, the response sequence is first to target 205, then to 206, and finally to 290. The results for an insider scenario which includes disabling off-site power are shown in Table 7 (Case No. 17). It is assumed that the arrival of the security force within 2 minutes (average) of insider access to target 290 is sufficient to interrupt the sabotage attempt. When the case 17 results are compared with the results of Case 2 , it is evident that the additional post-detection time required to sabotage target 290 greatly enhances the probability of sabotage interruption.

The amount of time required for the sabotage task at target 290, given the insider does not have explosives, is uncertain. The effect of varying the sabotage task time at target 290 (Task 11 ) is shown in Figure 16.

The effects of adding enforcement of the two-man rule to Case 17 are shown in Case 18 (see Table 7). As can be seen, the results for Case 18 show considerable improvement over those for Case 14 . In addition, Figure 17 indicates for response within 2 minutes of access to target 290 that these results have a low sensitivity to the probability of detection for the two-man rule. Figure 18 illustrates how an effective two-man rule can provide reasonable PPS performance even for very short sabotage task times. 


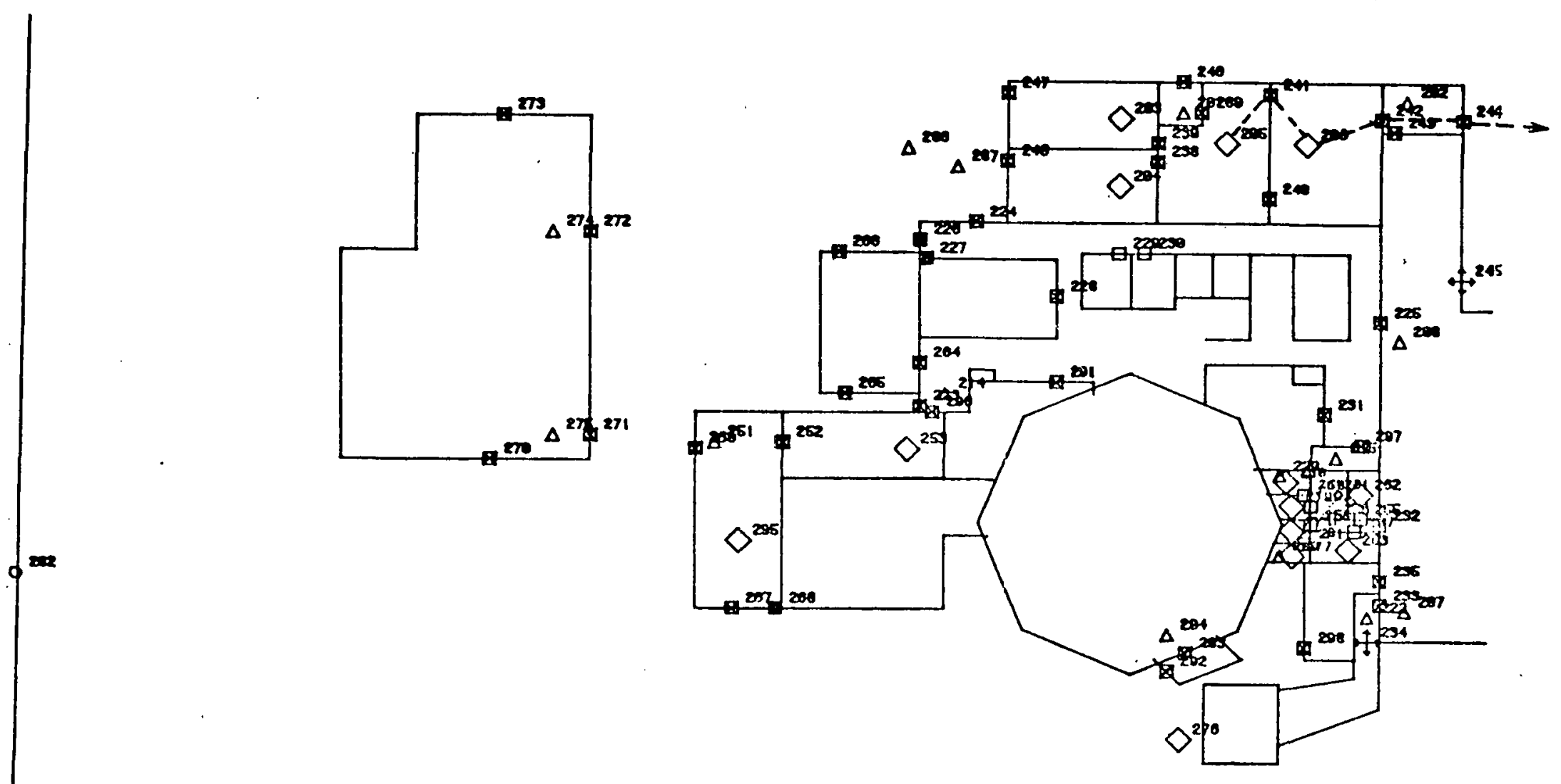

LEVEL 2 (GROUND LEVEL)

QUARTER 3 


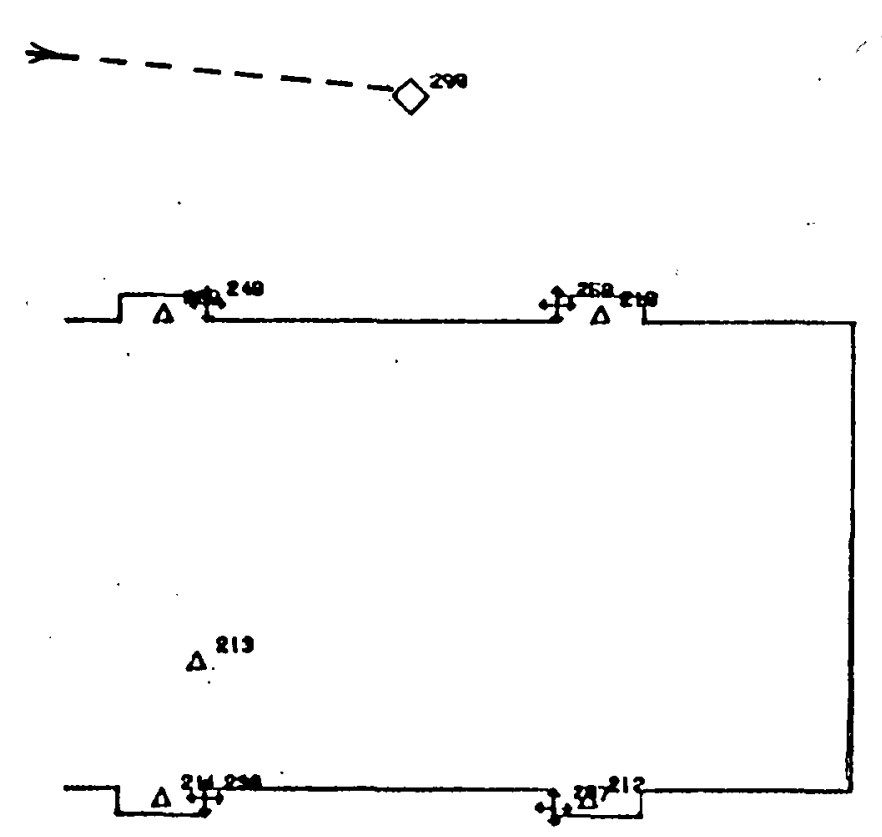

LEVEL 2 (GRÓUND LEVEL)

QUARTER 4
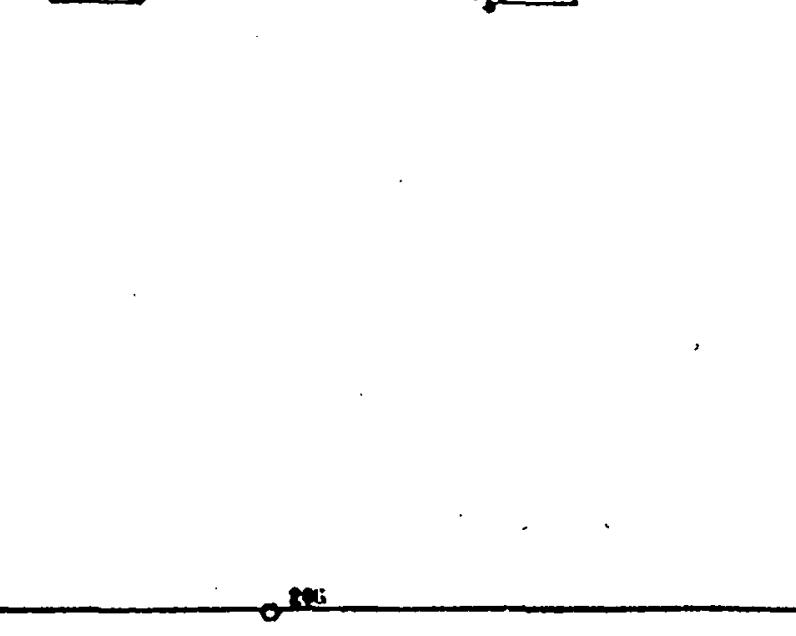

Figure 15. Level 2 (Ground Level, Quarter 4) Showing Insider Path 


\section{Table 7}

Sabotage Scenario with off-Site Power Disabled

\begin{tabular}{|c|c|c|c|c|c|c|c|c|}
\hline $\begin{array}{l}\text { Case } \\
\text { No. } \\
\end{array}$ & & $\begin{array}{r}\text { Sabotac } \\
\text { Targe } \\
\text { Sequen }\end{array}$ & & $\begin{array}{c}\text { Initial } \\
\text { Detection } \\
\end{array}$ & $\mathrm{P}_{\mathrm{d}}$ & $\begin{array}{l}\text { Initial } \\
\text { Response } \\
\text { Location }\end{array}$ & $\begin{array}{c}\text { Response } \\
\text { Time } \\
\text { (minute) } \\
\end{array}$ & $\mathrm{P}_{\mathrm{I}}$ \\
\hline 17 & 205 & +206 & +290 & $\begin{array}{l}\text { Access to } \\
206\end{array}$ & 0.95 & At 205 & 3.45 & 0.84 \\
\hline 18 & 205 & +206 & +290 & $\begin{array}{l}\text { Upon } \\
\text { sabotage } \\
\text { completion } \\
\text { at } 205\end{array}$ & 0.95 & At 205 & 3.45 & 0.97 \\
\hline
\end{tabular}




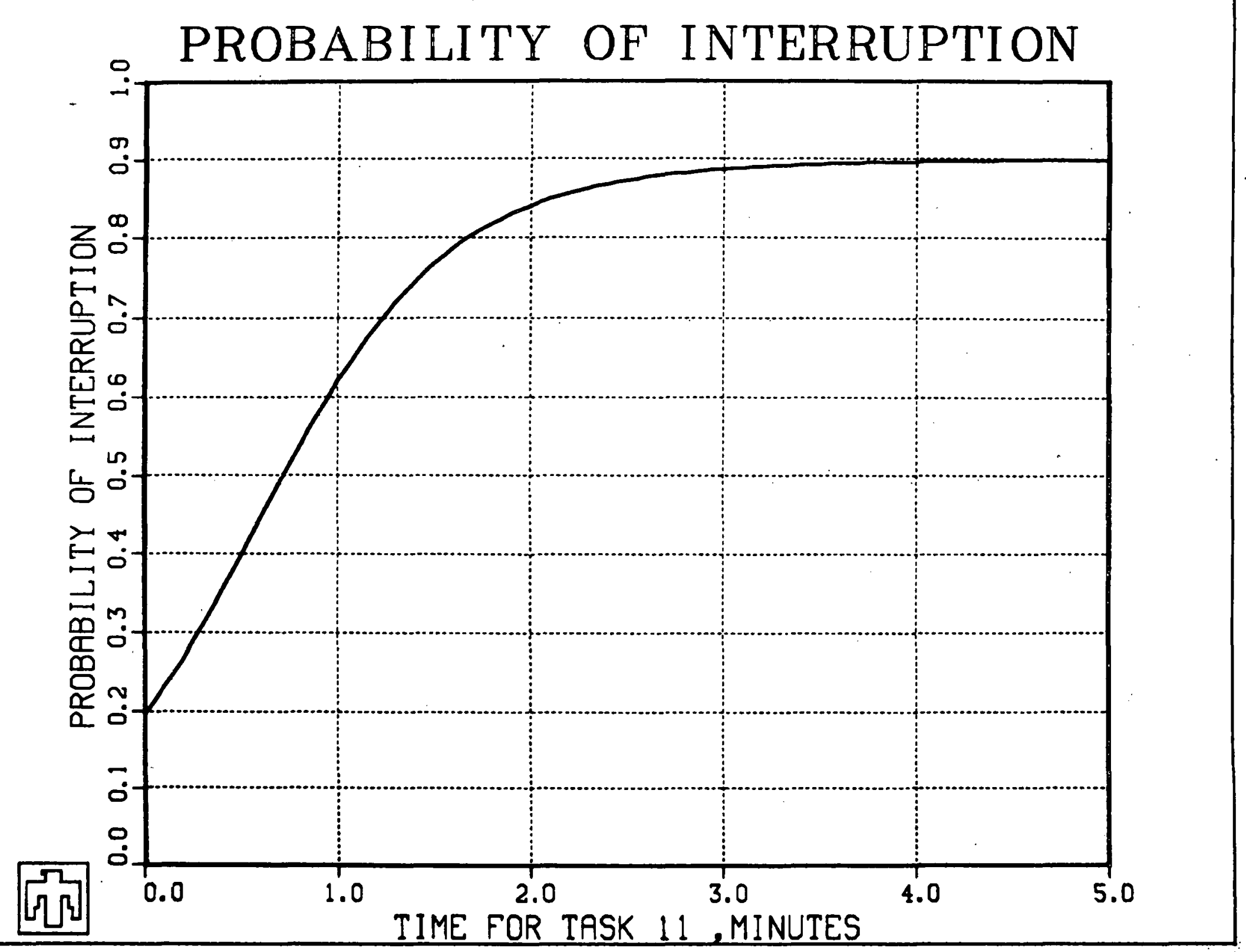

Figure 16. $P_{I}$ vs. Time for Task 11 at Target 290 (Case 17) 


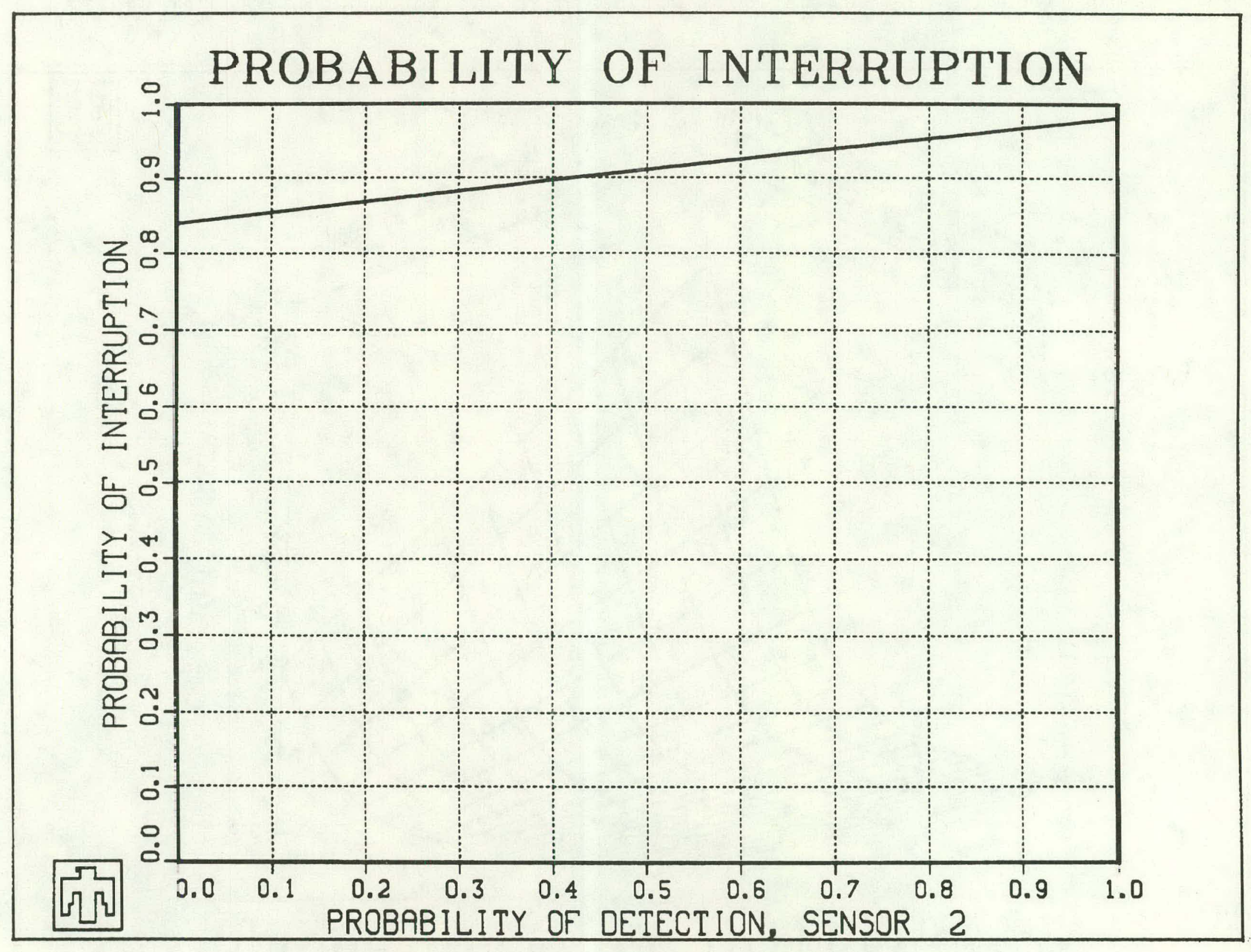




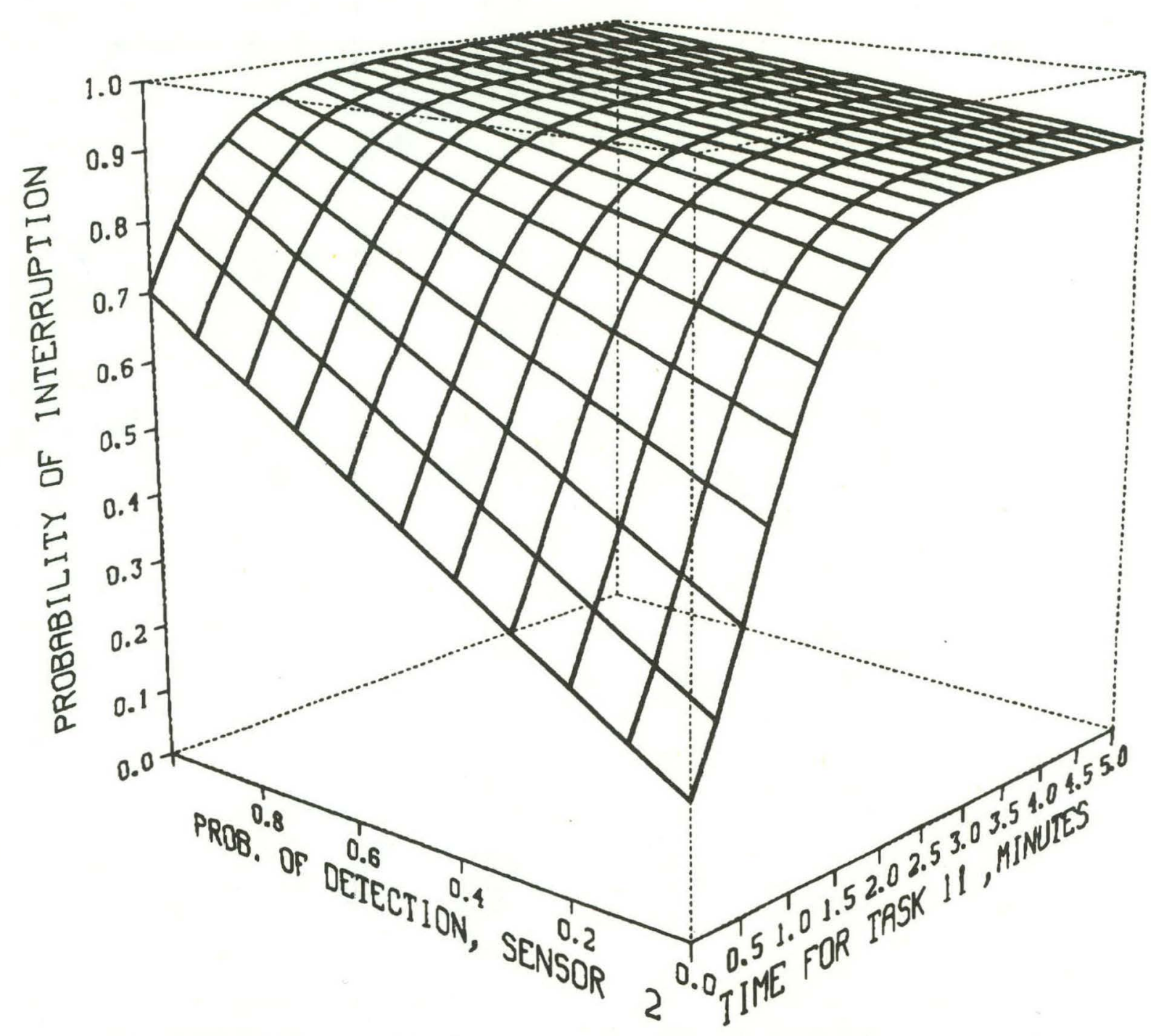

Figure 18. PI vs. Probability of Detection with Two-Man Rule (Sensor 2) and Time for Task 11 


\section{CONCLUSIONS}

The preceding chapters of this report have presented a reactor safeguards system structure as well as results from two basic approaches to preventing radioactive material release caused by insider-induced unsafe reactor conditions. These two approaches are operational recovery and sabotage prevention. This chapter presents conclusions based on these results.

\section{$5.1 \quad$ SYSTEM STRUCTURE}

A functional hierarchy has been developed in which all system functions known to play a role in preventing the release of radioactive material from an operating reactor have been identified. This functional hierarchy can provide a unifying framework upon which to develop a broad-based system assessment methodology.

\subsection{OPERATIONAL RECOVERY}

For cases of core meltdown, damage control response times seem to limit opportunities for disabled component repair/replacement to long-term functions, e.g., the HVAC, the containment heat removal system, etc. In cases in which core meltdown is not impending,* damage control response may not present any problem, but the ability to sense disabled components appears inadequate, particularly for standby components that have been subtly altered.

\subsection{SABOTAGE PREVENTION}

The conclusions which follow concerning the utility of the work rules are confined to the examples analyzed. Although the example data are considered typical, wherever work rule applications seem unsatisfactory, parameter values usually can be modified, at a cost, to obtain satisfactory system performance.

- Operational Zoning

If the saboteur has authorized access to all but the last vital area in a sabotage sequence, then operational zoning as a means of sensing unauthorized arcess is likely to place detection too late in the sabotage sequence for a timely response. Adaitional restrictions on authorized access for personnel could improve PPS performance but only for sabotage combinations of three or liore targets. This could have implications for the "key" (minimum protected set) vital-area concept.

`Limited, symbolic, or protracted sabotage attempts. 


\section{- Area Zoning}

For target combinations seemingly well-suited to area zoning the PPS performance was marginal when area zoning was applied. Fol adjoining or closely located vital-area combinations, area zoning became equivalent to operational zoning, with the same conclusions applicable.

\section{- Team Zoning}

Team zoning, applied as the two-man rule, provided the earliest detection time in the sabotage sequences analyzed. Therefore, on the positive side, this rule offers the greatest potential for effective PPS performance. However, on the negative side, this rule may be the least reliable due to the vagaries of human performance in a surveillance mode. 


\section{RECOMMENDATIONS}

The following recommendations regarding reactor safeguards system structure, operational recovery, and sabotage prevention are suggested. for further development.

\subsection{SYSTEM STRUCTURE}

The development of a uniform, logical, and defensible assessment method for insider sabotage protection is recommended. The structure described in Chapter 2 could serve as a framework to unify responses to component and system questionnaires which can provide explicit, comprehensive treatment of both subjective and objective aspects of operational, safety, and physical protection systems.

\subsection{OPERATIONAL RECOVERY}

A comprehensive, in-depth impact-benefits study should be made in the area of sensing vital component tampering and failures. This study should address the subject from operations, safety, and safeguards viewpoints.

\section{3 SABOTAGE PREVENTION}

Defensible methods for assessing the impact of safeguards system options on both operations and safety should be developed. The availability of such methods would provide a means of making and supporting objective decisions regarding proposed options. The question of Type I vital areas in connection with insider sabotage should be investigated to determine the conditions, if any, for which there are no Type I vital areas. If such conditions exist, then the impact on PPS requirements should be assessed. 


\section{REFERENCES}

1. P. Lobner et al., Light-Water Reactor Operations Control Analysis (U), SAI/LJ 79:1112.1 (La Jolla: Science Applications Inc., September 1979) (CNSI).

2. D. M. Ericson and G. B. Varnado, Nuclear Power Plant Design Concepts for Sabotage Protection, NUREG/CR-1345, SAND80-0477 (Albuquerque: Sandia National Laboratories, January 1981).

3. L. A. Goldman and P. Lobner, "Protection Against Unauthorized Activities by Plant Personnel (Task 2) -- System Ranking," SAI 01581-337LJ (La Jolla: Science Applications, Inc., September 1981). [Draft].

4. T. L. McDaniel et al., "Evaluation of the Insider Threat of Light Water Reactor Sabotage (U)" SAI/LJ DC 80:2100 (La Jolla: Science Applications, Inc., November 1980) (CNSI). [Draft].

5. L. D. Chapman et al., SAFE Users Manual, Vols. I-III, NUREG/ CR-1246, SAND79-2247 (Albuquerque: Sandia National Laboratories, August 1981).

6. H. J. Jerison and R. M. Pickett, "Vigilance:

A Review and Reevaluation," Human Factors, 5 (1963), 211-38. 


\section{APPENDIX A}

Example Facility Layout Drawings

Appendix A contains layout drawings (Figures A-l through A-13) of the example facility used in this application. This hypothetical facility has nine levels, labeled Level 0 through Level 8 , with Level 0 the lowest level and Level 8 the highest. Level 2 is the groundfloor level. Lines in the drawings represent barriers, such as walls and fences, and nodes represent doors, gates, stairwells, other access points, and targets. Node labels in the drawings identify the facility nodes. The label for a node is located slightly above and to the right of the node. The set of symbols used in the example application to indicate the different node types in the facility drawings is shown in Table $A-1$.

Table A-1

Facility Node Symbols

Node Symbol

0

血

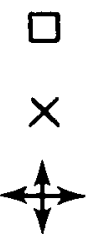

凶

$x$

$\triangle$

$\diamond$
Description

Fence node

Roll-up door

Watertight door

Containment vault door

Standard, unlocked door or open portal

Locked door

Pseudo-node

Stairwell

Target 


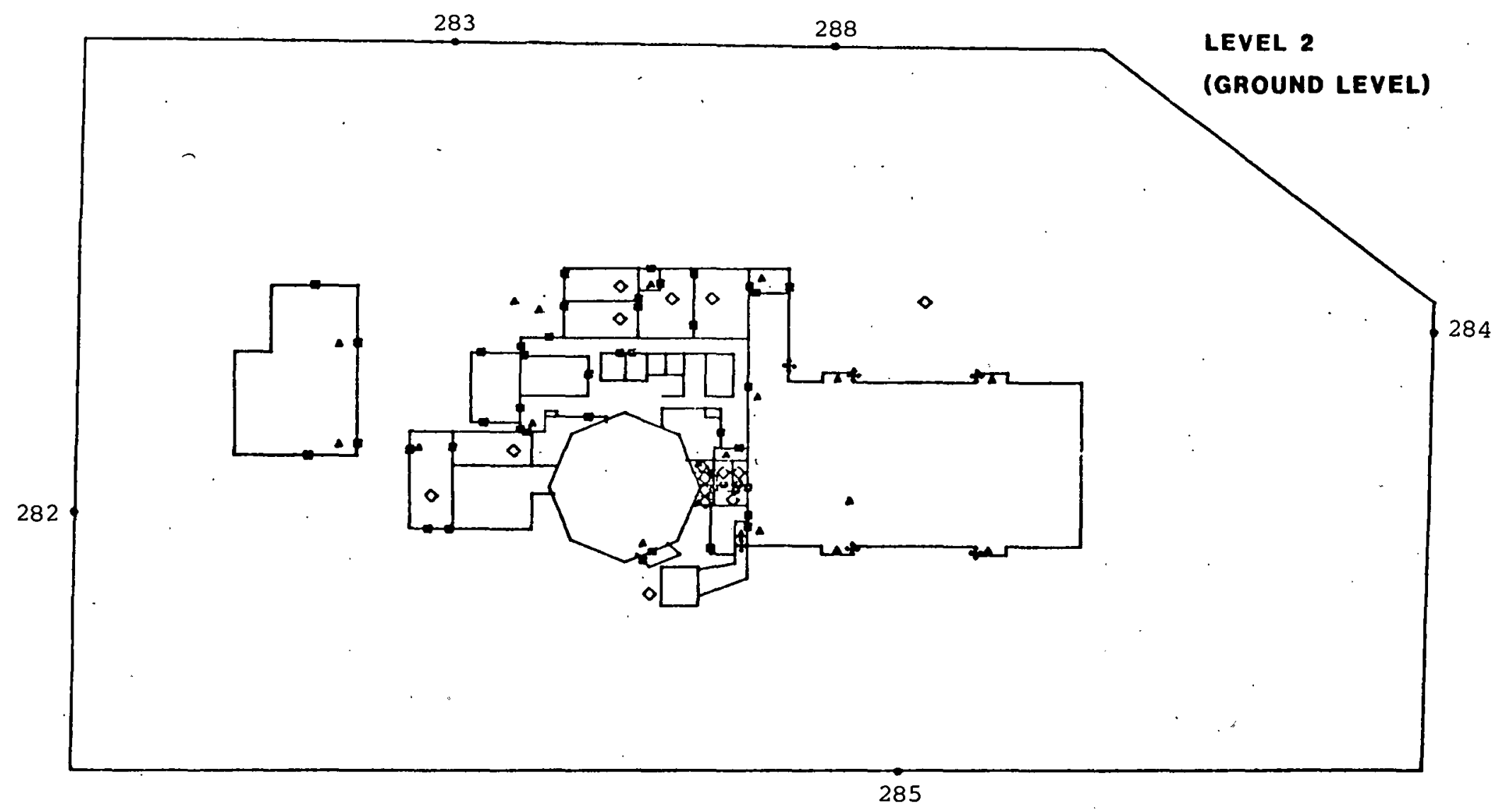

Figure $\dot{A}-1$. Level 2 (Ground Level) 
LEVEL O

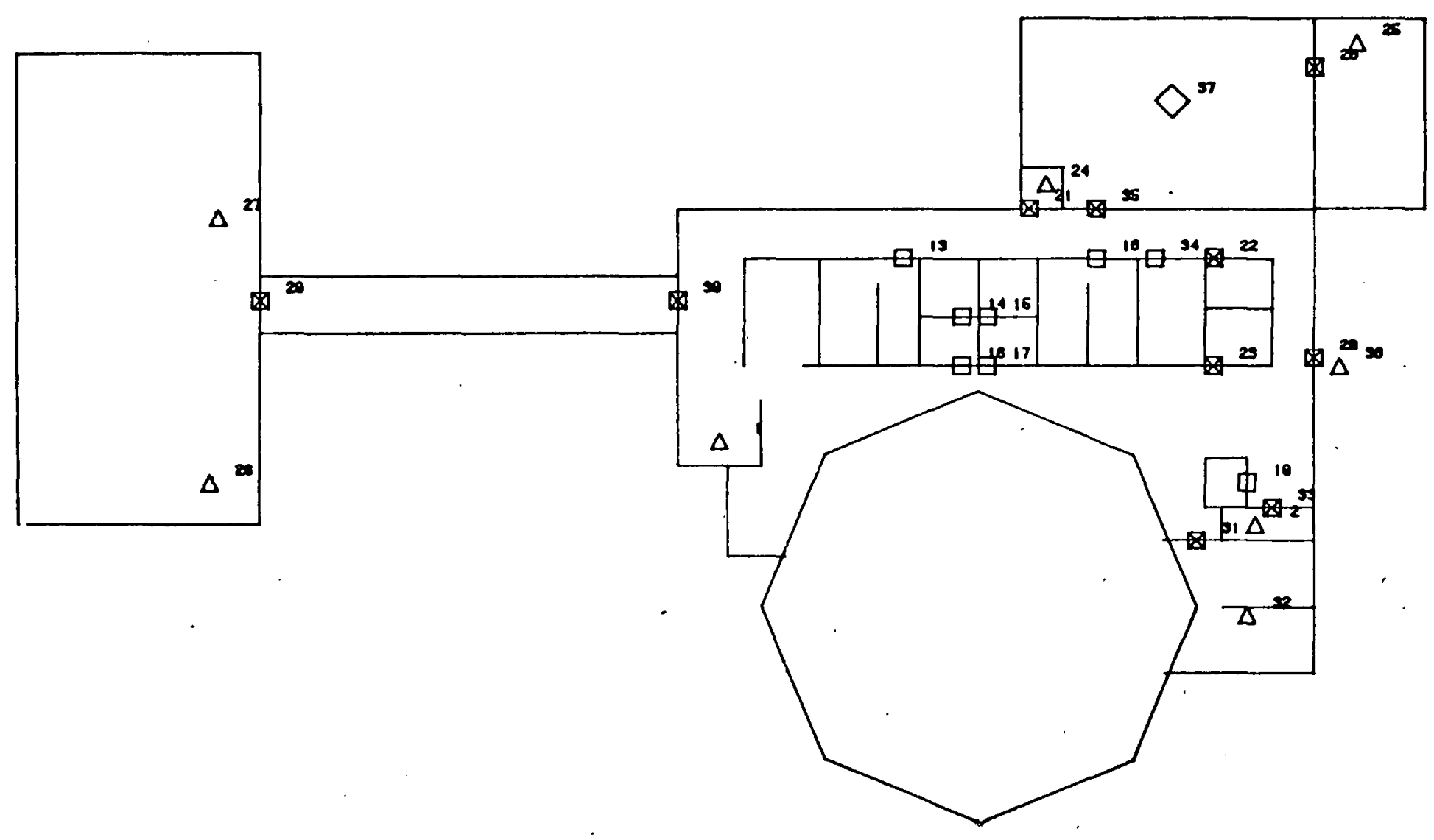

Figure A-2. Level 0 


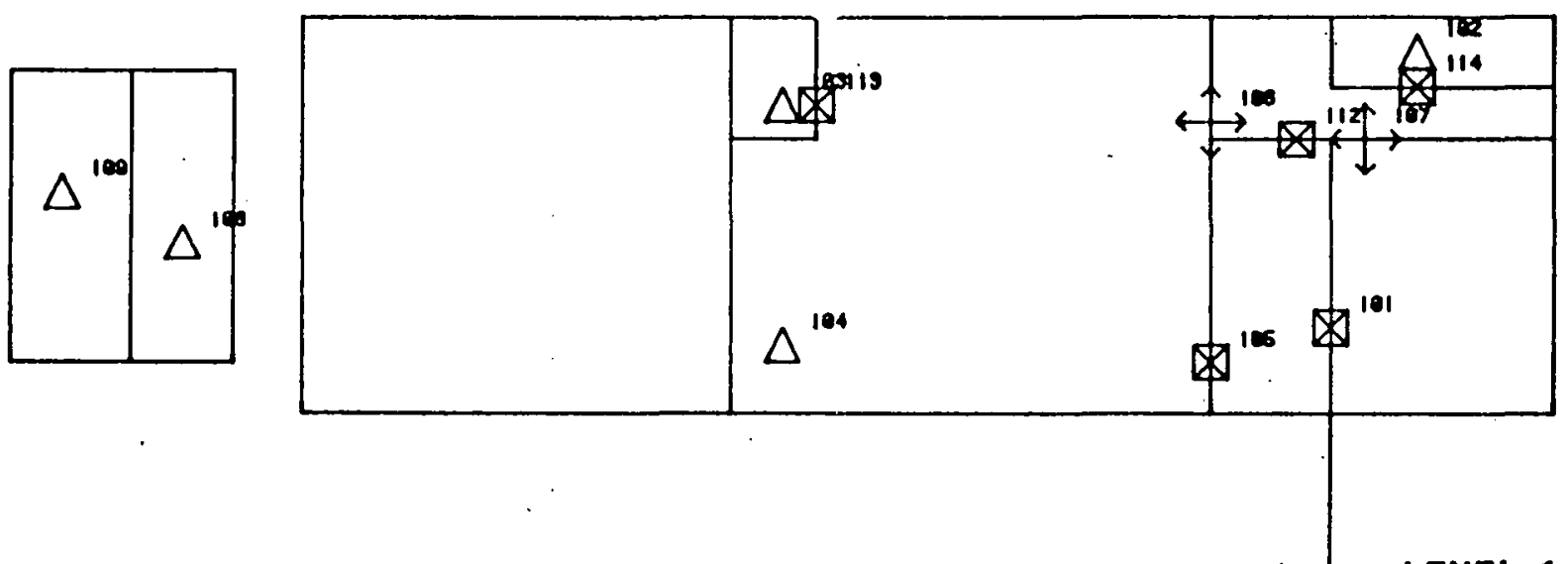

LEVEL 1

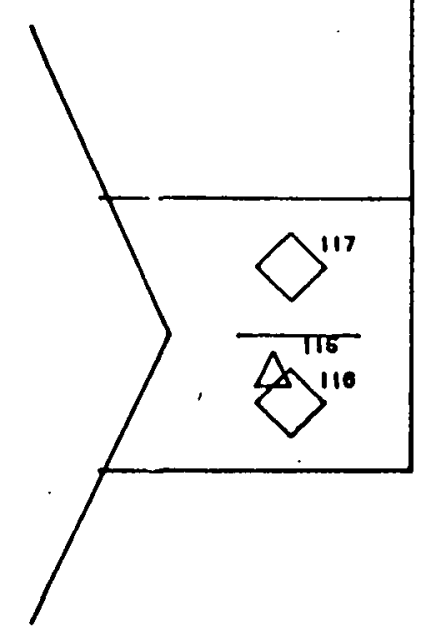

Figure A-3. Level 1 
LEVEL 2 (GROUND LEVEL) QUARTER 1

QUARTERS LABELED

\begin{tabular}{|l|l|}
\hline 1 & 2 \\
\hline 3 & 4 \\
\hline
\end{tabular}

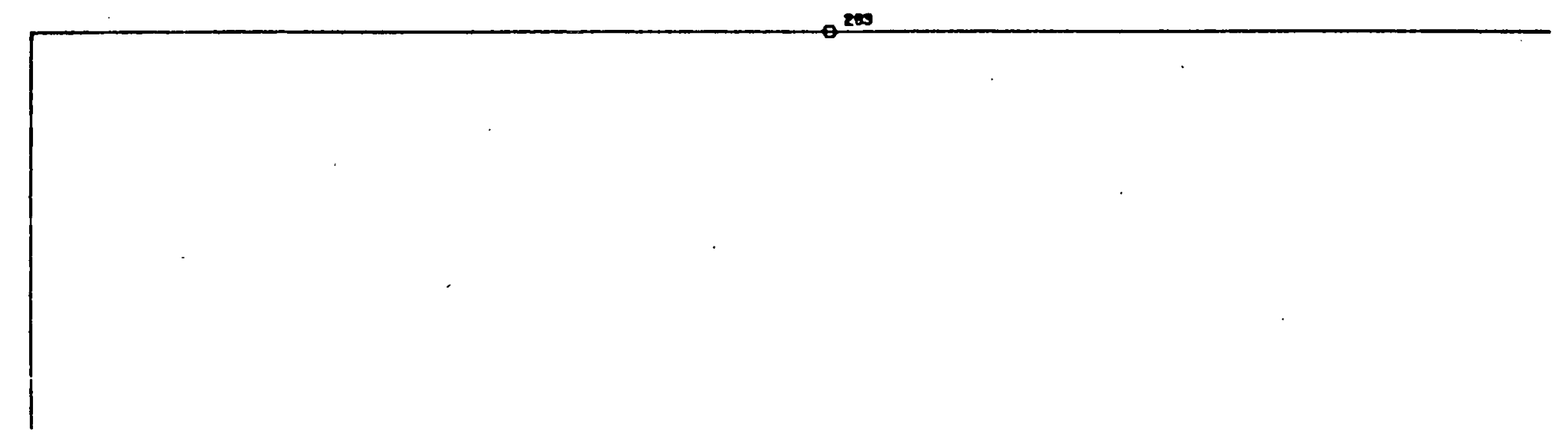

Figure A-4. Level 2 (Ground Level) 
LEVEL 2 (GROUND LEVEL)

QUARTER 2

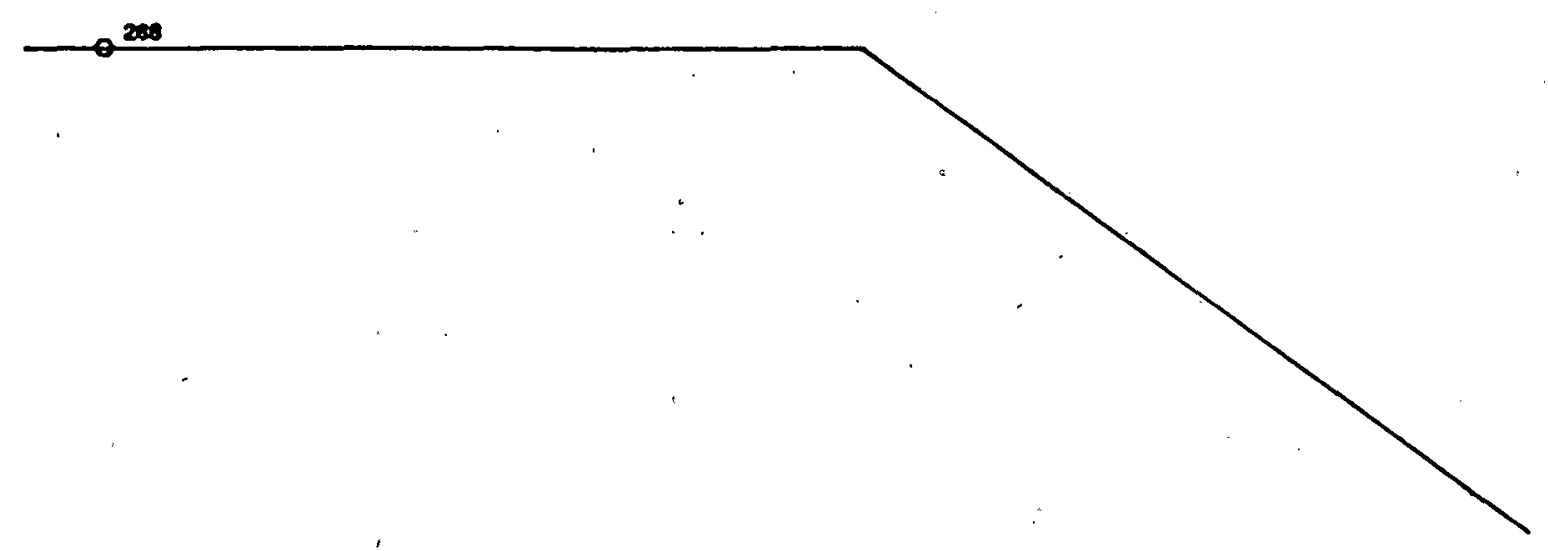

Figure A-5.. Level 2 (Ground Level) 

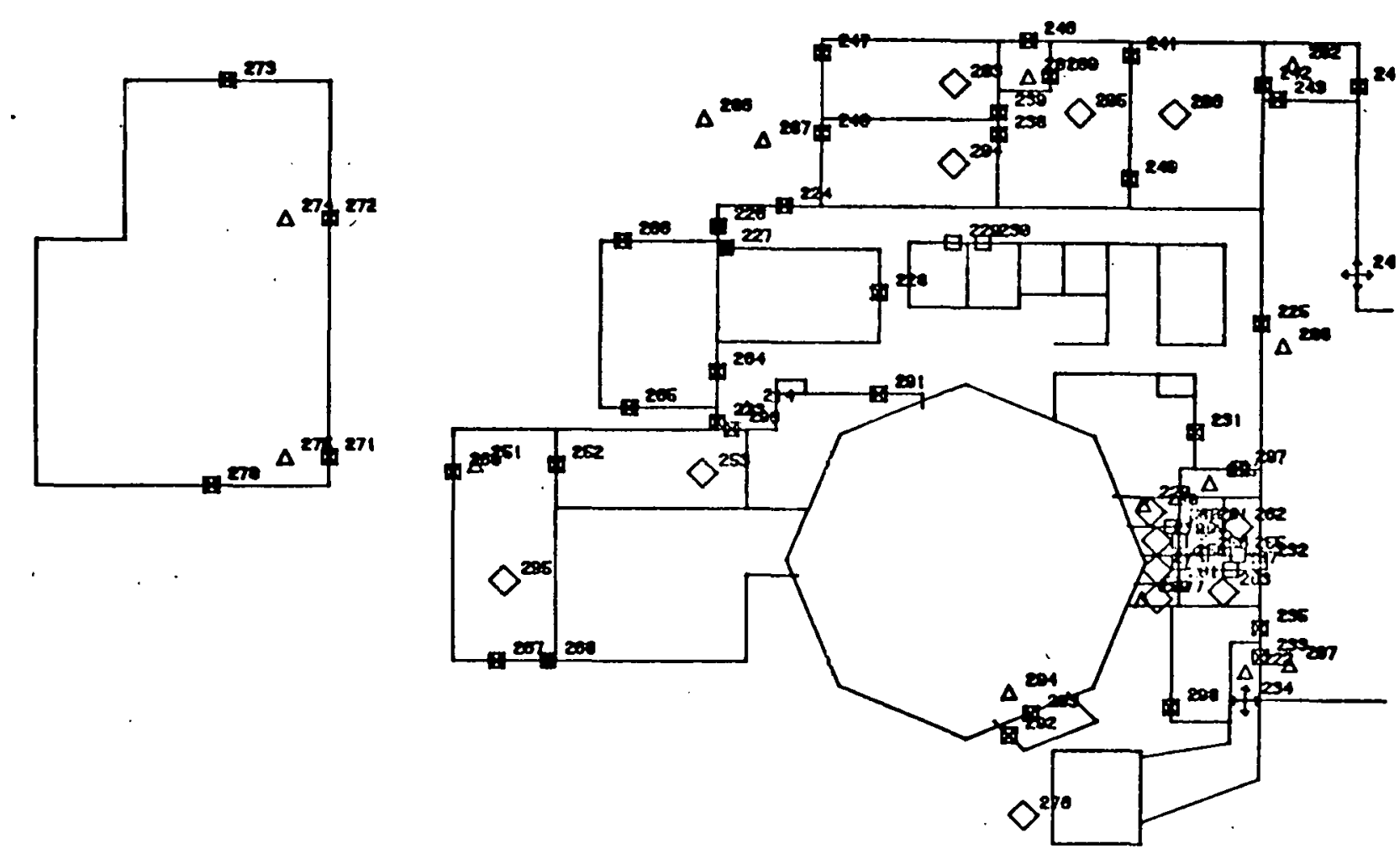

LEVEL 2 (GROUND LEVEL)

QUARTER 3 


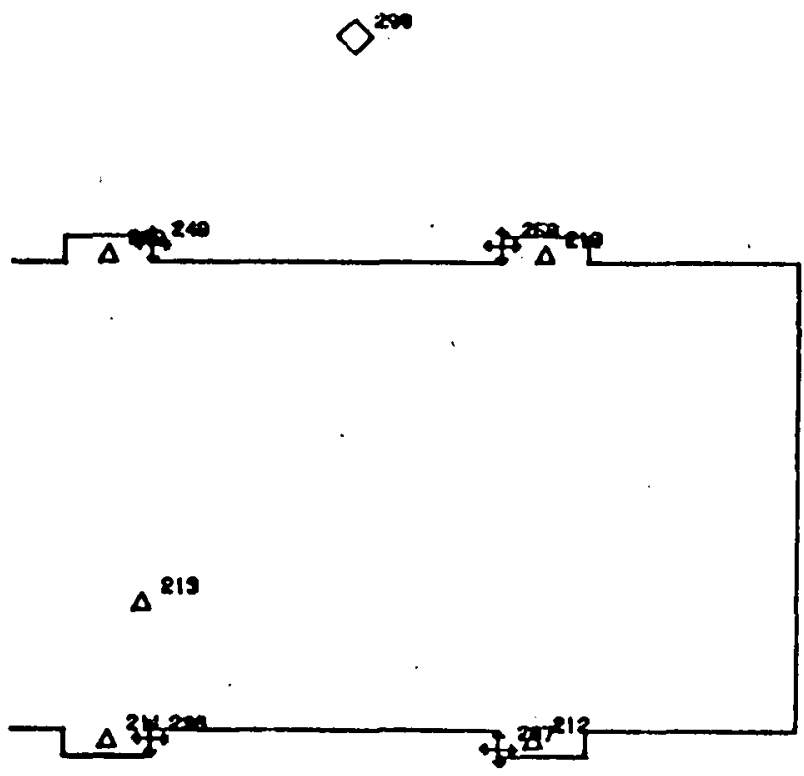

LEVEL 2 (GROUND LEVEL)

QUARTER 4

Figure A-7. Level 2 (Ground Level) 


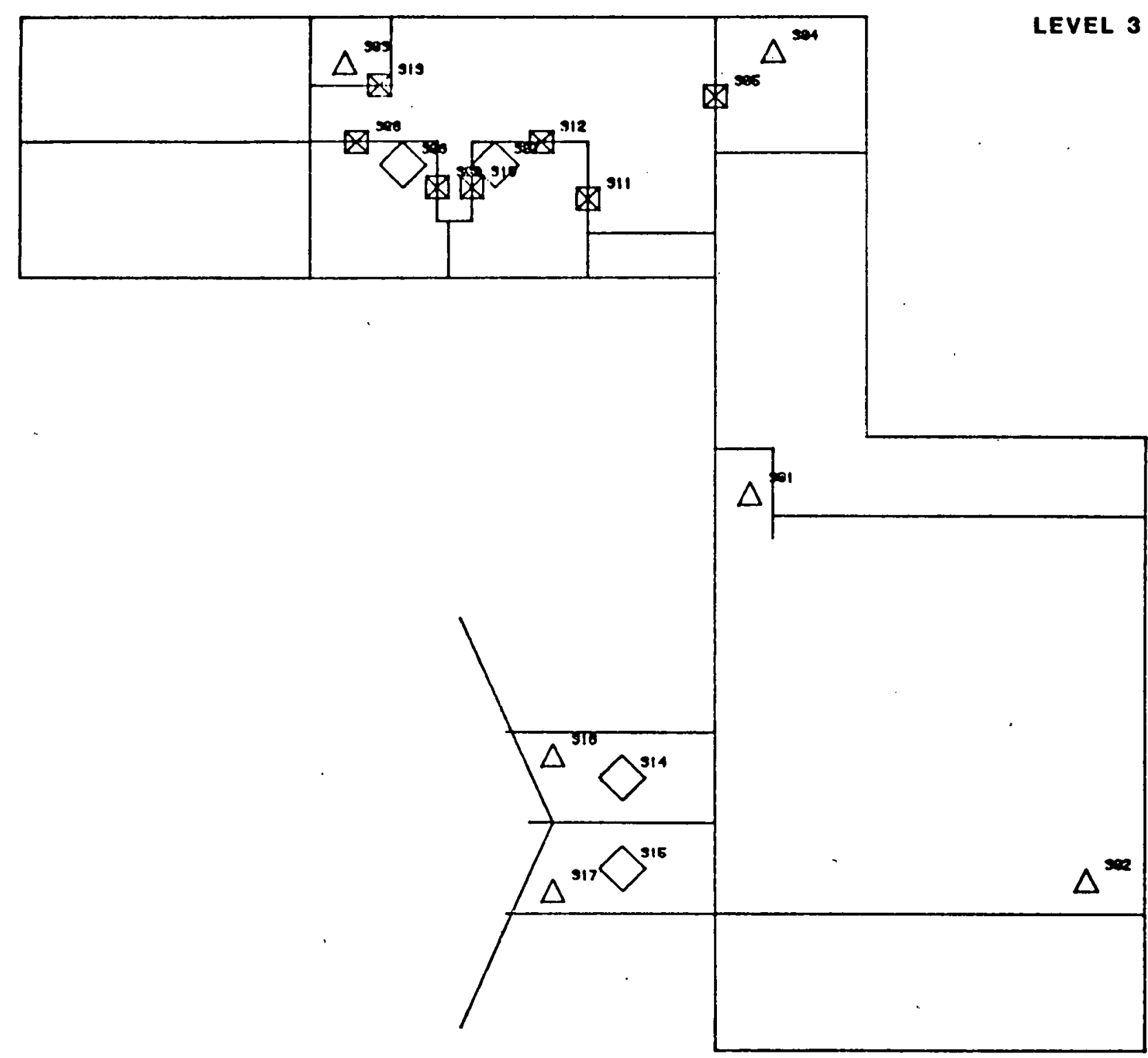

Figure A-8. Level 3 


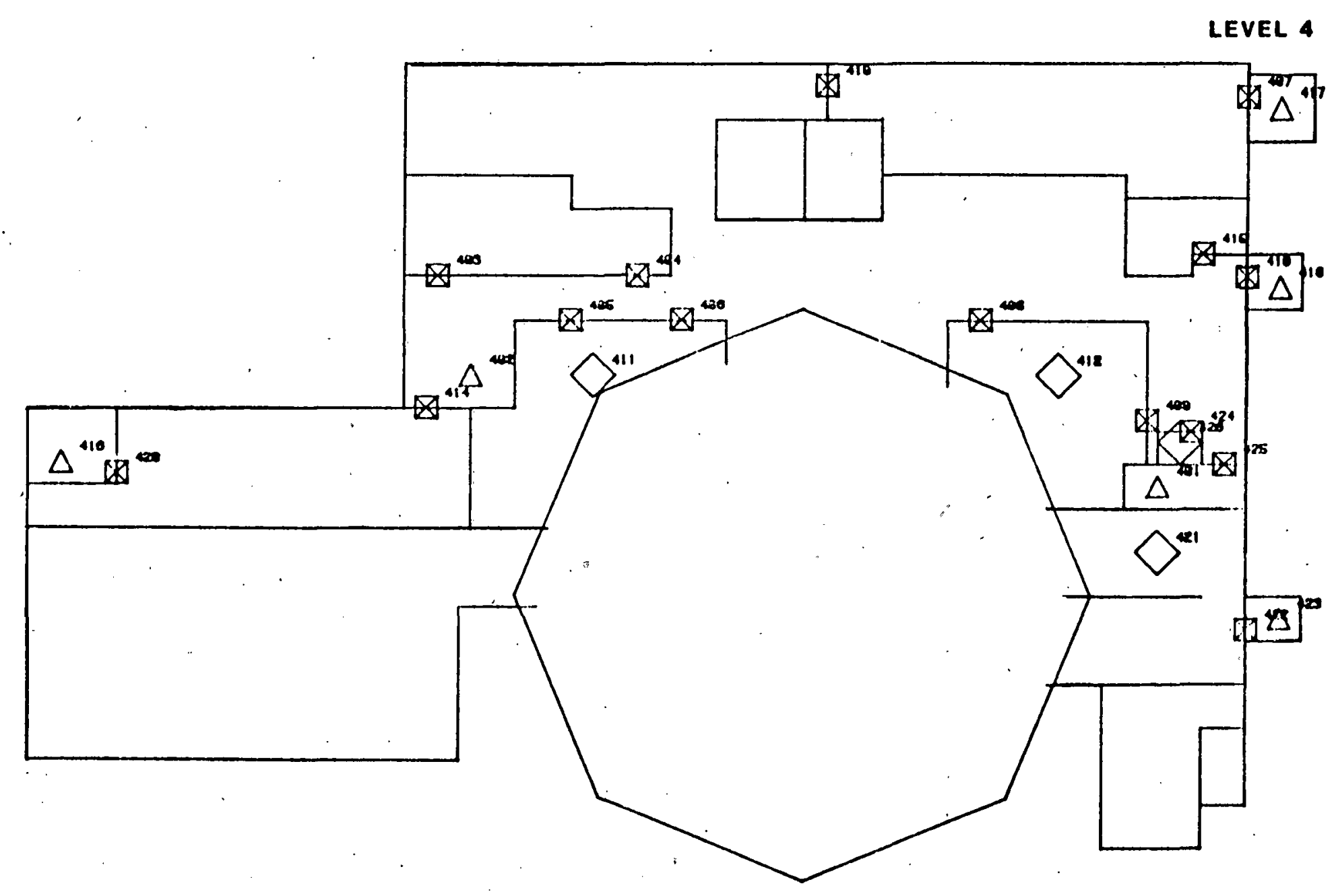

Figure A-9. Level 4, 


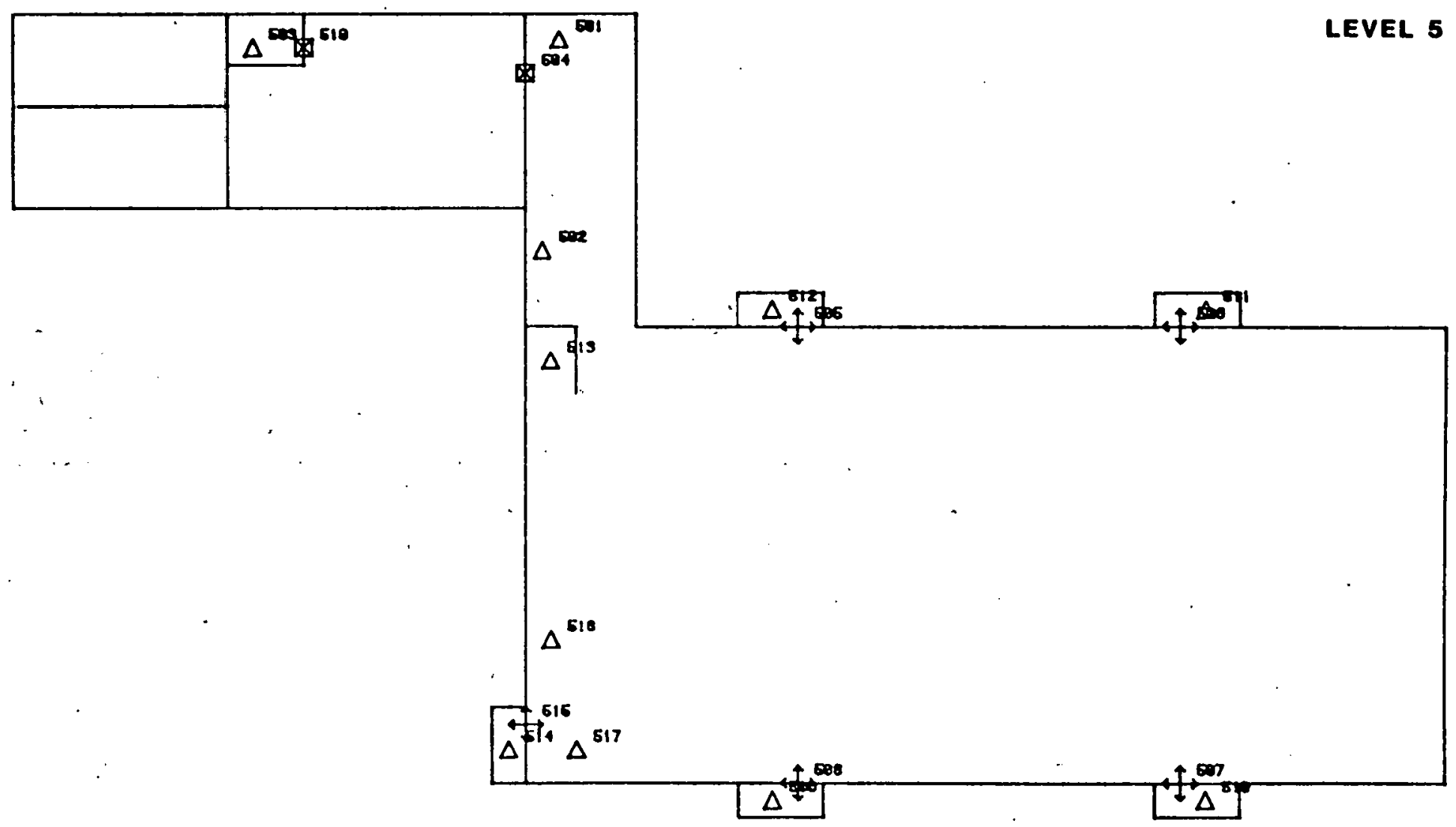

Figure A-10. Level 5 


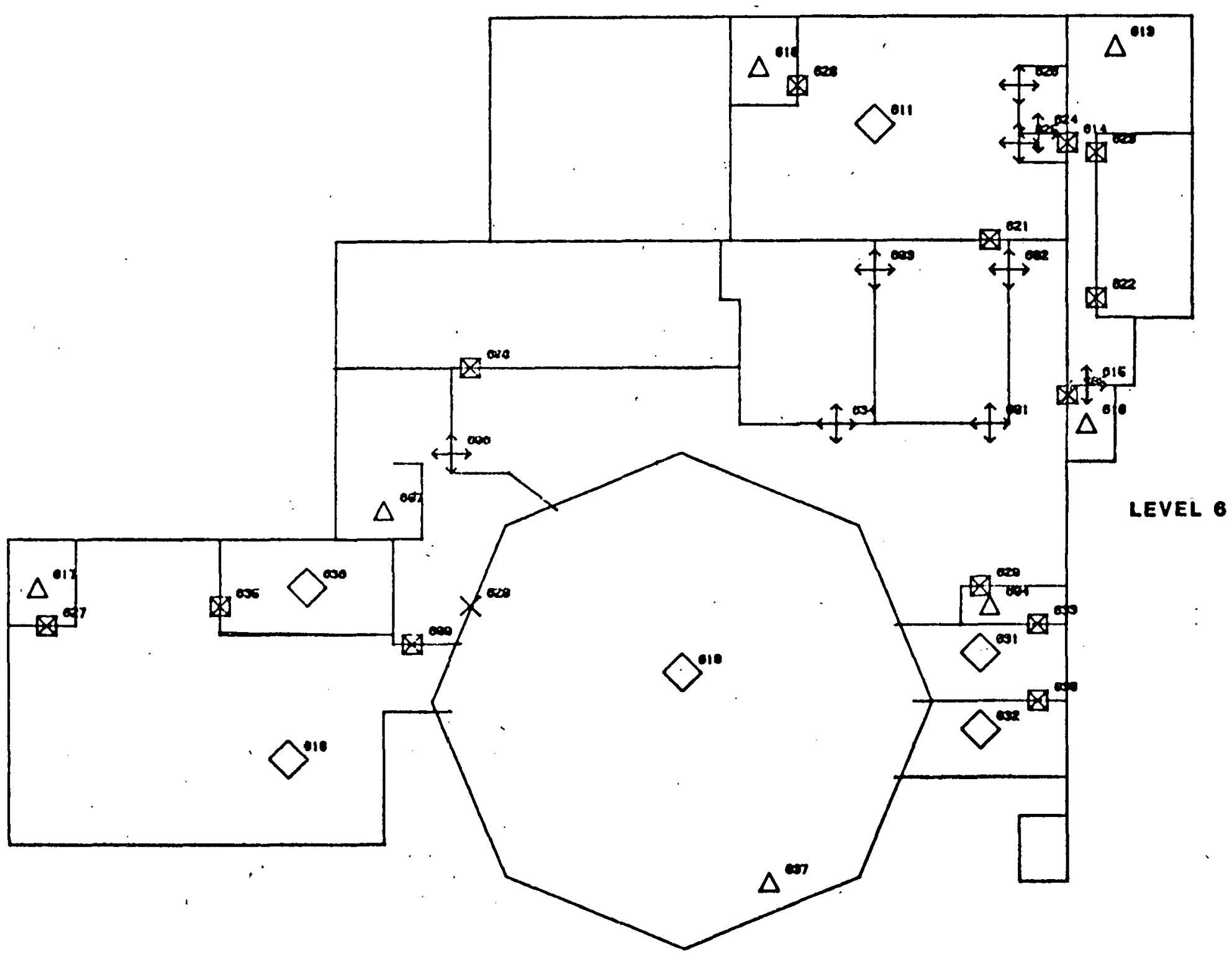

Figure A-11. Level 6 


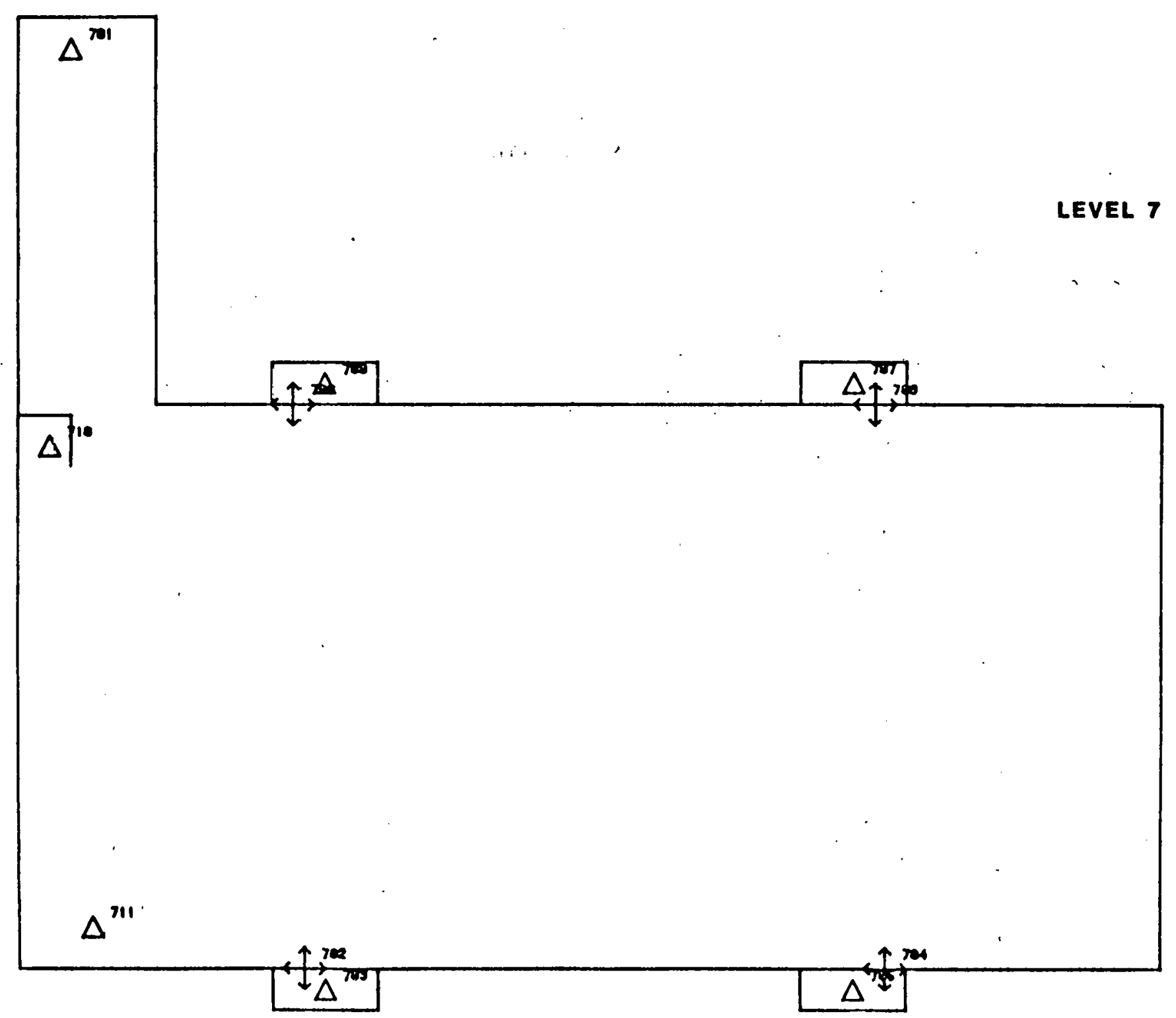

Figure $\mathrm{A}-12$. Level 7 


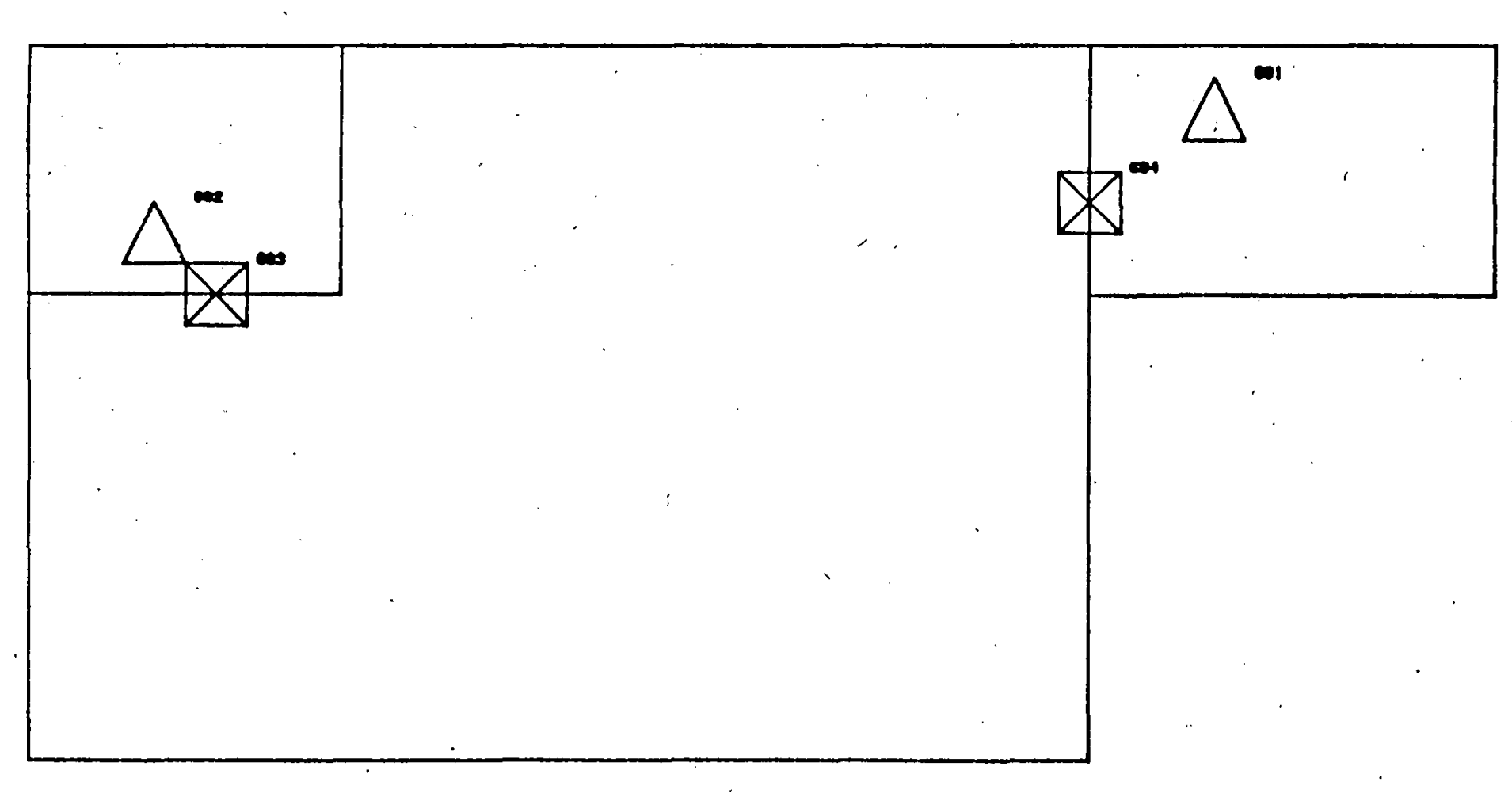

Figure A-13. Level 8 
Appendix $B$ contains a listing of the time delay in minutes (TD) and probability of detection (PD) for each node in the hypothetical facility (Table B-l), a compilation of the data necessary to define all the stairwells in the example facility (Table B-2), a summary of assumptions and data used for generating security force response times to targets in the example facility (Tables B-3 and B-4), aggregate response times to the targets (Table B-5), a list of targets in the example facility (Table B-6), and a list of Type'II target combinations in the example facility (Table B-7).

\section{Table B-1}

Node Data

\section{Type 3}

Fence nodes $(T D=0.2, P D=0.9)$

$\begin{array}{lllll}282 & 283 & 284 & 285 & 288\end{array}$

\section{Type 4}

Roll-up doors (TD $=1.5, \mathrm{PD}=0.95)$

$$
226 \quad 227 \quad 268
$$

Type 5

Watertight doors $(\mathrm{TD}=0.8, \mathrm{PD}=0.9)$

$\begin{array}{rrrrrrrrrr}13 & 14 & 15 & 16 & 17 & 18 & 19 & 34 & 229 & 230 \\ 232 & 255 & 256 & 257 & 258 & 259 & 260 & 261 & & \end{array}$

Type 6

Containment vault door $(\mathrm{TD},=10, \mathrm{PD}=0.9)$

620

Type 7

Unlocked, standard doors $(\mathrm{TD}=0.05, \mathrm{PD}=0.01)$

$\begin{array}{llllllllll}234 & 236 & 237 & 245 & 249 & 250 & 505 & 506 & 507 & 508 \\ 515 & 601 & 602 & 603 & 606 & 615 & 624 & 625 & 626 & 634 \\ 702 & 704 & 706 & 708 & & - & & & & \end{array}$

Personnel portals $(\mathrm{TD}=0.05, \mathrm{PD}=0.9$ )

$106 \quad 107$ 


\section{Table B-I (Continued) \\ Node Data}

Type 8

Locked, alarmed doors ( $\mathrm{TD}=1.0, \mathrm{PD}=0.95)$

$\begin{array}{rrrrrrrrrr}20 & 21 & 22 & 23 & 26 & 29 & 30 & 31 & 33 & 35 \\ 101 & 105 & 112 & 113 & 114 & 223 & 224 & 225 & 228 & 231 \\ 238 & 239 & 240 & 241 & 242 & 243 & 244 & 246 & 252 & 264 \\ 265 & 266 & 267 & 269 & 289 & 291 & 296 & 297 & 305 & 308 \\ 309 & 310 & 311 & 312 & 313 & 403 & 404 & 405 & 406 & 407 \\ 408 & 409 & 410 & 414 & 415 & 419 & 420 & 422 & 424 & 425 \\ 504 & 519 & 605 & 608 & 609 & 614 & 621 & 622 & 623 & 627 \\ 628 & 629 & 630 & 633 & 635 & 803 & 804 & & & \end{array}$

Locked, unalarmed door $(\mathrm{TD}=1.0, \mathrm{PD}=0.05)$

$$
\begin{array}{lllllll}
233 & 235 & 270 & 271 & 272 & 273 & 298
\end{array}
$$

Locked, hardened, alarmed door $(\mathrm{TD}=2.0, \mathrm{PD}=0.95)$ $247 \quad 248 \quad 292$

Locked, unalarmed hatch $(T D=2.0, P D=0.05)$

293

Type 9

All pseudo-nodes have $\mathrm{TD}=0$. and $\mathrm{PD}=0$.

Type 10

Stairwell nodes $(T D=0.01, P D=0$.

$\begin{array}{llllllllll}1 & 2 & 24 & 25 & 27 & 28 & 32 & 36 & 102 & 103\end{array}$

$\begin{array}{llllllllll}104 & 108 & 109 & 115 & 201 & 202 & 207 & 208 & 209 & 210\end{array}$

$\begin{array}{llllllllll}211 & 212 & 213 & 214 & 215 & 220 & 222 & 251 & 274 & 275\end{array}$

$\begin{array}{llllllllll}286 & 287 & 294 & 299 & 301 & 302 & 303 & 304 & 316 & 317\end{array}$

$\begin{array}{llllllllll}401 & 402 & 416 & 417 & 418 & 423 & 501 & 502 & 503 & 509\end{array}$

$\begin{array}{llllllllll}510 & 511 & 512 & 513 & 514 & 517 & 518 & 604 & 607 & 610\end{array}$

$\begin{array}{llllllllll}613 & 616 & 617 & 637 & 701 & 703 & 705 & 707 & 709 & 710\end{array}$

$711 \quad 801 \quad 802$ 
Table B-1 (Concluded)

Node Data

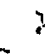

Type 11 - Targets $(P D=0$.

$(\mathrm{TD}=2$.

$\begin{array}{rlllllllll}37 & 116 & 117 & 203 & 204 & 205 & 206 & 253 & 262 & 263 \\ 276 & 277 & 278 & 279 & 280 & 281 & 290 & 295 & 306 & 307 \\ 314 & 315 & 411 & 412 & 421 & 631 & 632 & 636 & & \end{array}$

$(T D=5$.

$426 \quad 618$

$(\mathrm{TD}=10$.

$611 \quad 619$ 
Table B-2

Stairwells

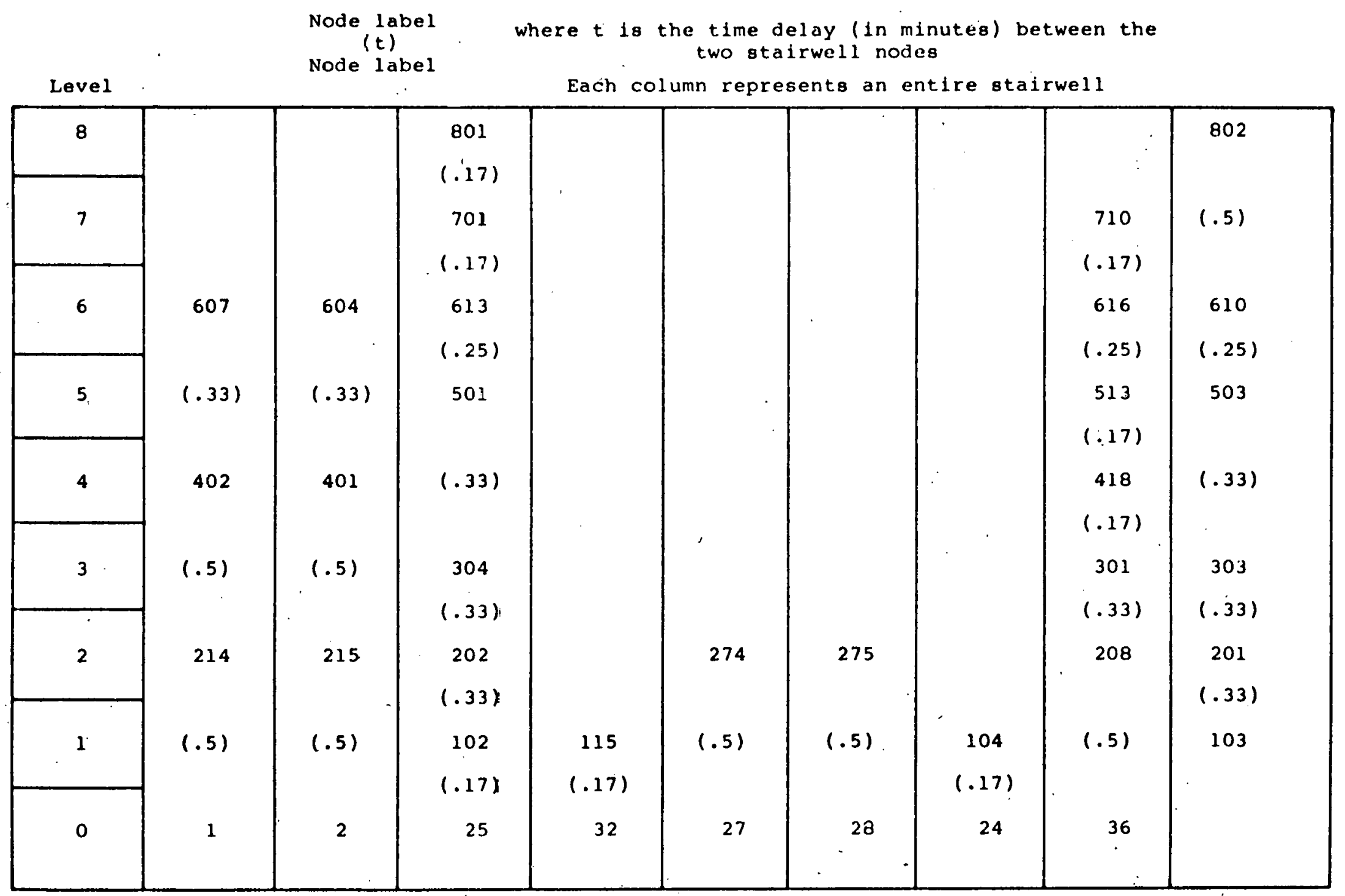


Table $\mathrm{B}-2$ (Continued)

Stairwells

Node label where $t$ is the time delay (in minutes) between the (t)

Node label two stairwel. 1 nodes

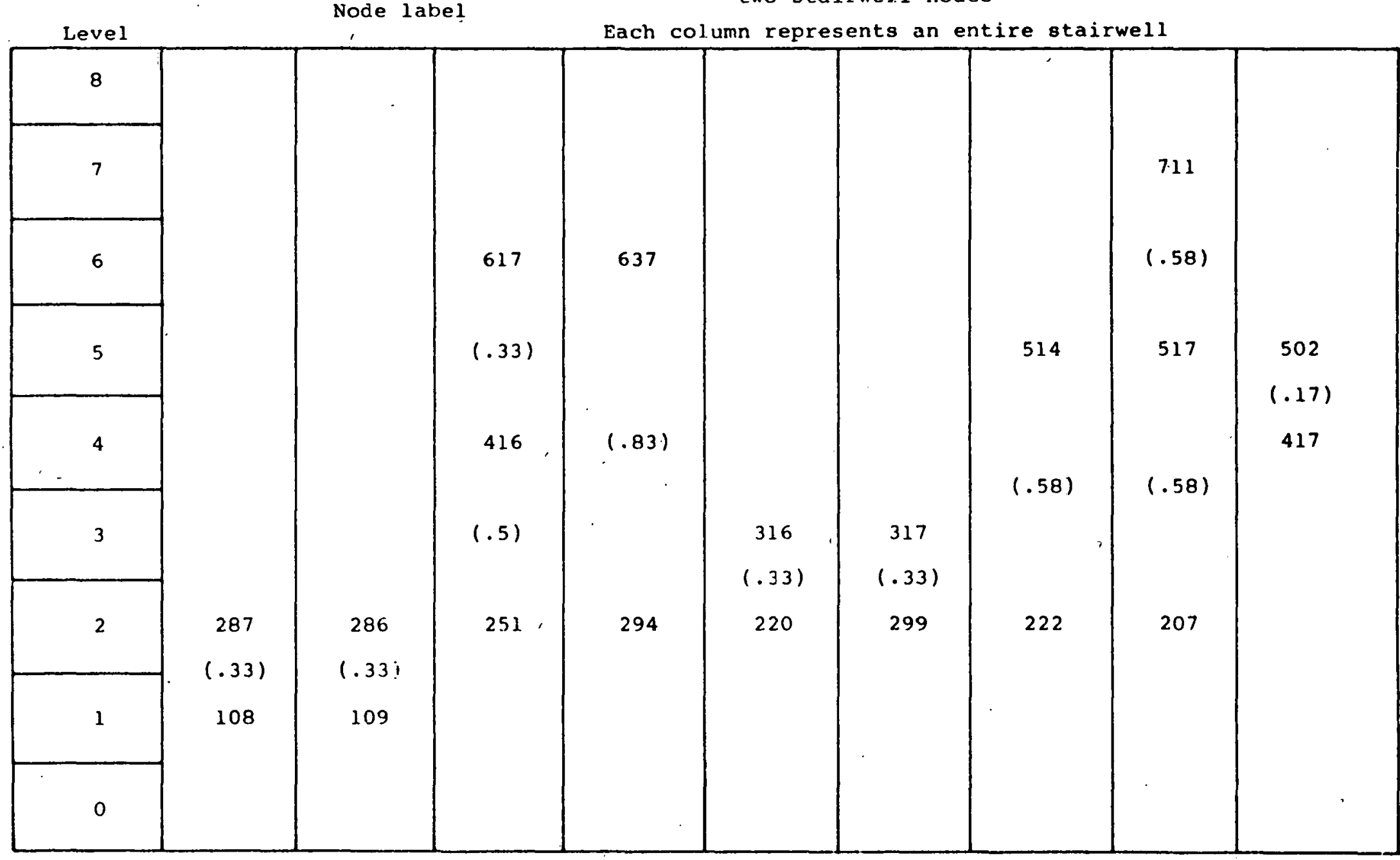


Table B-2 (Concluded)

Stairwells

Node label where $t$ is the time delay (in minutes) between the (t) Node label

Each column represents an entire stairwell

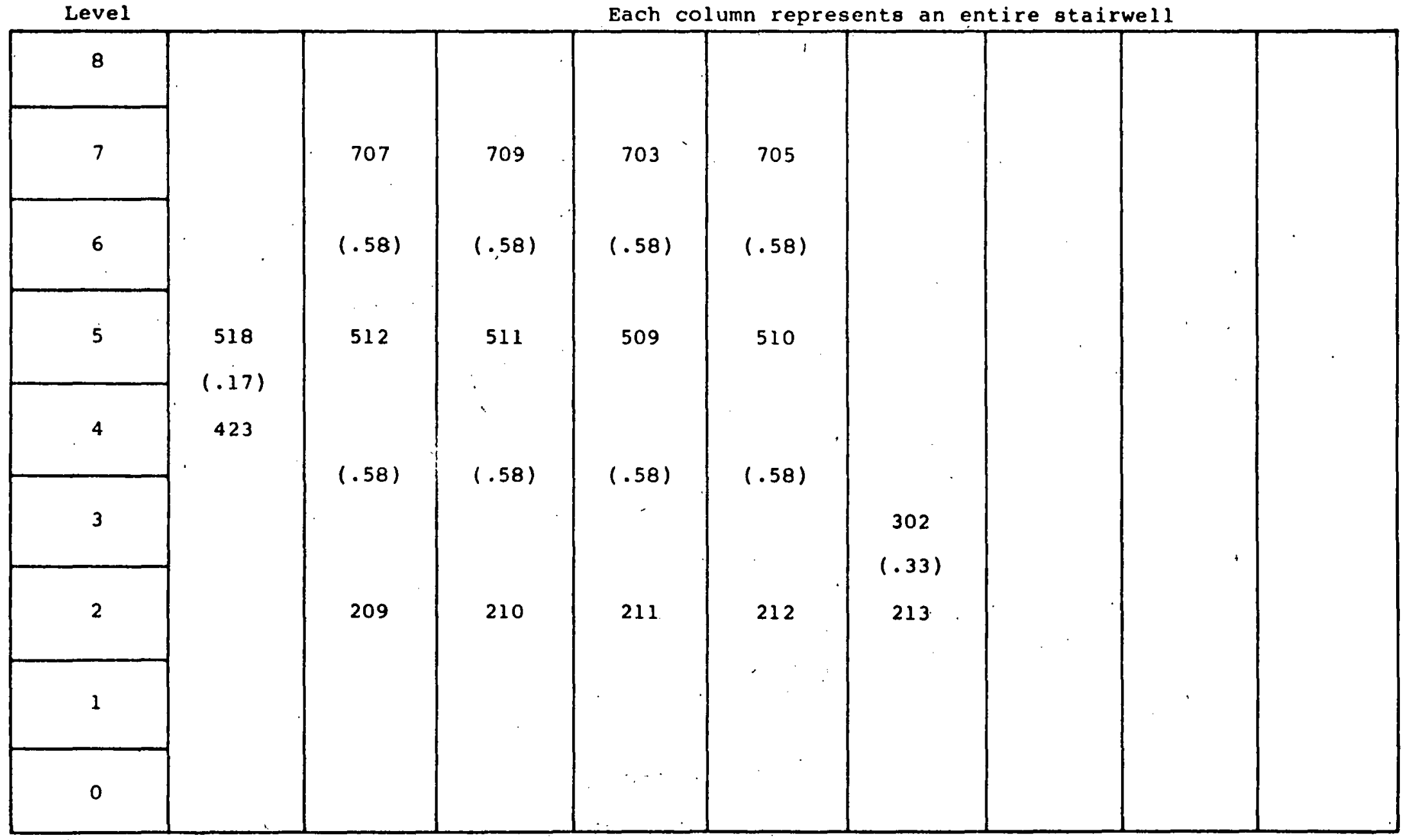


Table B-3

Data Used for Security Force Facility Model

\begin{tabular}{|c|c|c|c|c|c|c|c|c|c|}
\hline Node type & 3 & 4 & 5 & 6 & 7 & 8 & 9 & 10 & 11 \\
\hline Time Delay & 0 & .2 & .1 & 3. & .05 & .1 & 0 & 0 & 0 \\
\hline
\end{tabular}

(minutes)

Exceptions: node $293-2$.

node 292 - 100. (breakout door)

Security Force Assumptions:

Security station at node 284

Roving security officer

- patrols fence area

- two 1/2-hour patrols each 8-hour shift

Initial response is from roving security officer if on patrol

\section{Aggregate Response Time Formula}

The roving security officer will be on patrol 1 out of every 8 hours, so the probability that initial response will come from the security station is $7 / 8$ and the probability that response will come from a roving patrol is 1/8. In the case of the roving patrol, it is assumed equally likely that the security officer is at any of the five fence nodes; that is, the probability that he starts at a particular fence node is $1 / 5$. The aggregate response time to a particular target is then calculated by the following equation:

$$
\begin{aligned}
R t= & P \text { (response from security station) } x \text { (time from security } \\
& \text { station to target) }+P \text { (response from patrol) } x \text { (average } \\
& \text { time from patrol to target) } \\
= & 7 / 8 t_{284} \\
& +1 / 8(1 / 5)\left(t_{282}+t_{283}+t_{284}+t_{285}+t_{288}\right) \\
= & .9 t_{284}+.025\left(t_{282}+t_{283}+t_{285}+t_{288}\right)
\end{aligned}
$$

where $t_{i}$ is minimum time from start node $i$ to the target. The final column of Table. B-4 shows the aggregate response times calculated for each target in the example facility.

The user should keep in mind that these security force response times are very optimistic. They account only for travel time and, hence, assume immediate response without any time for assessment or other delays. They also assume direct response to the endangered target; whereas, in reality, the security force will not know exactly 
where the adversary is going and probably will not respond, initially to the target. However, the use of these response times can be justified.

Table $B-4$

Response Times (Minutes)

\section{Start Node}

\begin{tabular}{|c|c|c|c|c|c|c|}
\hline \multirow[b]{2}{*}{ Target } & & \multirow[b]{2}{*}{$\begin{array}{l}\text { Aggregate } \\
\text { Time }\end{array}$} \\
\hline & $\underline{282}$ & 283 & 284 & 285 & 288 & \\
\hline 37 & 2.8 & 2.2 & 2.8 & 2.4 & 1.7 & 2.8 \\
\hline 116 & 3.0 & 2.9 & 3.2 & 2.5 & 2.4 & 3.2 \\
\hline 117 & 3.1 & 2.9 & 3.3 & 2.6 & 2.4 & 3.3 \\
\hline 203 & 1.9 & 1.0 & 2.7 & 2.3 & 1.3 & 2.6 \\
\hline 204 & 1.8 & 1.1 & 2.7 & 2.3 & 1.4 & 2.6 \\
\hline 205 & 2.1 & 1.1 & 2.5 & 2.0 & 1.1 & 2.4 \\
\hline 206 & 2.3 & 1.4 & 2.2 & 1.8 & 1.1 & 2.2 \\
\hline 253 & 1.4 & 1.5 & 2.9 & 2.1 & 1.9 & 2.8 \\
\hline 262 & 2.5 & 2.1 & 2.4 & 1.3 & 1.6 & 2.4 \\
\hline 263 & 2.5 & 2.1 & 2.4 & 1.3 & 1.6 & 2.4 \\
\hline 276 & 1.6 & 2.1 & 2.4 & 0.9 & 2.0 & 2.3 \\
\hline 277 & 2.7 & 2.3 & 2.5 & 1.5 & 1.8 & 2.5 \\
\hline 278 & 2.5 & 2.2 & 2.4 & 1.4 & 1.6 & 2.4 \\
\hline 279 & 2.6 & 2.3 & 2.5 & 1.5 & 1.7 & 2.5 \\
\hline 280 & 2.8 & 2.4 & 2.6 & 1.6 & 1.9 & 2.6 \\
\hline 281 & 2.5 & 2.2 & 2.4 & 1.3 & 1.6 & 2.4 \\
\hline 290 & 2.7 & 1.5 & 1.4 & 1.5 & 0.8 & 1.4 \\
\hline 295 & 1.2 & 1.4 & 3.2 & 1.7 & 1.9 & 3.0 \\
\hline 306 & 2.7 & 1.6 & 2.9 & 2.5 & 1.6 & 2.8 \\
\hline 307 & 2.7 & 1.7 & 2.8 & 2.4 & 1.6 & 2.7 \\
\hline 314 & 3.2 & 2.8 & 3.1 & 2.0 & 2.3 & 3.1 \\
\hline 315 & 3.1 & 2.7 & 3.0 & 2.9 & 2.2 & $3.0^{\circ}$ \\
\hline 411 & 2.2 & 2.1 & 3.2 & 2.5 & 2.4 & 3.1 \\
\hline 412 & 2.6 & 2.4 & 2.9 & 2.2 & 2.0 & 2.8 \\
\hline 421 & 3.3 & 3.0 & 3.2 & $2: 1$ & 2.4 & 3.2 \\
\hline 426 & 2.8 & 2.5 & 2.8 & 2.1 & 2.0 & 2.8 \\
\hline 611 & 3.2 & 2.1 & 3.3 & 2.7 & 2.1 & 3.2 \\
\hline 618 & 2.3 & 2.5 & 4.0 & 3.0 & 3.0 & 3.9 \\
\hline 619 & 5.7 & 5.6 & 7.0 & 6.2 & 6.0 & 6.9 \\
\hline 631 & 3.3 & 2.9 & 3.4 & 2.7 & 2.5 & 3.4 \\
\hline 632 & 3.5 & 3.1 & 3.6 & 2.8 & 2.7 & 3.5 \\
\hline 636 & 2.5 & 2.6 & 4.3 & 3.2 & 3.2 & 4.2 \\
\hline
\end{tabular}


Table $B-5$

Aggregate Response Times (Minutes)

FIRST TARGET IN COMBINATION RESPONDED TO BY SECURITY FORCE

\begin{tabular}{|c|c|c|c|c|c|c|}
\hline & & 204 & 205 & 206 & 262 & 307 \\
\hline \multirow{2}{*}{ 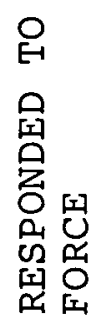 } & 204 & 2.6 & 2.7 & 2.7 & 4.1 & 3.8 \\
\hline & 205 & 2.9 & 2.4 & 2.5 & 3.8 & 3.6 \\
\hline \multirow{3}{*}{ 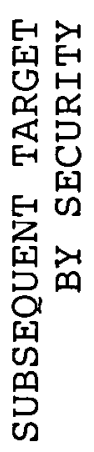 } & 206 & 3.1 & 2.7 & 2.2 & 3.5 & 3.7 \\
\hline & 262 & 4.3 & 3.8 & 3.3 & 2.4 & 5.1 \\
\hline & 307 & 3.7 & 3.3 & 3.2 & 4.8 & 2.7 \\
\hline
\end{tabular}

Table B-6

Example Facility Target Areas

TYPE I

$295 \quad 426 \quad 611 \quad 618 \quad 619$

TYPE II

$\begin{array}{llllllllll}37 & 116 & 117 & 203 & 204 & 205 & 206 & 253 & 262 & 263\end{array}$

$\begin{array}{llllllllll}276 & 277 & 278 & 279 & 280 & 281 & 290 & 306 & 307 & 314\end{array}$

$\begin{array}{lllllll}315 & 411 & 412 & 421 & 631 & 632 & 636\end{array}$ 
Table B-7

Type II Combinations

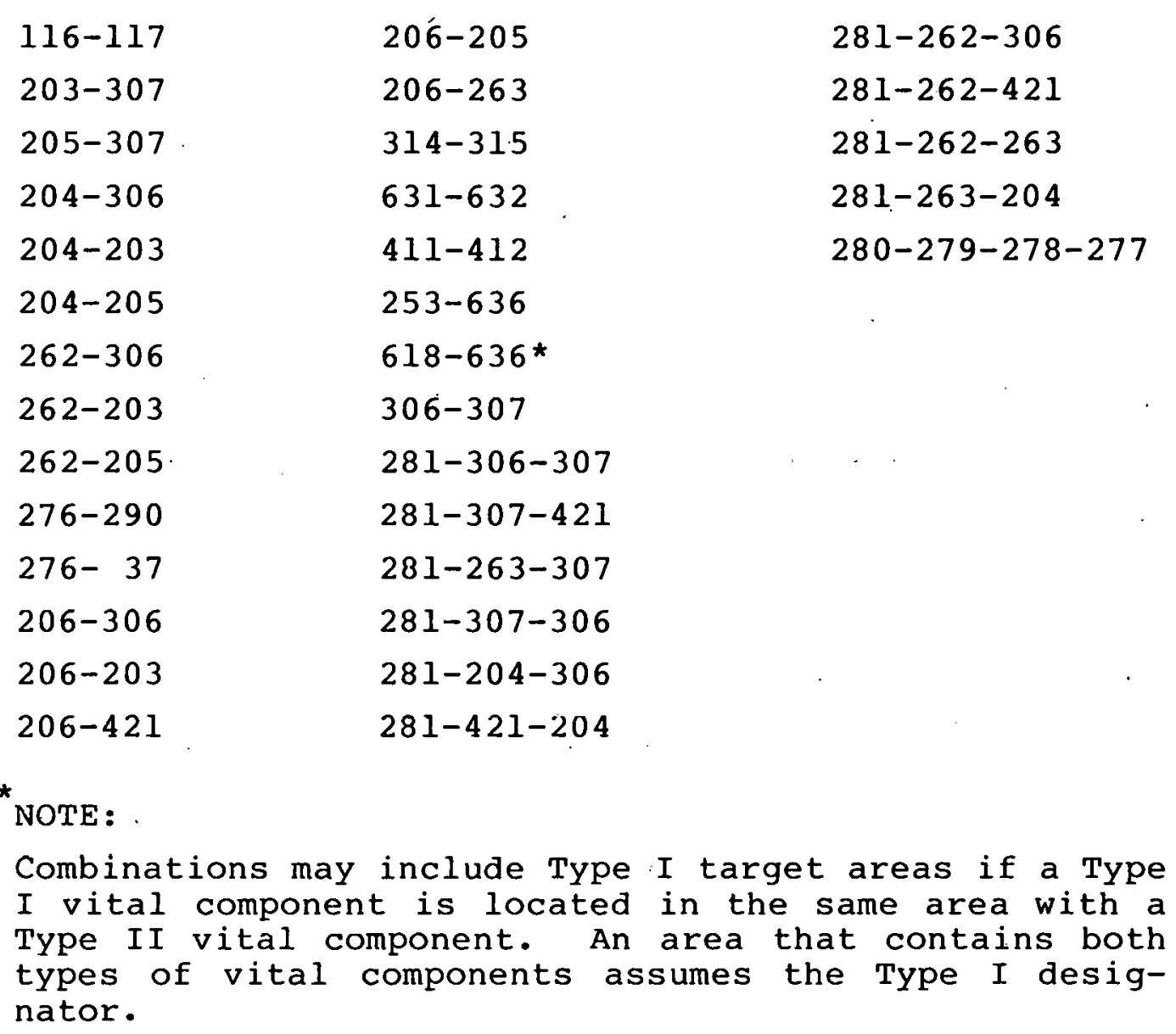


GLOSSARY OF TERMS AND ACRONYMS

Area Zoning

"Key" Vital Area

Operational Zoning

Team Zoning

Type I Vital Area

Type II Vital Area

\section{Terms}

Work rules that limit personnel access to a target or a combination of targets necessary to perform work functions.

A Type I vital area or a Type II vital area from a set of vital areas which a saboteur must visit in order to accomplish radioactive material release. The concept of establishing "key" vital areas is to provide protection for all Type. I vital areas within the facility and for at least one member of all sets of Type II vital areas at which radiological sabotage could be accomplished.

Work rules that prevent unauthorized action which could result in sabotage. These work rules incorporate such controls as access control monitors, tamper indicators, and/or close-out inspections.

Work rules that permit only authorized teams to have access to designated areas.

A single vital area in which radiological sabotage can be accomplished without the need for access into another area.

A vital area in which radiological sabotage can be accomplished only in conjunction with additional sabotage activity in at least one other vital area:

\section{Acronyms}

Auxiliary feedwater system

Component cooling water system

High-pressure safety injection

Heating, ventilation, and air-conditioning

Power-operated relief valve

Reactor coolant system

Steam generator

Salt water cooling system

Uninterrupted power supply 


\section{DO NOT}

MICROFIUM

DISTRIBITTION

U.S. NRC Distribution Contractor (CDSI)

7300 Pearl street

Bethesda, MD 20014

280 copies for R.S

250 copies for 15

25 copies for NTIS

Author selected distribution - 10 copies

(List available from author.)

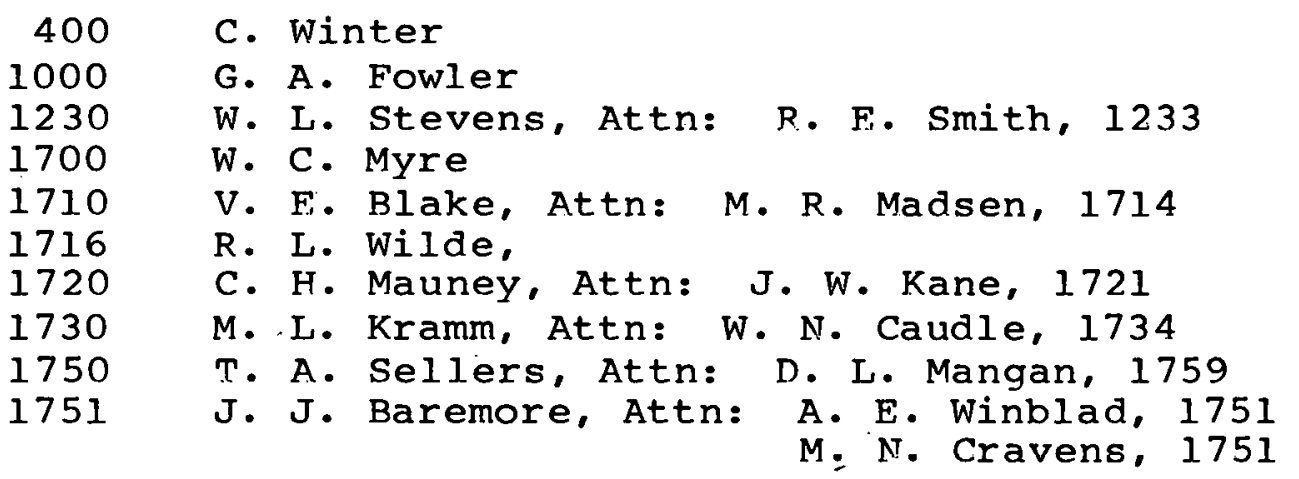

1752 M. J. Eaton

1754 I. G. Waddoups,

1760 J. Jacobs, Attn: J. M. deMontmollin, 1760A

1762 H. E. Hansen

J. D. Williams, 1769

1768 C. F. Olson, Attn: G. A. Kinemond, 1768

1765 D. S. Miyoshi

4400 A. W. Snyder

4410 D. J. McCloskey

4413 N. R. Ortiz

4414 G. B. Varnado

4416 L. D. Chapman (10)

4416 K. G. Adams

4416 J. A. Allensworth

4416 H. A. Bennett (5)

4416. L. M. Grady.

4416 C. P. Harlan

$4416 \quad R$. D. Jones

4416 B. J. Roscoe

4416 S. L. K. Rountree

4416 D. W. Sasser

5000 J. K. Galt

8214 M. A. Pound

3141 L. J. Frickson (5)

3151 W. L. Garner (3) 


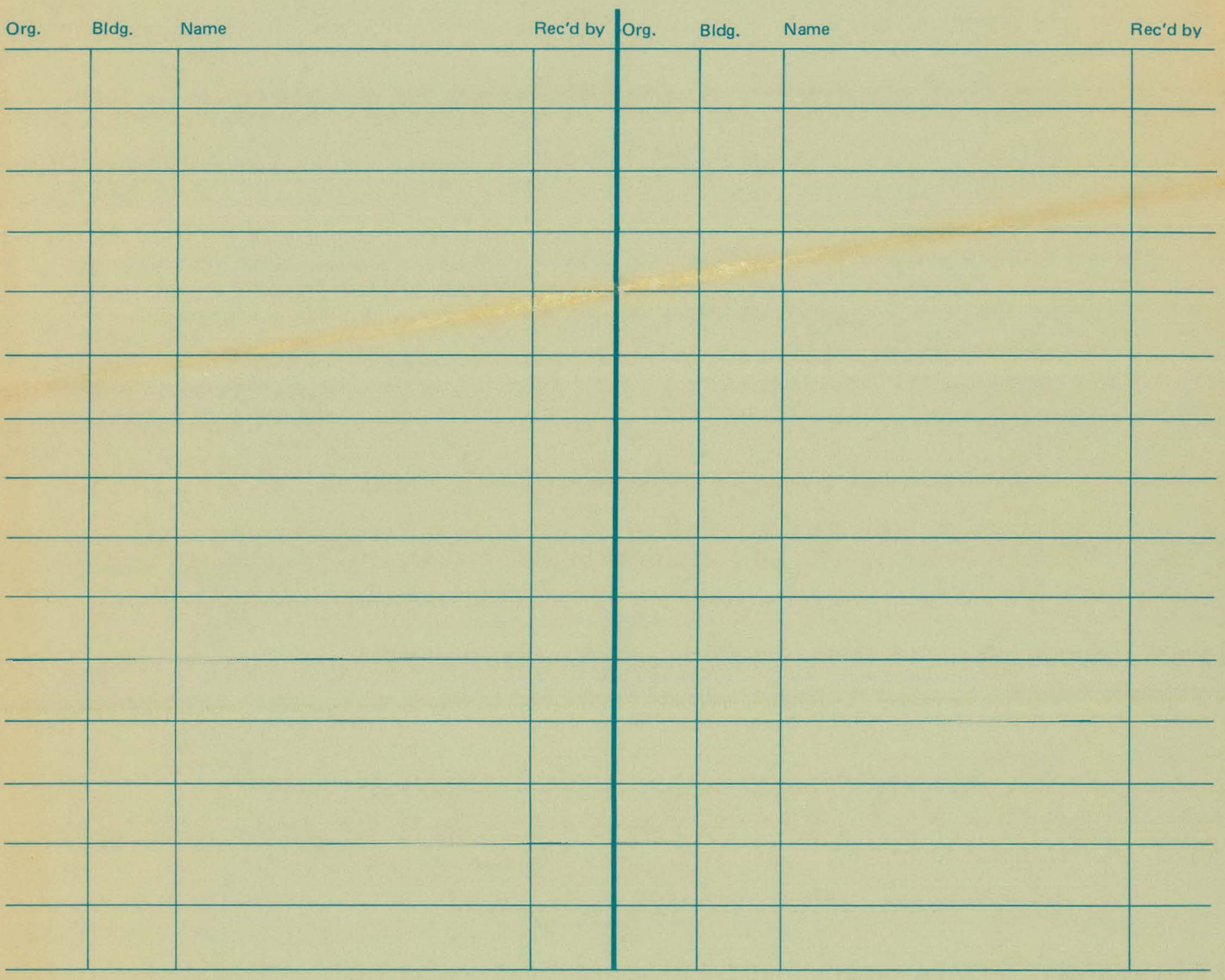

Sandia National Laboratories 